\title{
Development of Space Heating and Domestic Hot Water Systems with Compact Thermal Energy Storage
}

Report of the Working Group WB2 for the period February 2009 to December 2012

\author{
Jane H. Davidson, Josh Quinnell, Jay Burch, USA \\ H.A. Zondag, Robert de Boer, Christian Finck, Ruud Cuypers, \\ The Netherlands \\ Luisa F. Cabeza, Spain \\ Andreas Heinz, Dagmar Jahnig, Austria \\ Simon Furbo, Denmark \\ Florian Bertsch, Germany
}

A report of the IEA Solar Heating and Cooling / Energy Conservation through Energy Storage programme - Task 42/Annex 24:

\section{Compact Thermal Energy Storage: Material Development for System Integration}
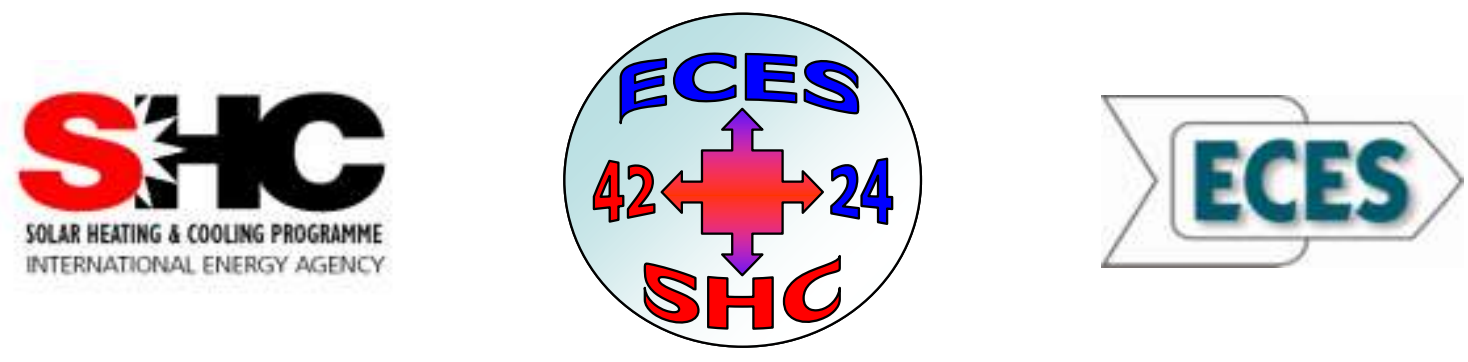


\section{TABLE OF CONTENTS}

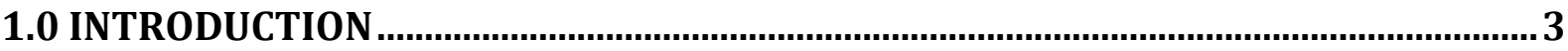

2.0 OVERVIEW OF MATERIALS AND CLASSIFICATION OF SYSTEMS ............................ 3

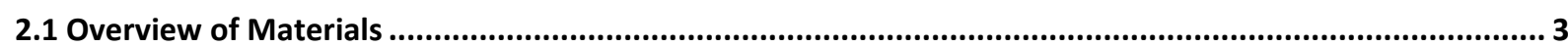

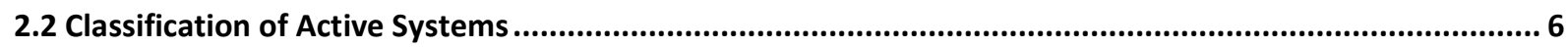

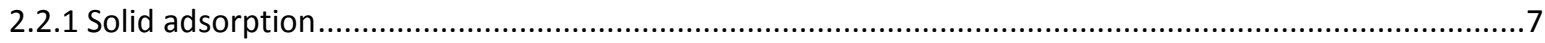

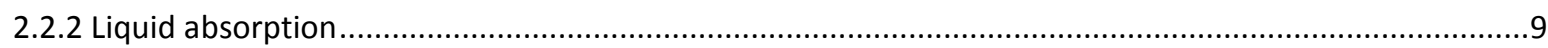

\subsection{SYSTEM DEVELOPMENT BY TASK CONTRIBUTORS ................................................ 9}

3.1 Liquid Desiccant Active Heating/Cooling and Hot Water ................................................................. 10

3.2 Heat Storage Based on a $\mathrm{NaCH}_{3} \mathrm{COO}$ Water Mixture for Solar Heating Systems .................................... 18

3.3 Solid Adsorption Closed-Cycle Active Solar Heating ....................................................................25

3.4 Use of PCM as Passive Storage System in Building Envelopes ........................................................... 28

3.5 Use of PCM Thermal Energy Storage Tanks in Heat Pump System .......................................................30

$3.6 \mathrm{MgCl}_{2} \cdot 6 \mathrm{H}_{2} \mathrm{O}$ Solid Desiccant for Active Solar Heating and DHW ..................................................... 32

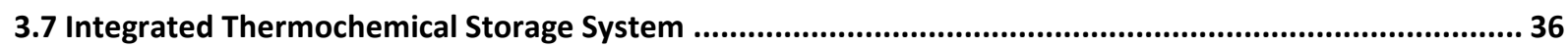

3.8 Solid Sorption/Reaction Open-cycle Active Solar Heating...................................................................40

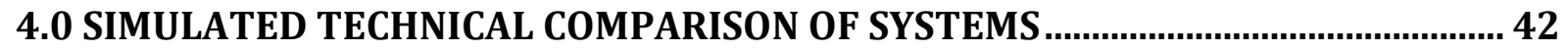

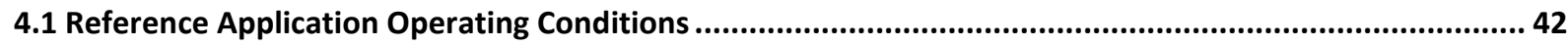

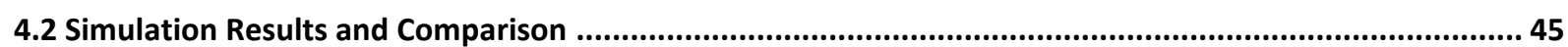

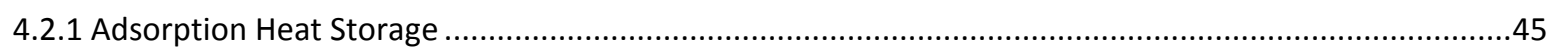

4.2.2 Water storage with integrated Phase Change Material (PCM) .......................................................49

5.0 RECOMMENDATIONS FOR MATERIAL AND SYSTEM DEVELOPMENTS ............... 53

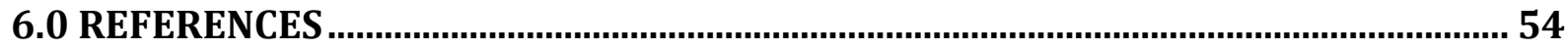

7.0 SHORT DESCRIPTION OF TASK 42 / ANNEX 24 .................................................. 57

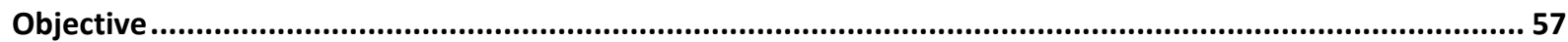

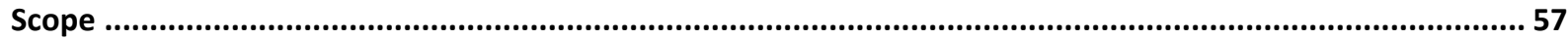

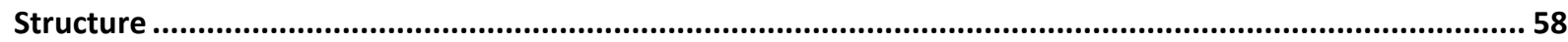




\subsection{Introduction}

Long-term, compact thermal energy storage (TES) is essential to the development of cost-effective solar and passive building-integrated space heating systems and may enhance the annual technical and economic performance of solar domestic hot water (DHW) systems. Systems should provide high energy storage density, charge and discharge temperatures that match the heat source used for charging and the intended load, adequate charge/discharge power, and employ storage materials that are stable over many cycles, non-toxic, environmentally safe. Moreover, these systems must compete effectively in the marketplace and therefore should provide an economic benefit compared to conventional heating and DHW systems, which have traditionally relied on sensible water storage.

The IEA joint Task/Annex 42/24 brings together experts in materials development and systems integration to develop advanced materials and systems for the compact storage of thermal energy. Working Group WB2 addresses applications of compact thermal energy storage for space heating and hot water $\left(20\right.$ to $\left.100{ }^{\circ} \mathrm{C}\right)$. The activities in this working group are aimed at guiding materials development, within the limitations of these two applications, and at development of systems that use compact storage medium with the goals of improved technical and economic performance compared to traditional approaches. Because solar assisted heating of buildings is the main focus of the SHC IEA, this topic is addressed by many of the contributors to this report. However, because there are many relevant applications for TES, the working group activities encompass other applications including systems for passive building integrated climate control.

The primary activities of the working group include:

- selection of candidate materials and system configurations;

- assessment of the technical performance of systems through laboratory tests of components and systems, case studies, modeling, and/or field studies;

- assessment of the economic performance through modeling and evaluation of market potential.

This report summarizes the contributions of the working group over the period from February 2009 through December 2012. The focus is on the development of system concepts (item 1 from the list above) and technical evaluation of proposed systems and the storage components of these systems through predictive modeling and laboratory testing.

\subsection{Overview of Materials and Classification of Systems}

\subsection{Overview of Materials}

Development of systems within the working group has focused on integration of phase change materials (PCMs) and thermochemical materials into active heating systems and integration of PCMs into building materials. Active systems that rely on PCMs and thermochemical storage require specialized components and operation to charge and discharge the storage vessel. Innovation at the system level is a necessary and a crucial step toward identifying desired material characteristics and successful use of newly developed storage materials.

A performance map in terms of the key constraints of material energy storage density and temperature is shown in Figure 2.1 for TES materials that have been used or are being 


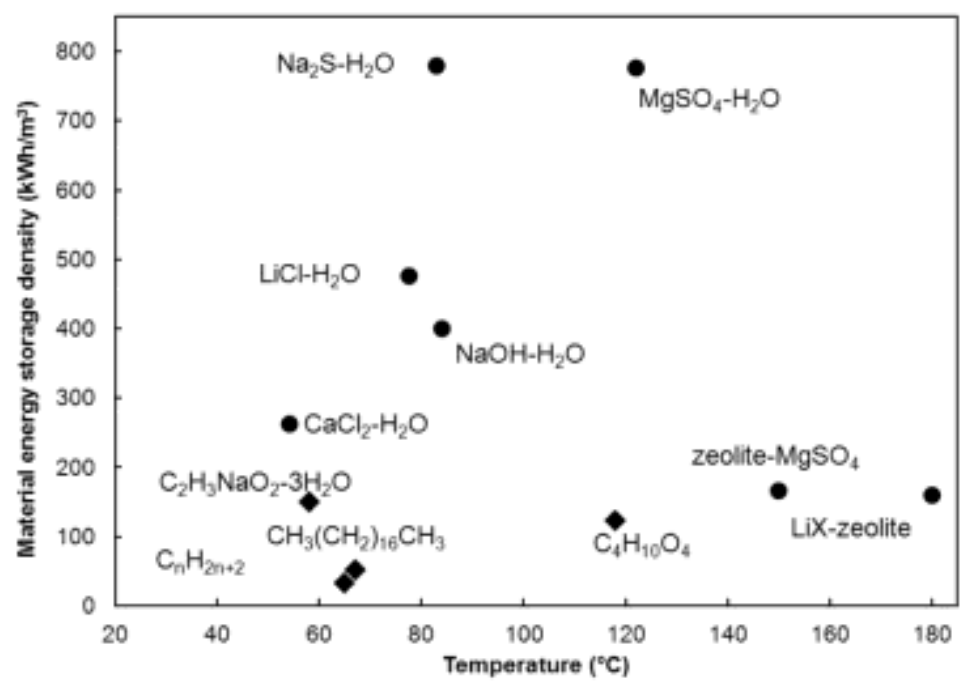

Figure 2.1: Material energy storage density versus charging temperatures for candidate TES materials. Latent (४), thermochemical (•) [Taken from Quinnell and Davidson, 2012a].

investigated for solar hot water and space heating. Reported energy density ranges from 35 to $780 \mathrm{kWh} / \mathrm{m}^{3}$ for materials with charging temperatures between 20 and $180{ }^{\circ} \mathrm{C}$.

Thermochemical storage has the highest energy density followed by PCM and sensible energy storage. Generally, materials with larger energy density require higher charging temperatures. Note that these energy density values are with respect to the volume of the storage material and do not include the volume of supporting equipment. In general, material energy density depends on the thermodynamic states of the storage system at charging and discharging conditions. In practice, system level energy density may be lower due to a number of factors including limitations in heat and mass transfer, and kinetics for thermochemical reactions, as well as the added volume of components required to add and extract energy from the storage vessel.

PCMs are well suited for applications in which the operating temperature is limited to a small range close to the phase transition temperature. The material energy storage density depends on the enthalpy of fusion, the heat capacity and the temperature limits of the system:

$$
\lambda_{P C M}=\rho_{\min } \int_{T_{\text {min }}}^{T_{\max }} h_{f u s}(T) d T+\lambda_{\Delta T, \text { liquid }}+\lambda_{\Delta T, \text { solid }}
$$

where $\rho_{\min }$ is the minimum density (liquid phase), $\mathrm{h}_{\text {fus }}$ is the enthalpy of fusion, $\mathrm{T}_{\min }$ and $\mathrm{T}_{\max }$ are the temperature limits of the phase change process, and $\lambda_{\Delta \mathrm{T}}$ is the sensible energy storage densities in the liquid and solid phases. The specific heat of most PCMs is lower than that of water. Material energy densities due to the enthalpy of fusion range from $35 \mathrm{kWh} / \mathrm{m}^{3}$ for paraffin to $167 \mathrm{kWh} / \mathrm{m}^{3}$ for sodium acetate trihydrate) [Zalba et al., 2003]. A challenge for PCM storage is design of the system for adequate charging and discharging power. One constraint is the relatively low thermal conductivity of PCMs $(<1.1 \mathrm{~W} / \mathrm{m}-\mathrm{K})$ [Zalba et al., 2003]. Composite materials incorporating carbon have enhanced thermal conductivity and have been proposed for solar thermal applications (e.g. [Zhong et al., 2010 and Haillot et al., 2011]). However in some materials, increased thermal conductivity comes at the expense of energy density, which can be reduced by $35 \%$ or more due to the volume of the conductive 
material [Haillot et al., 2011]. Like water, PCMs have limited potential for seasonal storage but are explored here for extended periods.

A number of groups are working on the development of storage systems based on lowtemperature thermochemical reactions. Thermochemical reactions store heat in chemical bonds and thermal losses are negligible compared to the enthalpy of reaction. In its most simplistic form, the charge/discharge process for thermochemical storage is described by the pair of reactions [Bales, 2005]:

$$
\begin{aligned}
& A B+\text { Heat } \rightarrow A+B \\
& A+B \rightarrow A B+\text { Heat }
\end{aligned}
$$

The working material, $A B$, is heated until $A$ and $B$ are thermally dissociated; in this manner, thermal energy is stored as chemical potential. The thermal energy is reclaimed when $A$ and $B$ are recombined in an exothermic process. Despite the apparent simplicity of these reactions, in reality, suitable reactants have been difficult to identify for solar heating. One limitation is the charging temperature attainable with flat plate and evacuated tube collectors, $\sim 150^{\circ} \mathrm{C}$ or lower.

Sorption storage, which refers to the potential energy of desiccant materials to adsorb/absorb water vapor and release heat, has been identified as a promising match to solar collectors and space heating systems (e.g. [Bales, 2005 and Bales, 2006]). The energy storage is due to the enthalpy of sorption, $\mathrm{h}_{\mathrm{s}}$, which is the energy released when water vapor is sorbed onto a solid surface or into the volume of a liquid. It is the sum of the binding energy of the water and host material molecules in the condensed state, $h_{b}$, and the enthalpy of vaporization of the water, $\mathrm{h}_{\mathrm{fg}}$ :

$$
h_{s}=h_{b}+h_{f g}
$$

The sorption energy storage capacity depends on the operating limits on mass fraction, S, (concentration) of water in the host material:

$$
\lambda_{\Delta S}=\rho_{\min } \int_{S_{\min }}^{S_{\max }} h_{f g}(S)+h_{b}(S) d S
$$

where $\mathrm{S}$ is expressed as $\mathrm{kg}-\mathrm{H}_{2} \mathrm{O} / \mathrm{kg}$-total, and $\mathrm{S}_{\max }-\mathrm{S}_{\min }$ represents the total water uptake that is useful for energy storage. The mass of water that can be added and removed from the storage is function of the temperature and pressure in the system. To-date, sorption storage media have been selected primarily from commercially available materials, including physical adsorption of water vapor on porous molecular sieves, typically aluminosilicate zeolites [Jänchen , 2004 and Jänchen , 2005], or silica gel, and absorption using aqueous lithium chloride (LiCl) [Bales, 2006], lithium bromide (LiBr) [Le Pierres et al., 2008], sodium hydroxide $(\mathrm{NaOH})$ [Weber and Dorer, 2008], or calcium chloride $\left(\mathrm{CaCl}_{2}\right)$ [Hui et al., 2011]. Reported material energy densities, based on the enthalpy of sorption, are 130 to $780 \mathrm{kWh} / \mathrm{m}^{3}$ [Hauer, 2008 and Bales et al., 2008]). The binding energy typically contributes less than 35\% to the stored energy. The majority of the storage is from the enthalpy of vaporization of water. The energy capacity due to the enthalpy of vaporization increases with the amount of water absorbed. Technically, the enthalpy of vaporization is usually not stored, but transformed from a low-temperature source to a higher temperature for the load. In other words, the energy to vaporize water must come from within the system or be supplied by an external source (e.g. 
the ground or a solar thermal collector). Hence, unlike sensible and latent storage, sorption system energy density depends on the availability and the quality of the thermal energy sources and sinks. System level energy density may be substantially lower than material energy density due to the relative complexity of system integration.

\subsection{Classification of Active Systems}

Systems may be classified according to their interaction with the surroundings [Quinnell and Davidson, 2012a]. Figure 2.2 illustrates the classification of solar thermal systems and describes the three system types in terms of thermodynamic terms. The basic system illustrated in Figure 2.2(a) does not require external sources or sinks. Water and PCM stores fall into this classification as does the liquid sorption system described in section 3.1 of this report. Open- and closed-cycle sorption TES systems include energy transformation (i.e. heat pumping) and thus require heat or mass transfer with the surroundings independent of the solar energy, the load, and thermal loss. Closed-cycle sorption systems transform energy from the source to the load via heat transfer (Figure 2.2(b)). Open-cycle sorption systems transform energy via mass transfer with the surroundings (Figure 2.2(c)). The total enthalpy of sorption is available for both open- and closed-cycle systems. However, the enthalpy of vaporization is not stored, but transformed from a low temperature source to the temperature of the thermal load. Thus, the energy density depends on the availability and the quality of the thermal sources and sinks.

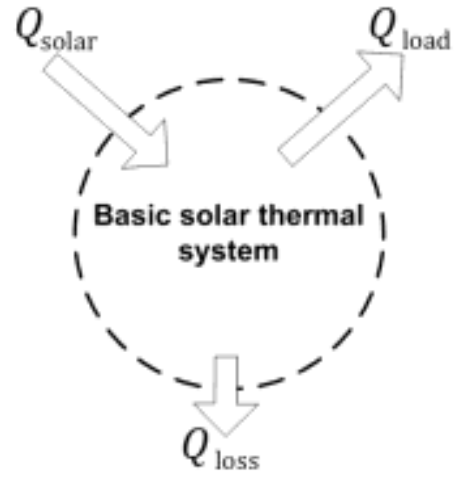

(a)

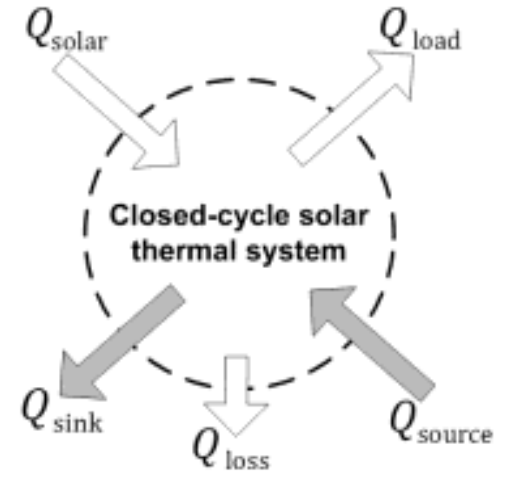

(b)

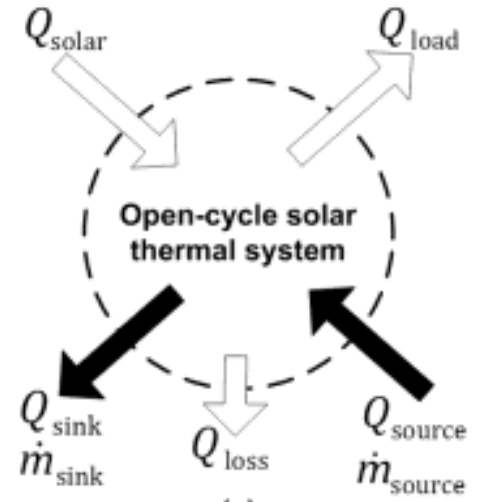

(c)

Figure 2.2: Thermodynamic classification of solar energy storage systems: (a) simplest system; (b) closedcycle system that transforms energy from the source to the load via heat transfer; and (c) open-cycle system that transforms energy via mass transfer to the surroundings [Taken from Quinnell and Davidson, 2012a].

The charge/discharge cycle of sorption storage systems comprises two primary steps. During charging, water is desorbed from the desiccant ideally using a sustainable heat source such as solar or waste heat. The water vapor is condensed and stored (closed-cycle) or released to the ambient (open-cycle). During discharging, the sorbent is rehydrated. For solid sorption (adsorbents), stored water may be evaporated using a low temperature source such as the ground (closed-cycle) or discharge may be accomplished using ambient air (open-cycle). Open cycle discharge requires sufficient water content in the ambient air stream. This requirement limits discharge operation to climates in which moist ambient air is available during the heating season. Rehydration releases the heat of sorption. 


\subsubsection{Solid adsorption}

Beyond material selection, design and operation of a thermochemical solid adsorption storage vessel/reactor is crucial for successful implementation of long-term storage. The key challenge is ensuring adequate heat and mass transport within the medium. Material thermal conductivity of solid sorbents is low (reported values for zeolite are $0.08-0.16 \mathrm{~W} / \mathrm{m}-\mathrm{K}$ [Wang et al., 2006]) and packed beds have even lower effective conductivity and less favorable kinetics. Moreover, in practice, the useful energy density is limited by thermodynamics. Because the vapor pressure of the adsorbent increases with temperature, a high rate of adsorption (high discharge power) translates to the inability to fully discharge the stored energy [Gantenbein, 2006].

The adsorption reaction may be implemented within the storage vessel or the reactants may be transported to a separate reactor(s). In the former, the storage is referred to as an integrated storage/reactor. In the latter, the storage and reactor are referred to as separated. Figure 2.3 illustrates closed- and open-cycle systems, both with an integrated storage/reactor. The advantages of the integrated storage/reactor system are compactness and reduction of mechanical parts. The disadvantages are the requirement of a porous architecture to facilitate adsorption/desorption within the storage vessel and the inability to charge and discharge simultaneously. Figure 2.3(a) shows a closed-cycle system in which heat exchangers are embedded within the storage medium to transfer heat from the solar reactor to the load. These systems typically operate at low pressure. Charging (desorption) is indicated by dashed lines and discharging (adsorption) is indicated by solid lines. During charging, the storage/reactor is heated to drive off water vapor, which is condensed and stored in a separate vessel. The heat from the condenser is rejected to the surroundings or may be used to meet the load. To discharge the system, the stored water is transported to an evaporator where a low temperature source provides the energy for evaporation. The evaporated water passes through the storage/reactor where it is readsorbed releasing the chemical binding energy.

Figure 2.3(b) illustrates an open-cycle system in which the heat exchangers are external to the integrated storage/reactor. During charging, the heated air stream is circulated through the storage/reactor to desorb water vapor. To discharge the system, moist ambient air is passed through the storage/reactor. It exits the storage/reactor as warm dry air which is passed through a load-side heat exchanger. There is no condenser or evaporator. The advantages of the open-cycle are that there are fewer components, the system operates at atmospheric pressure, and the heat exchangers do not scale with the volume of the storage. The disadvantage is that a source of warm moist air is required during the heating season.

Figure 2.4 illustrates a closed-cycle absorption system. The system comprises multiple storage vessels, two reactors (for absorption/desorption), a condenser and evaporator, and heat exchangers. The concept is similar to a closed-cycle adsorption system with separated storage and reactor, but, in this case, physical transport of the sorbent and heat and mass transfer in the reactors is improved. Three storage vessels, one each for water, diluted (discharged), and concentrated (charged) solutions, are shown in this illustration to emphasize the necessity of preventing mixing prior to discharging. Mixing of the diluted and concentrated solutions releases the stored binding energy and converts the chemical potential into sensible energy, 


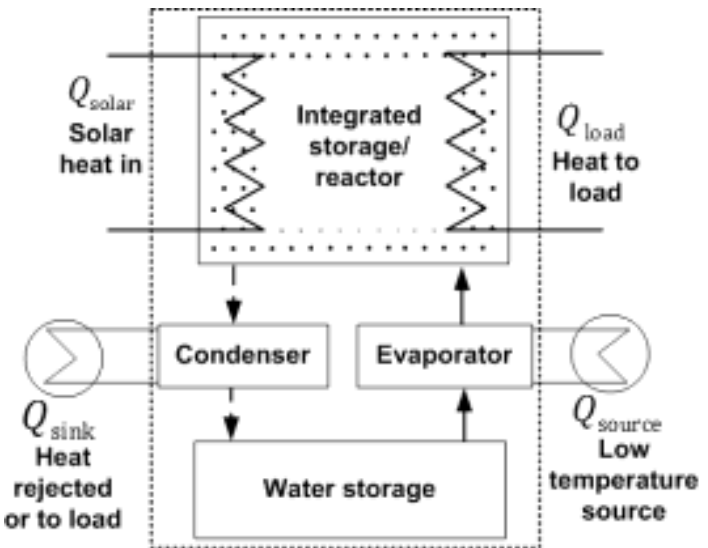

(a)

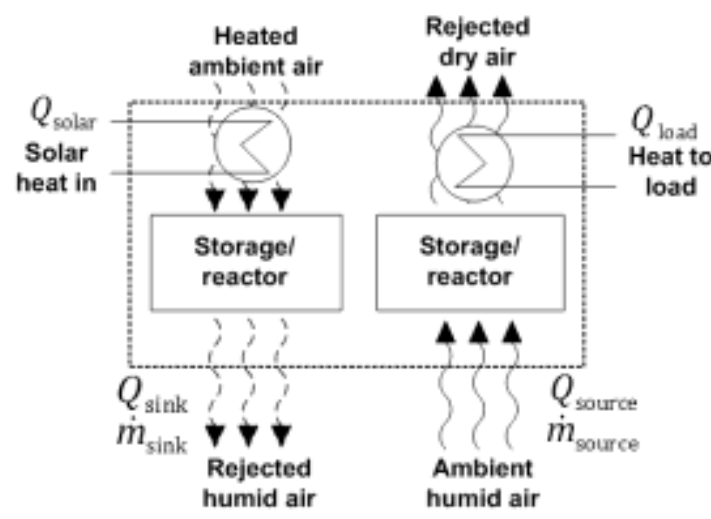

(b)

Figure 2.3: Schematic of closed- and open-cycle adsorption storage systems. Charging operation (desorption) is indicated by dashed lines and discharging operating (adsorption) is indicated by solid lines. (a) In the closed (low pressure) system, there is a single integrated/storage reactor with embedded heat exchangers where heat is added (charging) or removed (discharging). During charging, the energy of condensation is rejected or used to meet the load. During discharging, energy from a low temperature source evaporates water. (b) In the open system, there is a single integrated storage/reactor with external heat exchangers. During charging, incoming ambient air is heated. Water vapor evaporates into the air as

it passes through the integrated storage/reactor and humid air is rejected. During charging, humid

ambient air is passed through the integrated storage reactor, water vapor is adsorbed, and heat is extracted from the dry air exiting the integrated storage reactor [Taken from Quinnell and Davidson, 2012a].

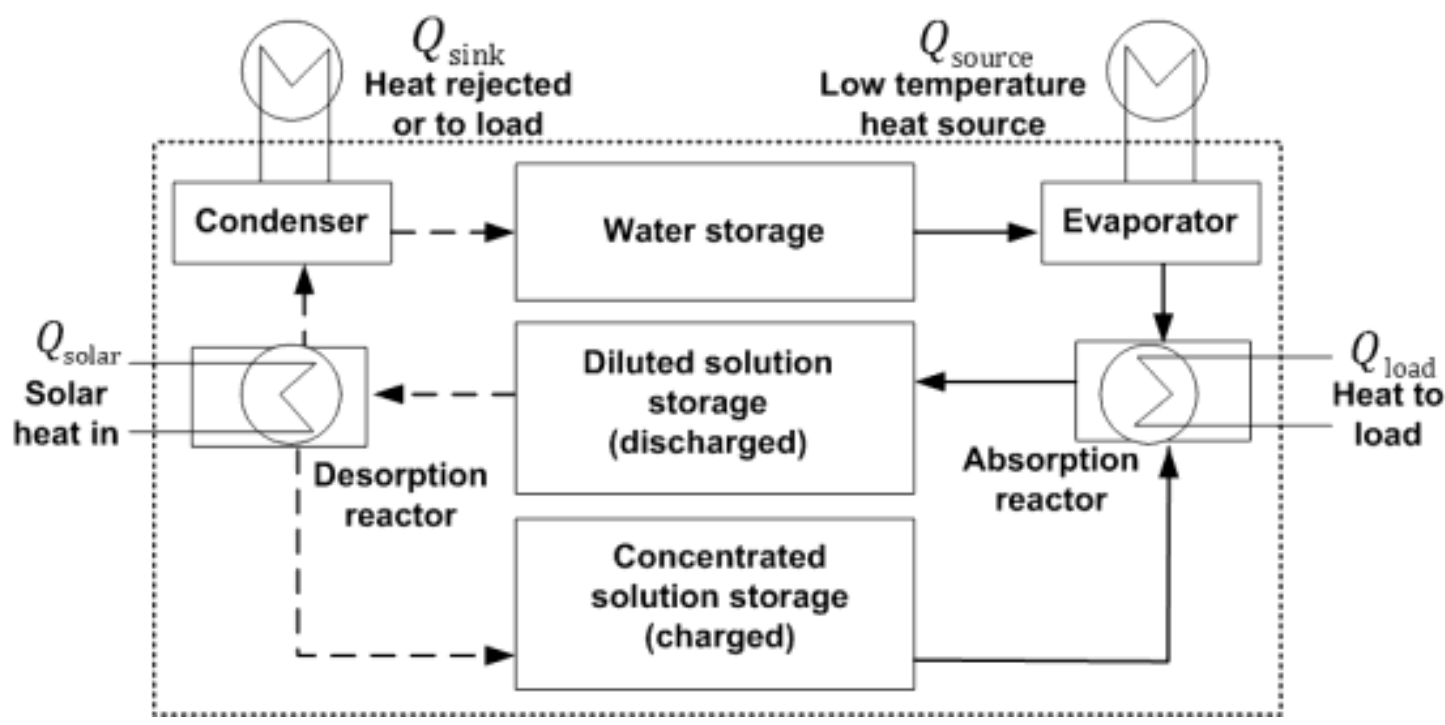

Figure 2.4: Schematic of a closed-cycle liquid absorption storage system. Charging operation (desorption) is indicated by dashed lines and discharging operating (absorption) is indicated by solid lines. In the closed (low pressure) system, there can be one or two separate reactors and multiple storage vessels for solution in different states (concentration). Heat is added (charging) or removed (discharging) via embedded heat exchangers in the reactors. During charging the energy of condensation is rejected or used to meet the load. During discharging energy from a low temperature source evaporates water. Solution from the storage vessels is pumped to and from the reactors [Taken from Quinnell and Davidson, 2012a]. 
which is subject to thermal loss to the ambient. The use of multiple storage vessels ensures long-term storage of chemical potential but decreases the system-level energy density and increases the cost.

\subsubsection{Liquid absorption}

Liquid desiccants are promising storage option because, in contrast to solid adsorption materials, they can be pumped and used as the working heat transfer fluid in solar collectors and heat exchangers. Faster heat and mass transfer rates are possible with liquid absorption. Materials recently investigated include aqueous solutions of $\mathrm{CaCl}_{2}$ [Quinnell et al., 2011], $\mathrm{LiCl}$ [Bales, 2006], $\mathrm{NaOH}$ [Weber, 2008], and $\mathrm{KOH}$ [Hui et al., 2011]. Hui et al. compare absorption materials for use in low pressure $(1.2-4.2 \mathrm{kPa})$ absorption cycles and have reported theoretical material energy densities up to $476 \mathrm{kWh} / \mathrm{m}^{3}$ [Hui et al., 2011], as shown in Table 2.1. Although energy density is an important criterion for selection, thermophysical properties, cost, and the cycle temperatures and pressures influence the choice of material. Lithium chloride $(\mathrm{LiCl})$, with desorption temperature of $66^{\circ} \mathrm{C}$, has the highest storage density of $476 \mathrm{kWh} / \mathrm{m}^{3}$, but also has a high absorption temperature range, 20 to $35^{\circ} \mathrm{C}$. Calcium chloride $\left(\mathrm{CaCl}_{2}\right)$, with a desorption temperature of $44^{\circ} \mathrm{C}$, has an energy density of 263 $\mathrm{kWh} / \mathrm{m}^{3}$ and a limited absorption temperature range of 20 to $23^{\circ} \mathrm{C}$. Sodium hydroxide $(\mathrm{NaOH})$, with a desorption temperature of $50^{\circ} \mathrm{C}$, has an energy density of $233 \mathrm{kWh} / \mathrm{m}^{3}$ and the highest absorption temperature of $45^{\circ} \mathrm{C}$.

Table 2.1: Aqueous absorption materials considered for low pressure (1.2 - $4.2 \mathrm{kPa})$ absorption cycles for space heating [Hui et al., 2011]. ${ }^{1}$

\begin{tabular}{l|l|l|l|l|l}
\hline \hline Material & $\mathrm{CaCl}_{2}$ & $\mathrm{LiCl}$ & $\mathrm{LiBr}$ & $\mathrm{NaOH}$ & $\mathrm{KOH}$ \\
\hline $\begin{array}{l}\text { Maximum sorbent mass fraction, } \\
\text { kg-salt/kg-soln. }\end{array}$ & 0.40 & 0.44 & 0.59 & 0.35 & 0.51 \\
$\begin{array}{l}\text { Maximum material energy density, } \\
\mathrm{kWh} / \mathrm{m}^{3}\end{array}$ & 119 & 400 & 313 & 154 & 313 \\
$\begin{array}{l}\text { Maximum material energy density } \\
\left(80 \% \text { solid crystals), } \mathrm{kWh} / \mathrm{m}^{3}\right.\end{array}$ & 263 & 476 & 400 & 233 & 400 \\
$\begin{array}{l}\text { Absorption temperatures, }{ }^{\circ} \mathrm{C} \\
\text { Desorption temperature, }{ }^{\circ} \mathrm{C}\end{array}$ & $20-23$ & $\begin{array}{l}20-35 \\
65\end{array}$ & $\begin{array}{l}25-35 \\
72\end{array}$ & $\begin{array}{l}25-45 \\
50\end{array}$ & $\begin{array}{l}25-35 \\
63\end{array}$ \\
\hline \hline
\end{tabular}

${ }^{1}$ Values assume condenser temperature and evaporator temperatures of 10 and $30^{\circ} \mathrm{C}$, respectively.

${ }^{2}$ Maximum sorbent mass fractions are determined from maximum solubility at the evaporator temperature $\left(10^{\circ} \mathrm{C}\right)$.

\subsection{System Development by Task Contributors}

This section includes summaries of systems under development by the working group contributors. Table 3.1 provides a summary of the systems presented. The following information is included in each section:

- System schematic and description of operation including any limits

- Storage material properties and attributes

- Description of novel or unique component(s)

- State of development/commercialization 
Table 3.1: List of systems described in Section 3.1.

\begin{tabular}{|c|c|c|c|c|}
\hline $\begin{array}{l}\text { Report Section } \\
\text { and } \\
\text { Application }\end{array}$ & $\begin{array}{l}\text { Storage } \\
\text { Mechanism(s) }\end{array}$ & Storage Material & Status & Contact \\
\hline $\begin{array}{l}3.1 \text { Solar } \\
\text { CombiSystem } \\
+ \text { Cooling }\end{array}$ & $\begin{array}{l}\text { Sorption + } \\
\text { Sensible }\end{array}$ & $\mathrm{CaCl}_{2}(\mathrm{aq})$ & $\begin{array}{l}\text { Laboratory prototype } \\
\text { components }\end{array}$ & $\begin{array}{l}\text { USA } \\
\text { Jane Davidson, University of } \\
\text { Minnesota }\end{array}$ \\
\hline $\begin{array}{l}\text { 3.2 Solar } \\
\text { CombiSystem }\end{array}$ & $\begin{array}{l}\text { Latent }+ \\
\text { Sensible }\end{array}$ & $\begin{array}{l}\text { Sodium acetate } \\
\text { tri-hydrate PCM } \\
\text { and water }\end{array}$ & Laboratory prototype & $\begin{array}{l}\text { Denmark } \\
\text { Simon Furbo, Technical } \\
\text { University of Denmark }\end{array}$ \\
\hline $\begin{array}{l}\text { 3.3 Closed Solar } \\
\text { CombiSystem } \\
\text { (Numerical results } \\
\text { in 4.2.1) }\end{array}$ & $\begin{array}{l}\text { Sorption + } \\
\text { Sensible }\end{array}$ & $\begin{array}{l}\text { Silica gel } \\
\text { Zeolite }\end{array}$ & Pilot demonstration & $\begin{array}{l}\text { Austria } \\
\text { Dagmar Jaehnig, AEE INTEC } \\
\text { Germany } \\
\text { Florian Bertsch, University of } \\
\text { Stuttgart }\end{array}$ \\
\hline $\begin{array}{l}\text { 3.4 Passive climate } \\
\text { control }\end{array}$ & Latent & $\begin{array}{l}\text { Encapsulated } \\
\text { PCM }\end{array}$ & Laboratory demonstration & $\begin{array}{l}\text { Spain } \\
\text { Luisa Cabeza }\end{array}$ \\
\hline 3.5 Heat Pump & Latent & PCM & Small scale demonstration & $\begin{array}{l}\text { Spain } \\
\text { Luisa Cabeza }\end{array}$ \\
\hline $\begin{array}{l}3.6 \text { Solar } \\
\text { CombiSystem }\end{array}$ & $\begin{array}{l}\text { Sorption }+ \\
\text { Sensible }\end{array}$ & $\begin{array}{l}\mathrm{MgCl}_{2} \cdot 6 \mathrm{H}_{2} \mathrm{O} \text { salt } \\
\text { hydrate }\end{array}$ & $\begin{array}{l}\text { Matls. Char-acterization } \\
\text { and Laboratory Prototype }\end{array}$ & $\begin{array}{l}\text { The Netherlands } \\
\text { Robert de Boer, H.A. Zondag, , } \\
\text { ECN/TUE }\end{array}$ \\
\hline $\begin{array}{l}3.7 \text { Solar } \\
\text { CombiSystem } \\
+ \text { Cooling }\end{array}$ & & $\begin{array}{l}\text { Zeolites } \\
\text { Salt Hydrate: } \\
\mathrm{CaCl}_{2}\end{array}$ & Reactor prototype & $\begin{array}{l}\text { The Netherlands } \\
\text { Ruud Cuypers Christian Finck, } \\
\text { TNO }\end{array}$ \\
\hline $\begin{array}{l}3.8 \text { Open Solar } \\
\text { CombiSystem } \\
\text { (Numerical results } \\
\text { in 4.2.1) }\end{array}$ & $\begin{array}{l}\text { Sorption + } \\
\text { Sensible }\end{array}$ & hydrates & Laboratory demonstration & $\begin{array}{l}\text { Florian Bertsch, University of } \\
\text { Stuttgart }\end{array}$ \\
\hline $\begin{array}{l}4.2 .2 \\
\text { Combisystem }\end{array}$ & $\begin{array}{l}\text { Latent + } \\
\text { Sensible }\end{array}$ & PCM/Water & Numerical Simulation & $\begin{array}{l}\text { Austria, } \\
\text { Andreas Heinz, }\end{array}$ \\
\hline
\end{tabular}

\subsection{Liquid Desiccant Active Heating/Cooling and Hot Water}

The University of Minnesota and the U.S. National Renewable Energy Laboratory have collaborated on a liquid desiccant system that evolved from considering zero thermal energy buildings, where the dominant thermal loads (water heating, space heating, and space cooling and dehumidification) are met using on-site solar thermal energy only. Cooling is used in nearly all U.S. buildings, and is dominant in southern climates. Given the development of a novel atmospheric-pressure chiller using liquid desiccants (LD) and microporous membranes for drying and indirect evaporative sensible cooling at NREL [Kozubal, et al., 2011], it was appropriate to consider an atmospheric-pressure LD heat pump to assist in cost-effectively meeting all the heating loads. As both heating and cooling demand storage, an LD storage tank was conceived that stores both sensible and sorption energy. A schematic of the envisioned system is shown in Figure 3.1.1. The development of the system is in the early stage. Prototypes of tank, heat pump, and chiller have been built and tested. 


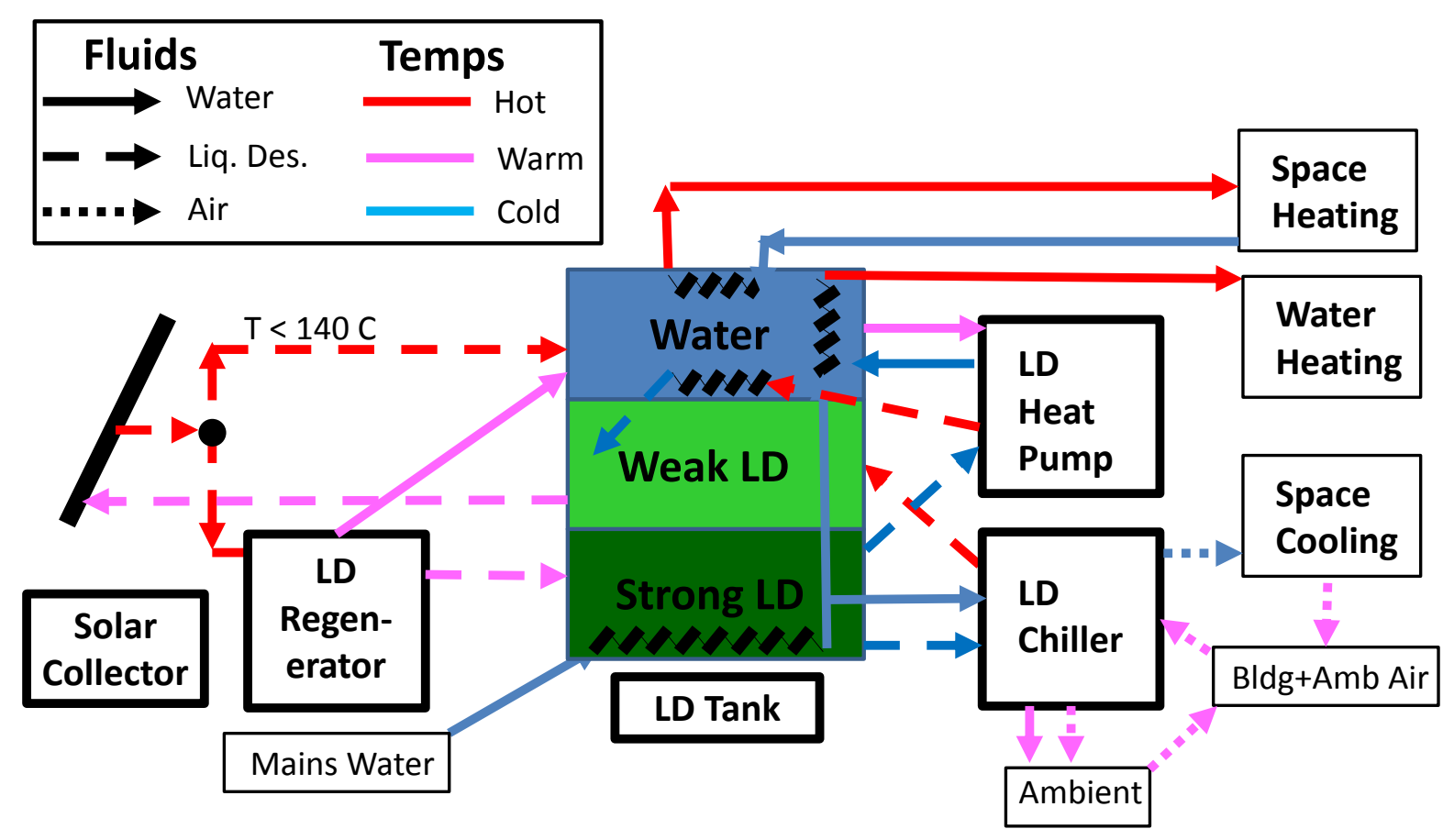

Figure 3.1.1: Schematic of liquid desiccant-based heating/cooling and DHW system.

Overview of system operation

The water at the top of the LD tank is kept hot from direct solar and from operation of the LD heat pump; heating loads are then met through heat exchangers. Solar heat drives the LD regeneration, producing strong $L D$ and hot water from weak LD. When the collector return is not hot enough to drive the regenerator, heat is stored directly in the water/thermal storage section of the tank. The regenerator is envisioned here as a two-stage device, with boiling in the first stage and heat from the condensed steam driving a second stage [Lowenstein, A., 2005]. Strong LD feeds the heat pump and chiller, both of which return weak LD to the storage tank...

$\mathrm{CaCL}_{2}$ is an inexpensive desiccant and for this application provides similar energy density as $\mathrm{LiCl}$ [Quinnell et al., 2011]. The accessible material storage density depends on the operating limits of the system. For the system depicted in Figure 3.1.1, the material energy storage density is based on a temperature rise from 47 to $105^{\circ} \mathrm{C}$ and $\Delta \mathrm{S}=0.2$. The minimum temperature is set by an assumed temperature lift in the heat pump of $8^{\circ} \mathrm{C}$ and a minimum delivery temperature of $55^{\circ} \mathrm{C}$. The maximum temperature is set here by the boiling point of $\mathrm{CaCl}_{2}$. The chemical storage density is based on the maximum solubility of the solute at $\mathrm{T}=$ $47^{\circ} \mathrm{C}$, which is $\mathrm{S}_{\max }=0.59$. $\mathrm{h}_{\mathrm{d}}$ is $366 \mathrm{~kJ} / \mathrm{kg}-\mathrm{H}_{2} \mathrm{O}(\mathrm{g})$. In this case, the useful material energy density is $106 \mathrm{kWh} / \mathrm{m}^{3}$, similar to that of $\mathrm{LiCl}$ for the same operating parameters.

The desiccant solutions and water are stored in a single tank to minimize the storage volume and surface area subject to thermal loss. The required volume is half that that would be required if the water, diluted, and concentrated solutions were stored in separate tanks. The system does not require a source of ambient moisture or a source of low temperature heat because the enthalpy of vaporization can come entirely from within the tank. The LD heat pump lowers the lowest tank temperature that will still be able to meet the loads, increasing the tank $\Delta \mathrm{T}$ and energy density. The system operates at ambient pressure, reducing plumbing and storage tank costs as well as parasitic energy requirements to maintain a vacuum. The 
system rejects very little heat to ambient, in contrast to for example sorption cooling, where the enthalpy of condensation is rejected from the system to a heat sink such as an external cooling tower

\section{LD storage tank}

The key challenge to storing the water and liquid desiccant in a single tank is to avoid significant mixing of solutions of different $\mathrm{CaCl}_{2}$ mass fraction. Mixing must be avoided to avoid conversion of the stored chemical energy (represented by the absorption enthalpy) into sensible energy, which is subject to thermal loss. Mixing is minimized by using an immersed parallel-tube heat exchanger and a stratification manifold during charging and discharging operation (Figure 3.1.2(a))[Quinnell and Davidson, 2012b]. To illustrate the operation of the heat exchanger and manifold, consider charging operation. The fluid in the collector loop or from the regenerator enters the tank via the vertical heat exchanger and flows downward. As the heated solution descends through the heat exchanger, the tank is heated top-to-bottom via natural convection. The fluid motion is restricted to regions of uniform mass fraction because the thermal buoyancy force is less than the solute buoyancy force at the density interfaces, as illustrated in Figure 3.1.2(b). At the outlet of the heat exchanger, the fluid enters a stratification manifold where it rises until reaching a point of neutral buoyancy (equal $\mathrm{CaCl}_{2}$ mass fraction) and enters the tank. Over a wide range of the dimensionless parameters that govern mixing, the mass transfer between layers of differing $\mathrm{CaCl}_{2}$ mass fraction is low, typically with Sherwood numbers less than 100, and temperature stratification is maintained. Projected time scales for long term storage exceed 100 days.
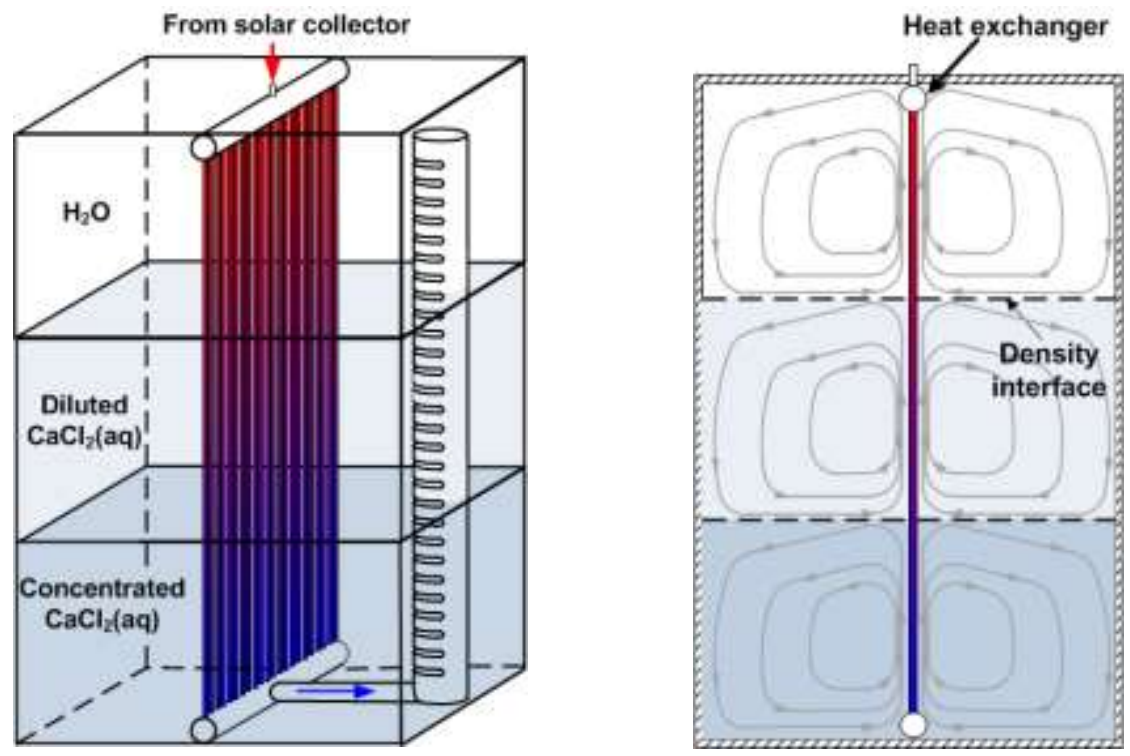

(a) (b)

Figure 3.1.2: Schematic of absorption/sensible storage tank: (a) illustration of immersed heat exchanger and stratification manifold in an unmixed storage with water, diluted and concentrated aqueous calcium chloride; (b) convective flow patterns during sensible charging.

A 1500 liter prototype tank has been built and tested with an emphasis on investigation of heat and mass transfer within the storage fluids during sensible charging [Quinnell and Davidson, 2012b]. Over a wide range of the dimensionless parameters that govern mixing, the mass transfer between layers of differing $\mathrm{CaCl}_{2}$ mass fraction is low, typically with 
Sherwood numbers less than 100 , and temperature stratification is maintained. Projected time scales for long term storage exceed 100 days.

A schematic and a photograph of the laboratory prototype storage vessel and instrumentation are shown in Figure 3.1.3. The prototype is a rectangular tank $(1.62 \times 1.01 \mathrm{x}$ $1.01 \mathrm{~m}$ ) made of glass to facilitate optical measurements of velocity and salt concentration fields. It is insulated with $5.1 \mathrm{~cm}$ thick rigid polystyrene insulation. A section of the insulation is removed to permit optical measurements of velocity and $\mathrm{CaCl}_{2}$ mass fraction. The immersed heat exchanger has 128 thin-walled polypropylene tubes plumbed in parallel. It is $0.99 \mathrm{~m}$ wide by $1.52 \mathrm{~m}$ tall with a total external heat transfer area of $3.57 \mathrm{~m}^{2}$. The tubes are each $6.35 \mathrm{~mm}$ O.D. and $0.45 \mathrm{~mm}$ thick and the tube-to-tube spacing is $1.27 \mathrm{~mm}$. The heat exchanger was fabricated by Fafco, a US manufacturer of solar collectors for pool heating.

Particle Image Velocimetry (PIV) and Planar Laser Induced Fluorescence (PLIF) were used to measure velocities and $\mathrm{CaCl}_{2}$ mass fractions over a 2-D imaging plane in the tank, as shown in Figure 3.1.3(a). The PIV system measures velocity by tracking the displacement of particles immersed in the tank fluid and the PLIF system measures $\mathrm{CaCl}_{2}$ mass fraction by measuring the fluorescence of a dye that is proportional to $\mathrm{CaCl}_{2}$ mass fraction. Transient experiments were conducted to simulate sensible charging over a range of operating conditions that represent the range of the dimensionless parameters that govern heat and mass transfer: the Rayleigh number, the buoyancy ratio of buoyancy forces due to differences in salt fraction and temperature difference, and the dimensionless fluid properties, Pr and Le. The dimensionless geometry is specified by the aspect ratio of a region of uniform salt concentration, $a$. Mass transfer is quantified by the dimensionless Sherwood number, Sh. Experiments were conducted for $8.4 \times 10^{8}<R a<5.5 \times 10^{10}, 0.8<N<18.2$, and $0.2<a<1.08$. Each experiment begins with a water region on top of a denser $\mathrm{CaCl}_{2}$ (aq) layer. Initially there was a $1-3 \mathrm{~cm}$ thick density interface between the two regions and each region was nearly isothermal. Sensible charging was initiated by flowing heated water through the heat exchanger. Fluid at the exit of the heat exchanger was not allowed to enter the tank. The experiments were terminated when the temperature of the fluid at the top of the tank reached the inlet temperature $(\sim 5-8 \mathrm{hr})$.

All transient experiments as well as a computational fluid dynamic study [Quinnell et al., 2011 and Quinnell and Davidson, 2012c] show that the density interfaces remain stable and the natural convection flows are confined to regions of uniform $\mathrm{CaCl}_{2}$ mass fraction. Representative data are provided for an experiment in which $\mathrm{Ra}$ is of order $10^{9}, \mathrm{~N}$ is of order 4, $\mathrm{Le}=404$, and $a=0.5$. 4). The $\mathrm{CaCl}_{2}$ mass fraction at the center of the upper region increases throughout the experiment from $0 \mathrm{~kg}-\mathrm{CaCl}_{2} / \mathrm{kg}$-soln. to $2.54 \times 10^{-4} \mathrm{~kg}-\mathrm{CaCl}_{2} / \mathrm{kg}$-soln. (Figure 3.1.4(a)). The final mass fraction is 75 times less than the mixing cup mass fraction (0.019 kg- $\mathrm{CaCl}_{2} / \mathrm{kg}$-soln.), demonstrating that for sensible charging mixing does not negatively impact energy storage density. Moreover, thermal stratification is developed and sustained (Figure 3.1.4(b)). 

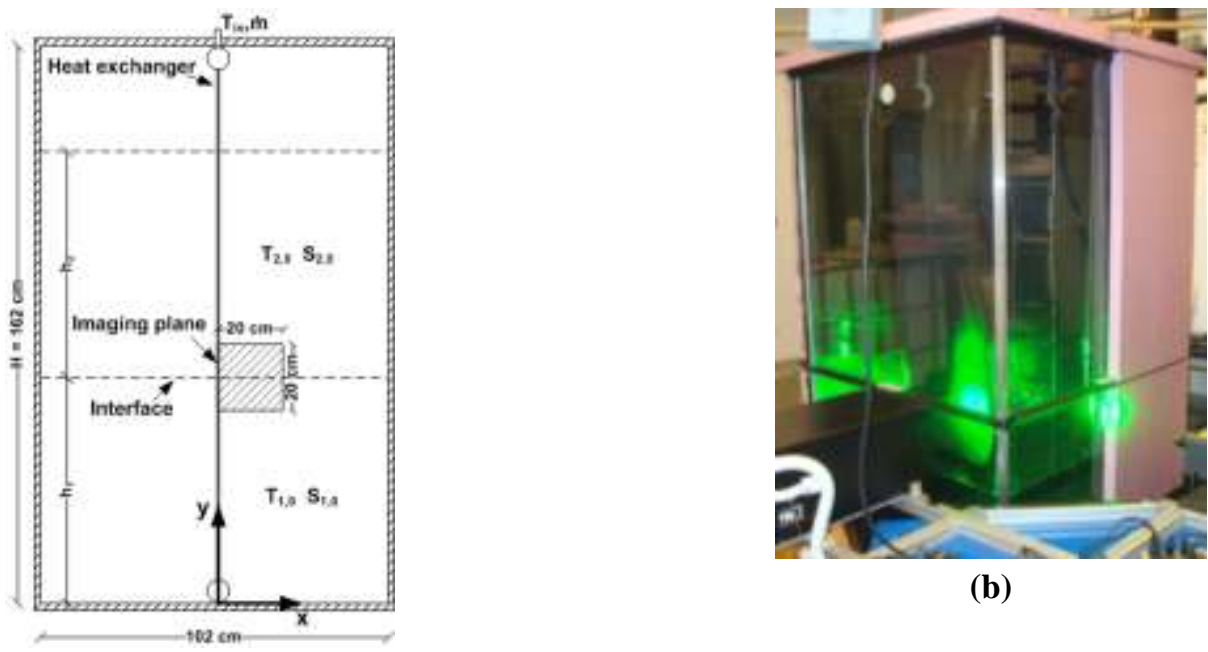

(b)

(a)

Figure 3.1.3: Prototype liquid $\mathrm{CaCl} 2$ storage tank: a) side view of the tank including dimensions and the location of the imaging plane for PIV and PLIF measurements; and (b) photograph of the prototype tank including laser sheet and PIV/PLIF imaging cameras [Quinnell and Davidson, 2012c].

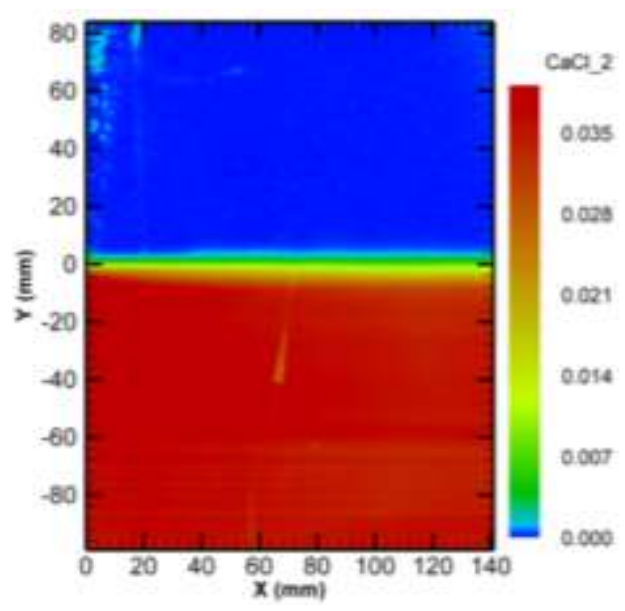

(a)

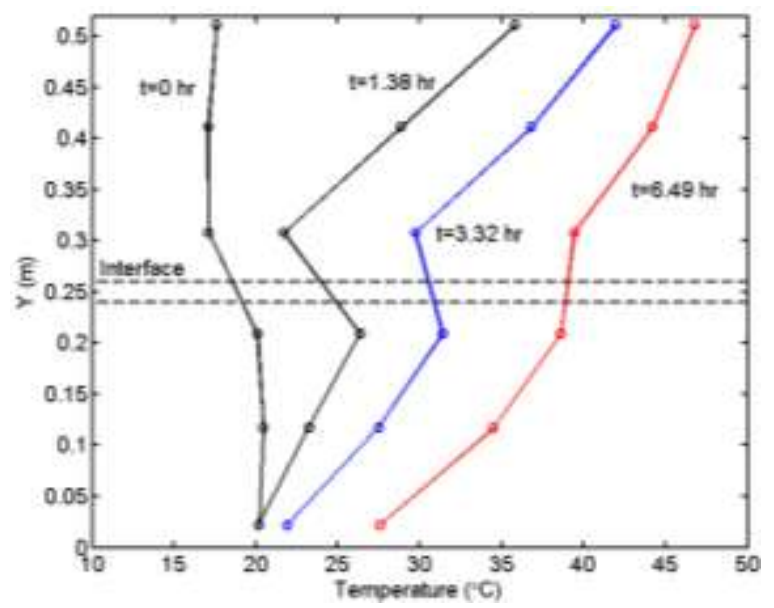

(b)

Figure 3.1.4: Illustration of ability of the ability of the immersed heat exchanger to eliminate mixing of solutions of different salt fraction and to establish thermal stratification in the liquid CaCl2 storage tank: (a) the $\mathrm{CaCl}_{2}$ distribution at the density interface for $R a=5.2 \times 10^{10}$ and $N=2.2$ after $6.55 \mathrm{hr}$ of heating by natural convection; (b) vertical temperature distributions during transient heating [Quinnell and Davidson, 2012b].

Sherwood and Nusselt correlations suggested by the data enable long-term storage tank models for to model mass transfer and heat transfer over seasonal timescales. The correlations allow the prediction of the loss of absorption potential due to mass transfer. The recommended correlations are $\mathrm{Sh}=0.001 \mathrm{Ra}^{0.28} \mathrm{~N}^{-0.69} \mathrm{Le}^{1.17}$ and $\mathrm{Nu}=0.45 \mathrm{a}^{0.5} \mathrm{Ra}^{0.28}$ for $7 \times 10^{3}<\mathrm{Ra}<3.3 \times 10^{9}, 1<\mathrm{N}_{0}<26.4,15<\mathrm{Le}<1.5 \times 10^{4}$, and $0.125<\mathrm{a}<1$ [Quinnell, 2012].

A useful metric for long-term storage performance is the time scale of loss in storage due to mixing in the tank. The timescale of sorption energy storage was estimated from a 1-D species balance on a region of water separated from a $\mathrm{CaCl}_{2}$ (aq) solution by a density interface, where the mixing time constant, is equivalent to the time it takes the water region to reach $63 \%$ of the final mixed $\mathrm{CaCl}_{2}$ mass fraction. For this calculation, we assume a fixed 
tank volume of $4 \mathrm{~m}^{3}$ and a fully charged tank equally split between water and $\mathrm{CaCl}_{2}$ (aq) with $0.59 \mathrm{~kg}-\mathrm{CaCl}_{2} / \mathrm{kg}$-soln. at $95^{\circ} \mathrm{C}$. We assume the sensible storage is discharged at $T_{L}=47^{\circ} \mathrm{C}$ and absorption storage is discharged at $0.35 \mathrm{~kg}-\mathrm{CaCl}_{2} / \mathrm{kg}$-soln. The ambient temperature is assumed to be $20^{\circ} \mathrm{C}$. The time constants obtained from experimental measured values of Sherwood number are comparable to the maximum 140 day storage period need for space heating in a cold climate. The reported results do not consider mixing due to fluid entry to the tank; however experiments with a porous manifold showed good control of fluid motion.

The second major component of the tank, the stratification manifold, is under investigation. The challenge of a manifold in the present system is the implementation within large density distributions (2 to 60\%). The University of Minnesota is working on the development of a fabric deformable manifold. We have developed a TRNSYS type for the liquid desiccant tank and it is available upon request. It does not currently include the immersed heat exchanger.

\section{LD heat pump ( $L D-H P)$}

In the LD-HP, an LD flow is separated from a counter-flowing water stream with two membranes that pass water vapor to the LD, as in Figure 3.1.5(a). The vapor absorbed in the LD lifts the LD outlet temperature above the inlet temperature $\left(\Delta \mathrm{T}_{\text {lift }}\right)$. The membranes are separated by a narrow air gap which improves performance by reducing sensible heat loss between the hot LD and cool water. $\Delta \mathrm{T}_{\text {lift }}$ depends on source temperature and LD concentration. When $\left(\mathrm{T}_{\text {set }}-\mathrm{T}_{\mathrm{amb}}\right)$ $<\Delta \mathrm{T}_{\text {lift, }}$, the HP can produce energy to meet DHW and space heating loads during that period. Using ambient energy at a lower temperature than heat in the tank (or other sensible heat store) allows more of the collected heat to stay in the local long-term storage, but it uses more LD and increases regeneration needs.

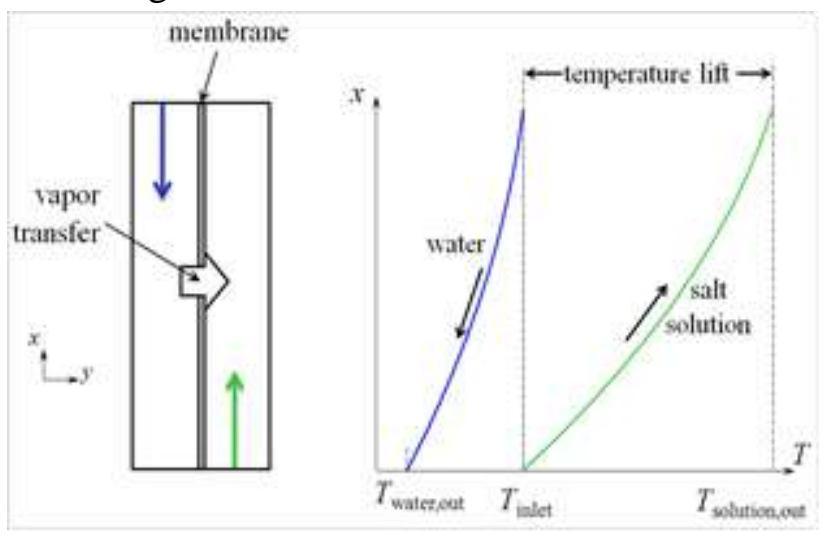

(a)

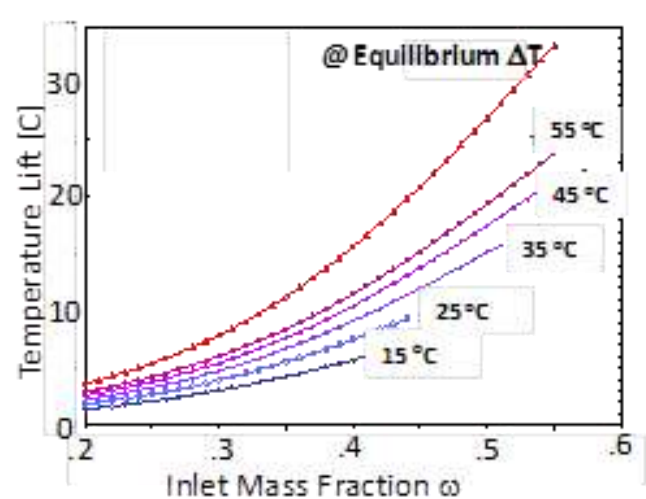

(b)

Figure 3.1.5: LD heat pump: a) schematic (left) and temperatures (right) in fluids; b) temperature lift maximum and as function of the inlet mass fraction, for five inlet temperatures.

A bench-scale prototype of the liquid desiccant heat pump was built and tested in 2010-2011. The prototype had $0.25 \mathrm{~m}^{2}$ of transfer area, which was built with alternating rows of hollow-fiber membranes: one set of rows contained liquid desiccant, the other row water. During testing of the prototypes, the heat flux across the membranes ranged from around 20 to $120 \mathrm{~W} / \mathrm{m}^{2}$. The testing, which considered different flow rates, inlet temperatures, and desiccant concentrations, matched the modeling predictions within 10\% (see Figure 3.1.6). 


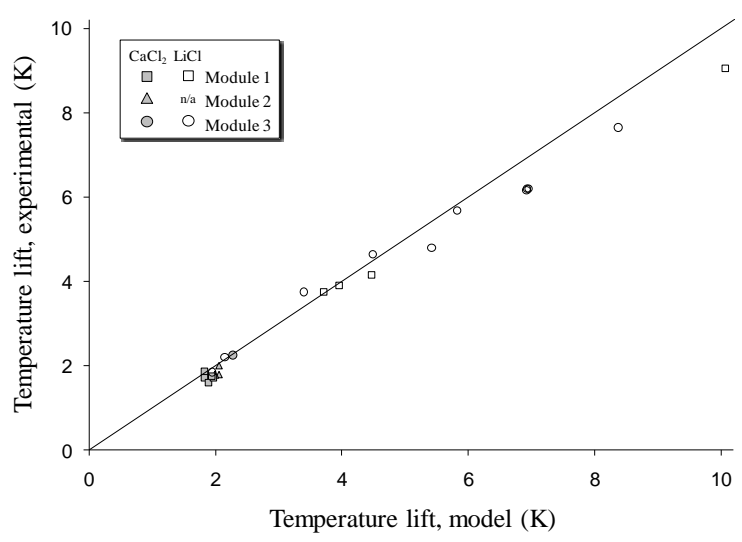

Figure 3.1.6: Model-experiment comparison of temperature lift of membrane heat pump (adapted from [Woods, et al., 2011]).

\section{LD air conditioner $(L D-A C)$}

The LD-AC is a two-stage device (Figure 3.1.7), using de-humidification followed by indirect evaporative cooling. It is termed a desiccant-enhanced evaporative air conditioner (DEVAP) [Kozubal, et al., 2011]. A numerical model of this process was recently validated with experiments [Woods, et al., 2013]. As in Figure 3.1.7(a), the first stage of the DEVAP process is a dehumidifier that uses LD contained behind a membrane to remove moisture from the process air (state 1 to 1.5). Across a plastic plate from the LD, water evaporates into an exhaust airstream (3 to 4), which keeps the LD temperature and vapor pressure low. The second stage is a counter-flow indirect evaporative cooler. A portion of the cool, dry outlet air (state 2) serves as the inlet to the wet-side channels on either side of the process air (states 2 to 5). The DEVAP process is shown on a psychrometric chart in Figure 3.1.7(b). Electricity use is limited to fans and pumps. The electricity use over a year is roughly $85 \%$ less than with a conventional vapor compression AC. DEVAP essentially shifts cooling from electricity for the compressor to heat for the LD regenerator. Any heat source with adequate temperature can be used, although solar is used exclusively here. The required regeneration energy is a strong function of the climate humidity; humid climates have much more regeneration need than dry climates.

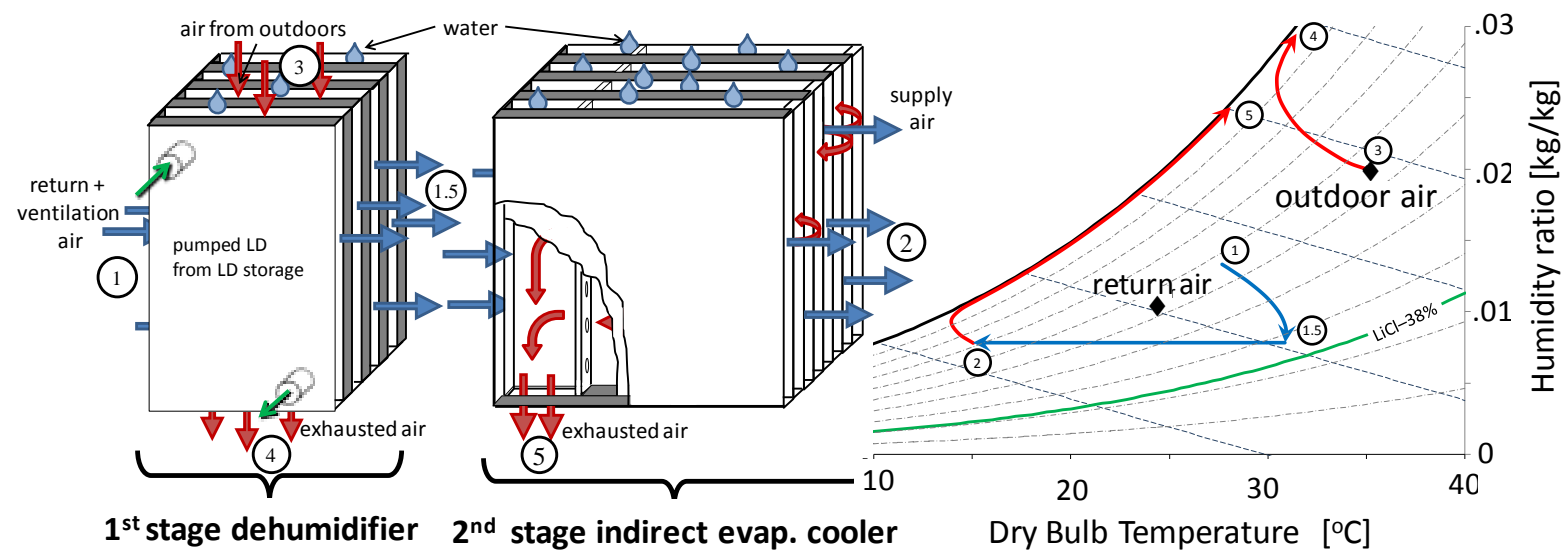

(a)

(b)

Figure 3.1.7: Liquid desiccant-based air conditioning. (a) schematic of two-stage DEVAP air conditioner; (b) process state diagram on psychrometric chart (adapted from [Kozubal, et al., 2012]). 
Each stage of the liquid desiccant DEVAP air conditioner was built and tested independently, as documented in [Woods, et al., 2013]. The first stage prototype provided approximately 0.5 tons of latent cooling, while the second stage prototype provided approximately 0.5 tons of sensible cooling. The prototypes were tested for different flow rates, temperatures, and humidities of the airstreams and temperatures and concentrations of the liquid desiccant. Figure 3.1.8 shows that the numerical model generally agreed with the experiments within $10 \%$.

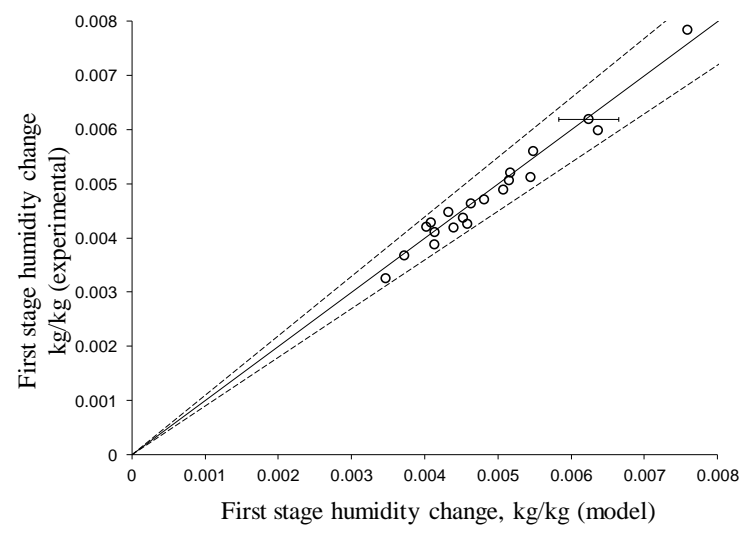

(a)

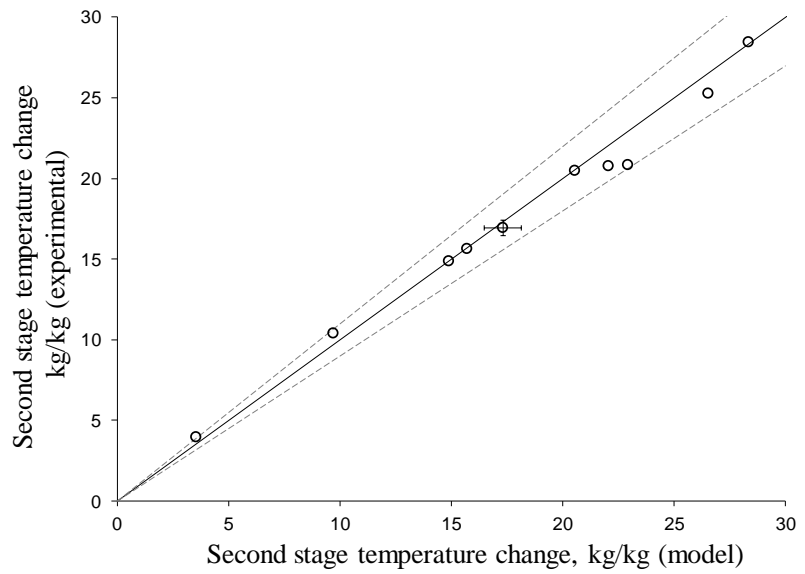

(b)

Figure 3.1.8: Model-experiment comparison for the DEVAP liquid desiccant chiller (a) first stage (b) second stage (adapted from [Woods, et al., 2013]). 


\subsection{Heat Storage Based on a $\mathrm{NaCH}_{3} \mathrm{COO}$ Water Mixture for Solar Heating Systems}

\section{Concept}

A conceptual diagram of the solar heating system conceived by the Technical University of Denmark is shown in Figure 3.2.1 [Schultz and Furbo, 2004; Schultz and Furbo, 2005; Furbo et al., 2006; Schultz and Furbo, 2006; Schultz and Furbo, 2007; Schultz, 2008; Streicher, 2008; Schultz et al., 2008; and Streicher et al., 2008]. The solar heating system with a compact seasonal heat storage based on stable supercooling of a sodium acetate water mixture is intended to cover the total yearly heat demand and hot water consumption of a low energy one family house. Calculations have shown that a $36 \mathrm{~m}^{2}$ solar heating system can fully cover the yearly heat demand of a low energy house in Denmark if the solar heating system is equipped with a $6 \mathrm{~m}^{3}$ seasonal heat storage with a sodium acetate water mixture supercooling in a stable way. The heat storage is divided into a number of separate heat storage modules.

The heat storage module concept is based on the advantage of stable supercooling. By using this concept the heat storage module will have no heat loss for a long period making seasonal heat storage possible. If a sodium acetate water mixture, which has a melting point of $58^{\circ} \mathrm{C}$, has been fully melted during the sunny summer, it can cool down in its liquid phase to the surrounding temperature and still preserve the latent heat related to the heat of fusion. The heat storage module can be left in this state with no heat loss until a heat demand occurs in the house in the winter, in which case solidification is activated, the heat of fusion is released, and the heat storage temperature increases almost immediately to the melting point. The principle of supercooling is shown in Figure 3.2.2 [Schultz and Furbo, 2007].

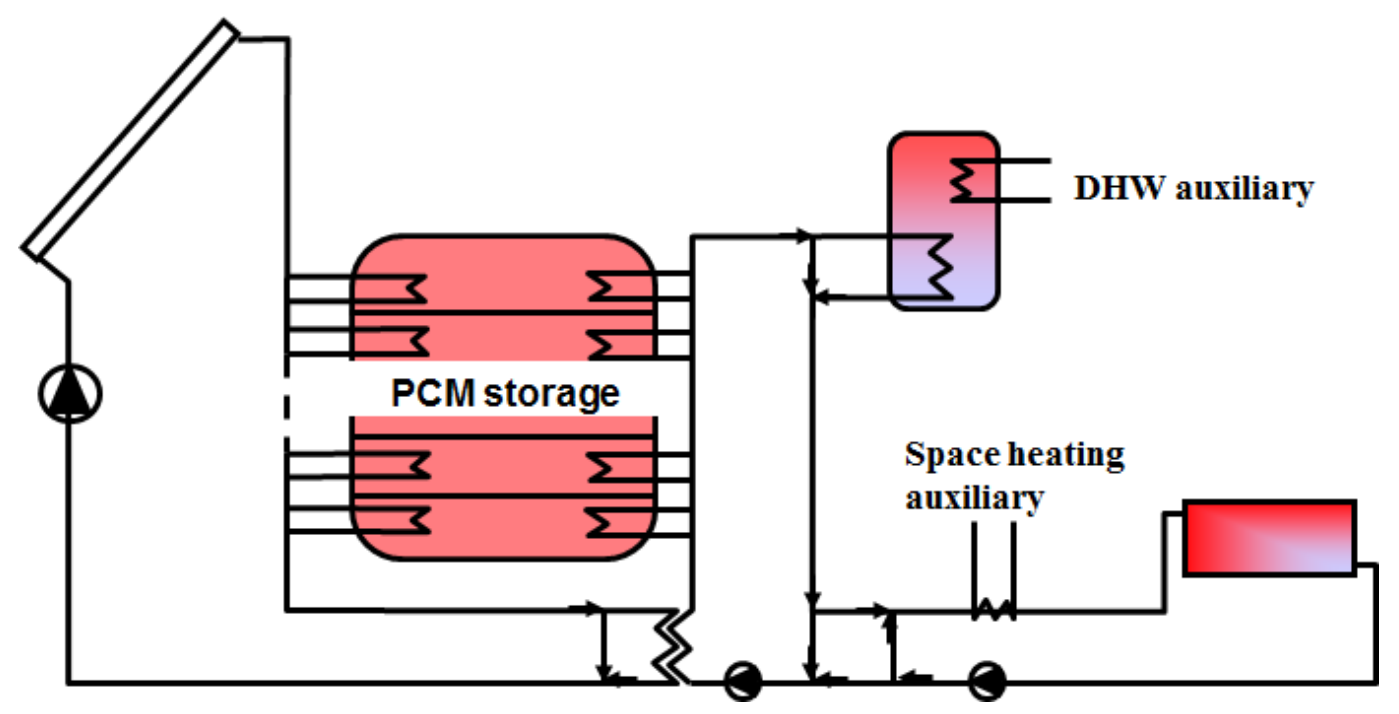

Figure 3.2.1: Schematic sketch of solar heating system with compact seasonal PCM heat storage. 


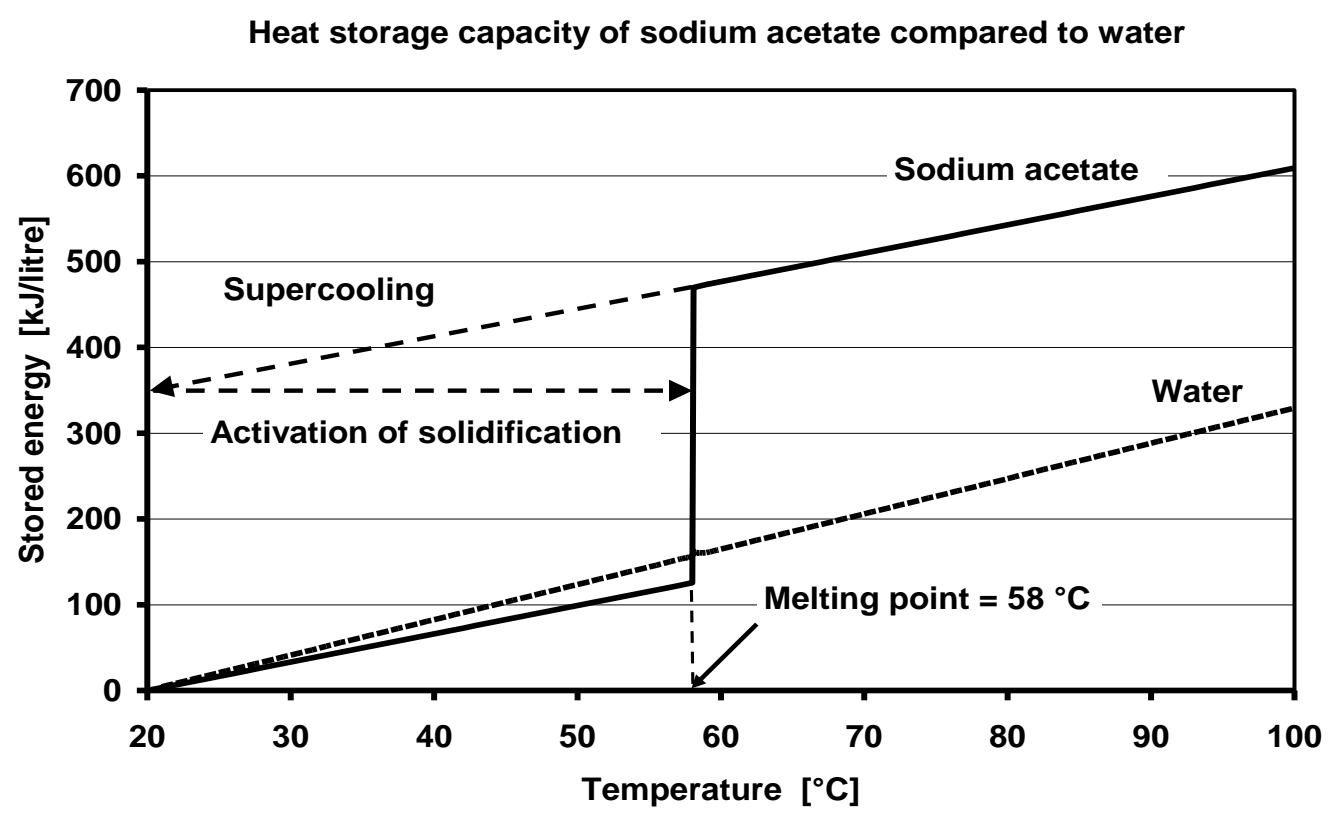

Figure 3.2.2: Illustration of energy content of sodium acetate compared to water as well as the supercooling process.

\section{Status of development}

Three differently designed heat storage modules with a sodium acetate mixture consisting of 58\% (weight $\%$ ) sodium acetate and $42 \%$ (weight $\%$ ) water have been tested in a laboratory heat storage test facility. The salt water mixture volumes of the heat storage modules are 234 1, 2081 and 1601 [Furbo et al., 2010; [Furbo et al., 2011; Fan et al., 2011; Fan et al., 2012; and Furbo et al., 2012].

Figure 3.2.3 shows a schematic sketch of the first heat storage module with approximated dimensions in $\mathrm{mm}$. The module material is steel and the wall thickness is $2 \mathrm{~mm}$. Both the upper and lower surfaces of the flat module are used as heat transfer areas for heat transfer to and from the module. Water, which is used as the heat transfer fluid, is pumped through two copper absorbers placed below and above the module as shown in Figure 3.2.4. Wooden slats are placed above and below the absorber strips in such a way that there will be a good thermal contact between the fins and the module surfaces. The construction is insulated with $100 \mathrm{~mm}$ mineral wool.

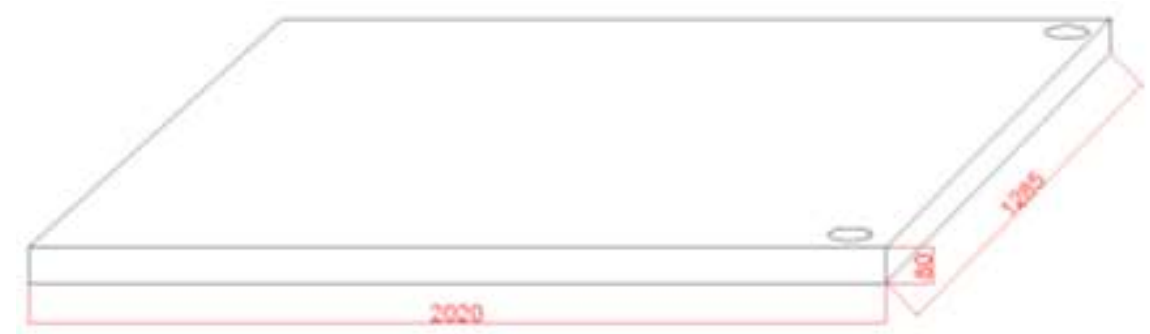

Figure 3.2.3: Principle sketch of the first heat storage module with two holes used to fill in the salt water mixture. 

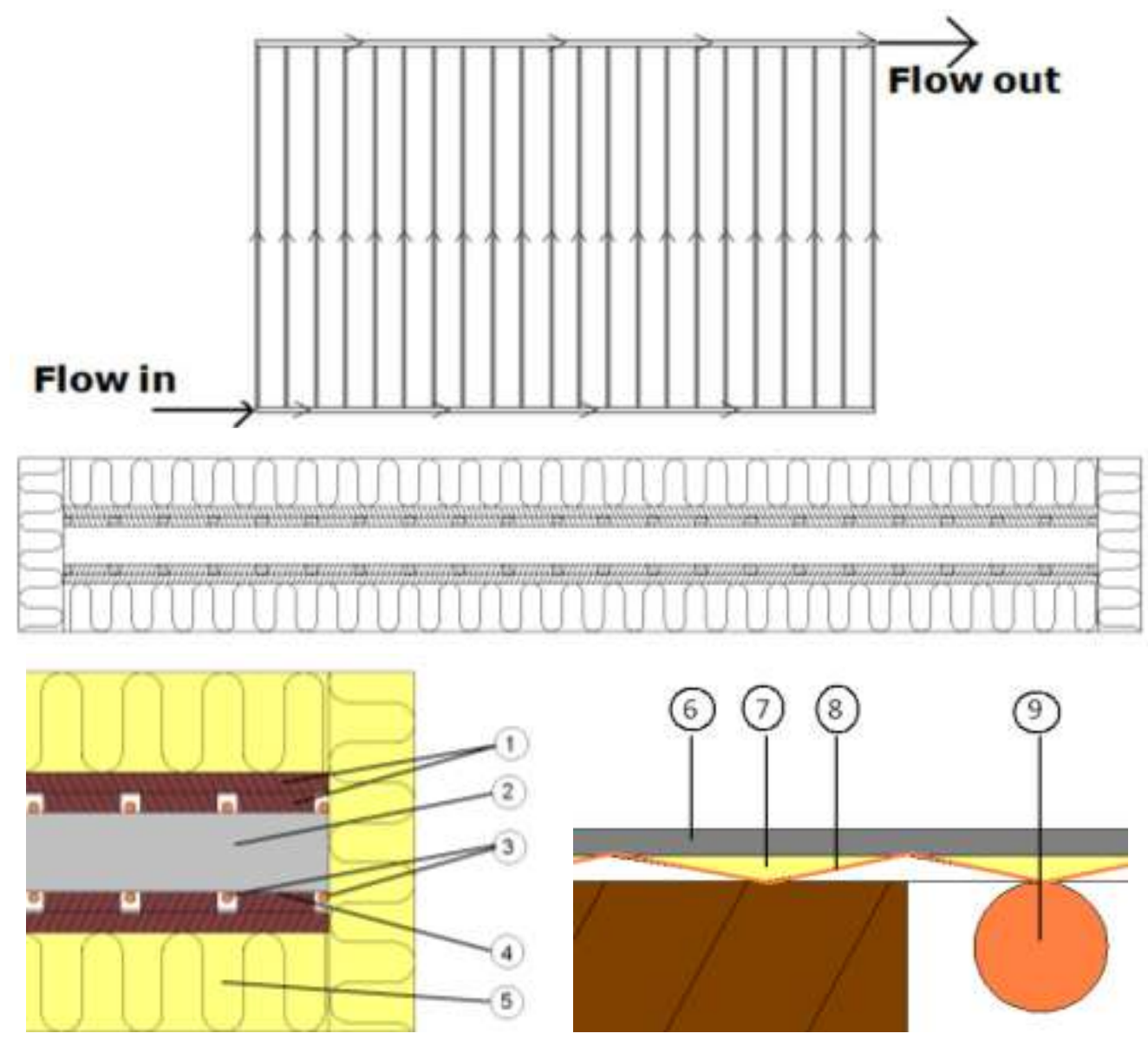

1: Wooden slats. 2: Salt water mixture in steel module. $3 \&$ 9: Copper pipes. 4 \& 8: Absorber fin. 5: Mineral wool. 6: Bottom of module. 7: Paste with good thermal conductivity.

Figure 3.2.4: Principle sketch of the first heat storage module with heat transfer system and insulation.
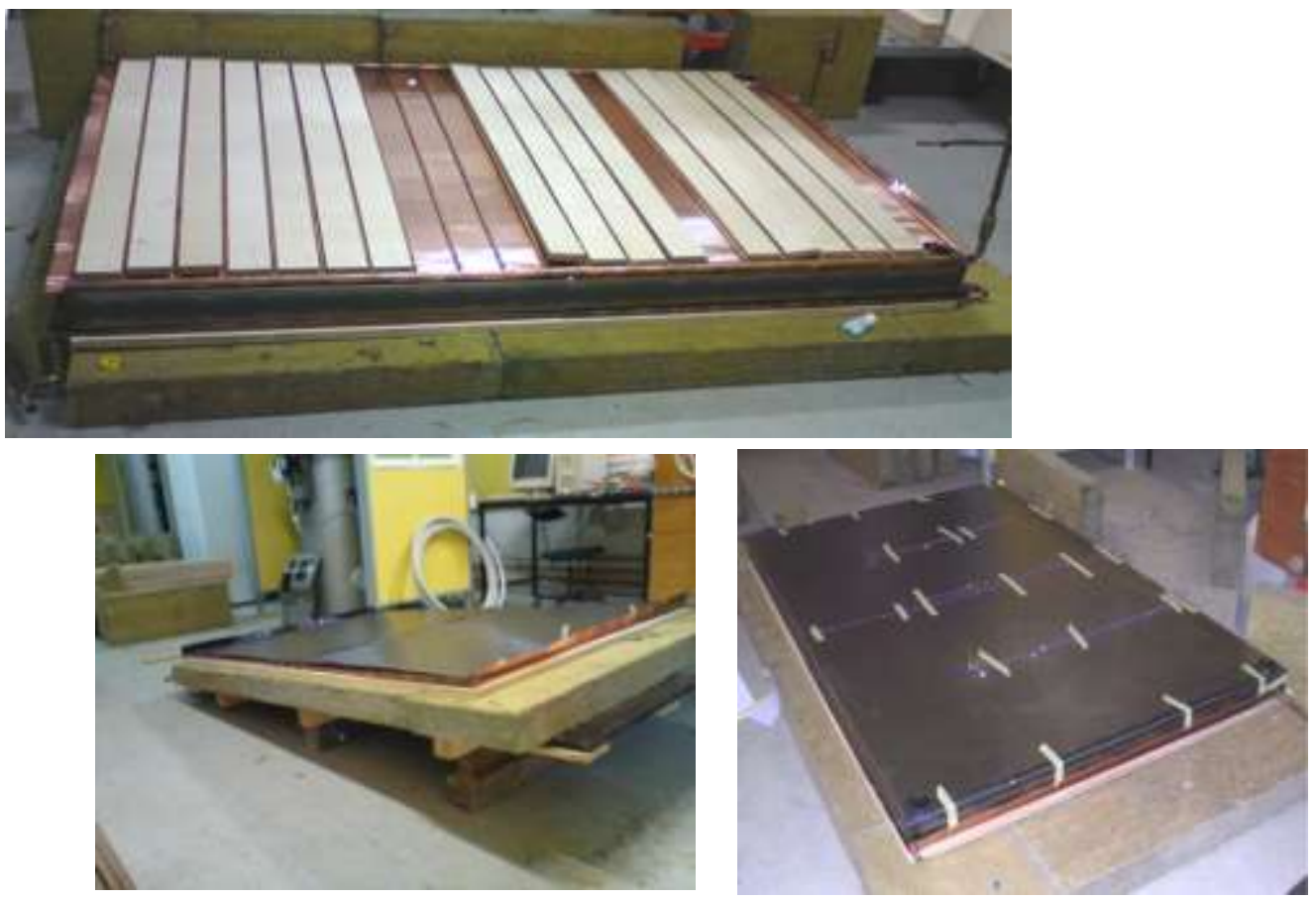

Figure 3.2.5: Photos of the first heat storage module.

IEA SHC/ECES - Task 42/24 - Compact Thermal Energy Storage 
The module is filled with $305 \mathrm{~kg}$ salt water mixture corresponding to a module volume of about 234 1. Figure 3.2.5 shows photos of the module inclusive thermocouples for measurements of the module surface temperatures. The flat module is placed with a small tilt from horizontal.

The heat storage module has been tested by means of two different heat transfer methods. Figure 3.2.6 shows photos of the heat storage module using the second heat transfer method. Figure 3.2.7 shows a schematic sketch of the lower part of the heat storage module. The heat storage module is placed in a stainless steel container with small separate rooms for water below and above the module. Silicone pipes are attached to the upper and lower surfaces of the module in such a way, that water pumped through the separate rooms will flow through the rooms in a serpentine way, guided by the silicon pipes. The water will therefore flow through the lower room in direct contact with all parts of the lower module surface, and water will flow through the upper room in direct contact with all parts of the upper module surface. Heat is transferred from/to the salt water mixture, to/from the upper or lower module surface and the water is flowing through the upper or lower room.
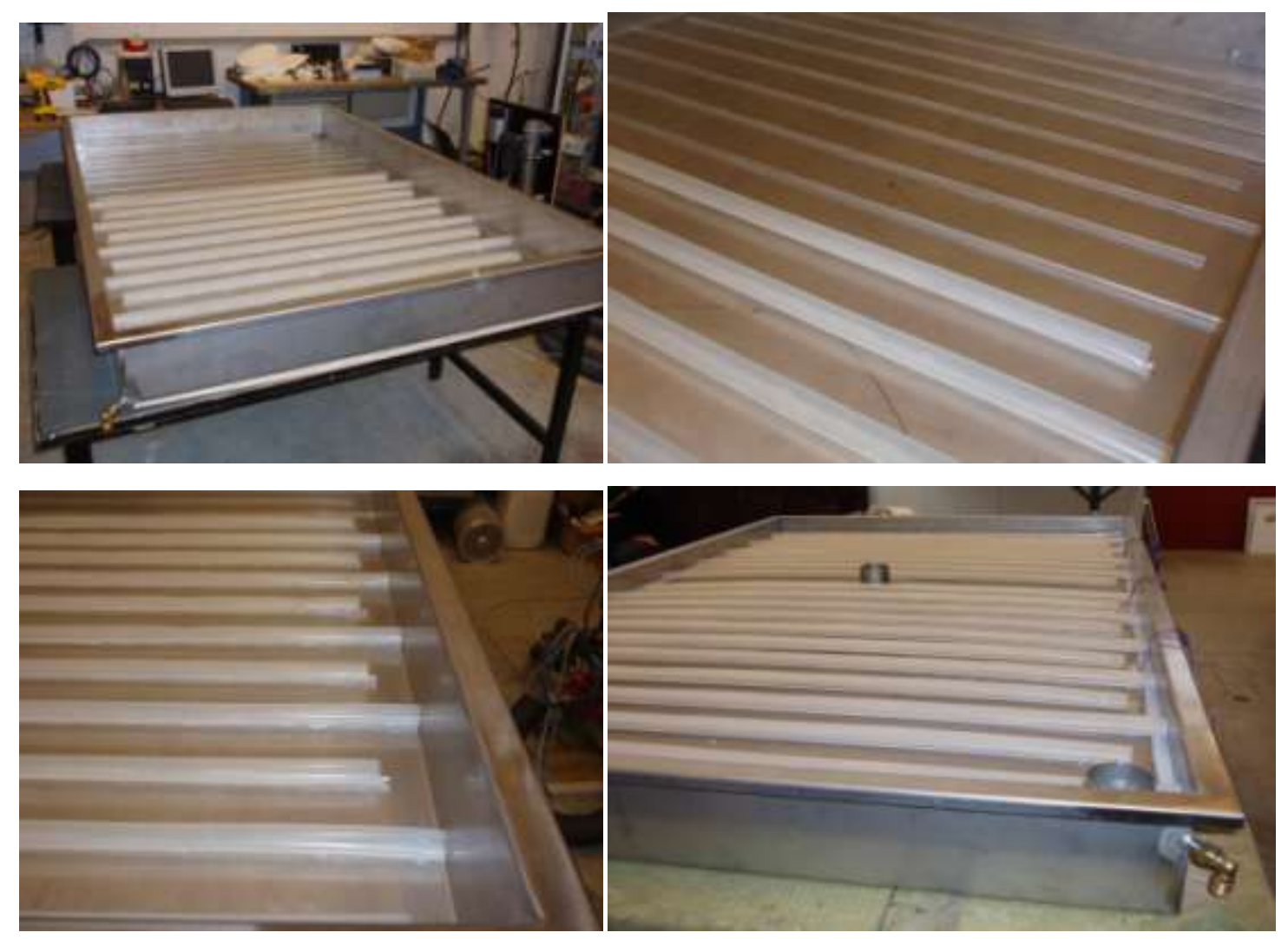

Figure 3.2.6: Photos of the first heat storage module with silicone pipes attached to the upper surface. 


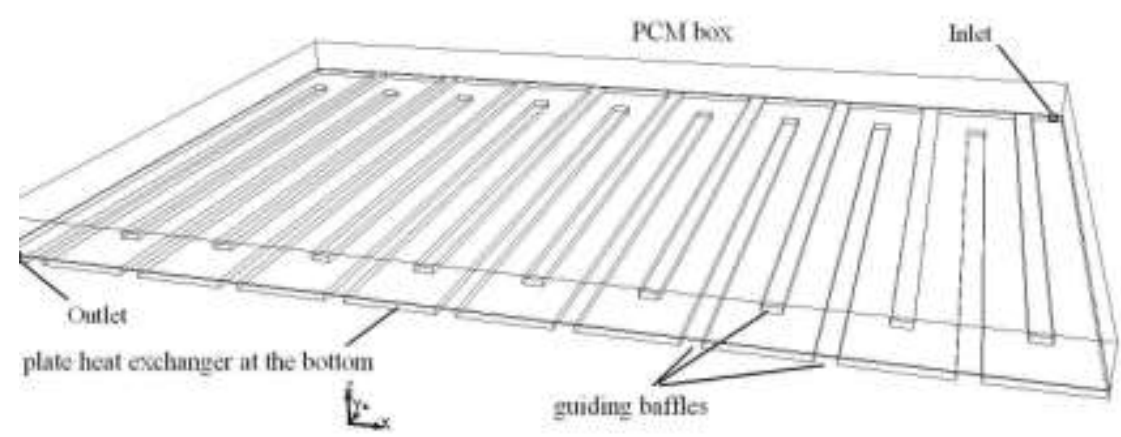

Figure 3.2.7: Schematic sketch of the lower part of the first heat storage module.

Figure 3.2.8 shows a photo of the second heat storage module and Figure 3.2.9 shows a schematic sketch of the heat exchangers of the second heat storage module. The heat storage module material is steel and all wall thicknesses are $2 \mathrm{~mm}$. The heat storage module is a flat sandwich construction with a $5 \mathrm{~cm}$ salt water mixture room surrounded by two $2 \mathrm{~mm}$ heat exchanger rooms with water below and above the salt water mixture room. The heat exchanger rooms are welded together with the salt water mixture room. Heat is transferred to and from the salt water mixture by means of water flowing through the heat exchanger rooms in a serpentine way. Rigid steel bars are welded together with the module with the aim to maintain the geometry of the module. The length and the width of the module are $3000 \mathrm{~mm}$ and $2000 \mathrm{~mm}$. The volume of the salt water mixture in the module is 2081.

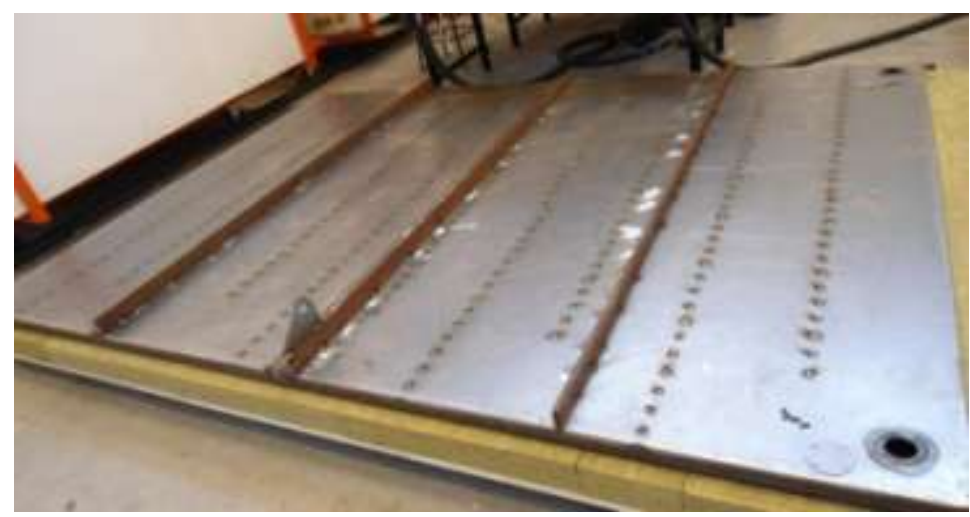

Figure 3.2.8: Photos of the second heat storage module with two holes used to fill in the salt water mixture.

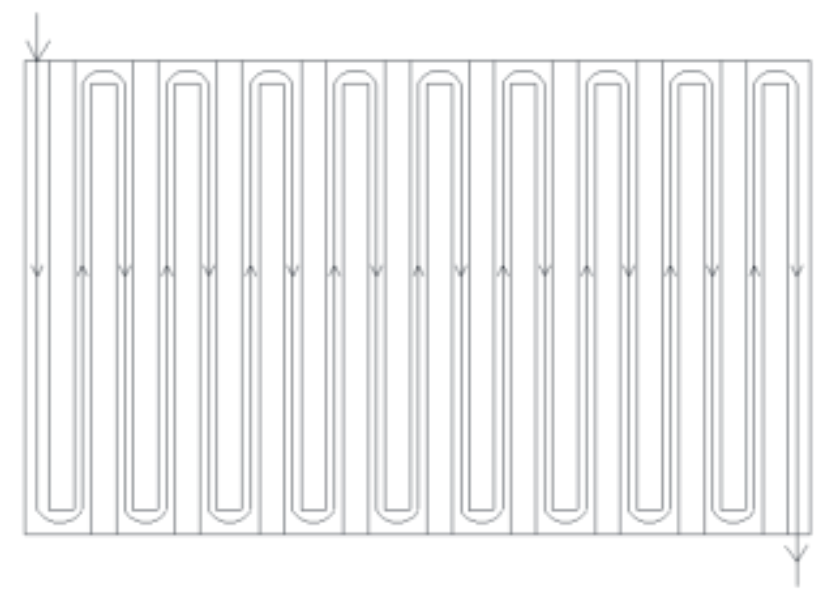

Figure 3.2.9: Schematic sketch of the heat exchanger of the second heat storage module. 


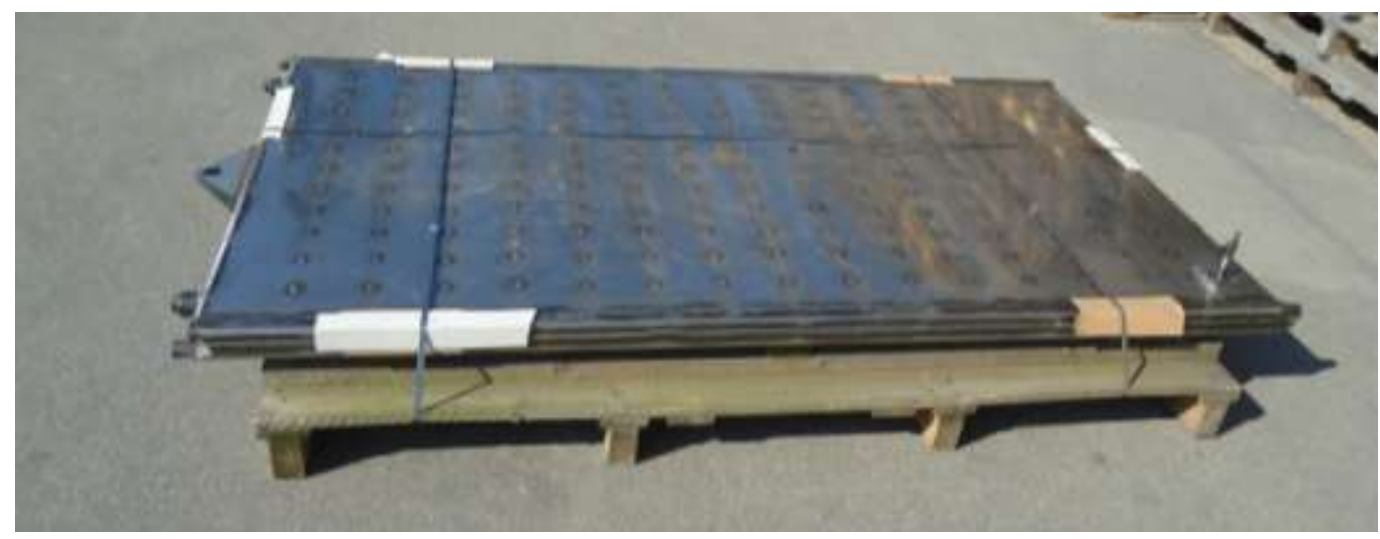

Figure 3.2.10: Photo of the third heat storage module with two holes at the left hand side of the module used to fill in the salt water mixture.

Figure 3.2.10 shows a photo of the third heat storage module. The heat storage module material is steel and all wall thicknesses are $2 \mathrm{~mm}$. The heat storage module is a flat sandwich construction with a $5 \mathrm{~cm}$ salt water mixture room surrounded by two $2 \mathrm{~mm}$ heat exchanger rooms with water below and above the salt water mixture room. The heat exchanger rooms are welded together with the salt water mixture room. Heat is transferred to and from the salt water mixture by means of water flowing through the heat exchanger rooms in 16 parallel channels. The length and the width of the module are $2.454 \mathrm{~m}$ and $1.208 \mathrm{~m}$. The volume of the salt water mixture is 1601.4 steel bars inside the salt water mixture room are welded together with the inner surfaces of the room in order to maintain the geometry of the module, and two pipes used to fill in the salt water mixture are located at one end of the module in such a way that the salt water mixture is filled in the module, when the module is in a vertical position. The pipes are placed in such a way, that a part of the salt water mixture will be placed outside the $2.454 \mathrm{~m}$ and $1.208 \mathrm{~m}$ plane.

A small brass tank shown in Figure 3.2.11 is in good thermal contact attached to the outer surface of the side of the modules. This brass tank, which has a pressure of 5 bar, can be filled with liquid $\mathrm{CO}_{2}$ from a pressure container. The boiling point of the $\mathrm{CO}_{2}$ in the brass tank is thus $-78^{\circ} \mathrm{C}$. The solidification of the salt water mixture can be started by cooling down a small part of the supercooled salt water mixture to $-16^{\circ} \mathrm{C}$ by boiling a small amount of $\mathrm{CO}_{2}$ in the small brass tank [Furbo et al., 2010].

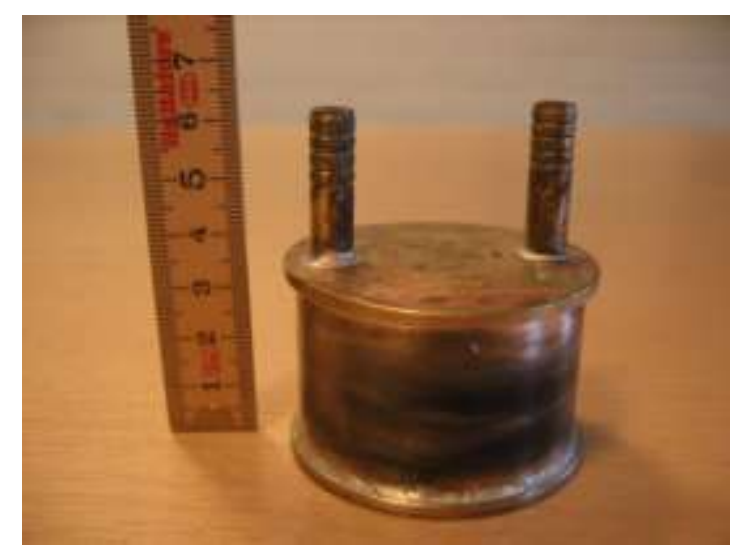

Figure 3.2.11: Brass tank with $\mathrm{CO}_{2}$ used for starting the solidification. 
The three heat storage modules have been tested in a laboratory heat storage test facility. The following short term tests have been carried out for the modules:

- Charge tests through the bottom of the modules

- Charge tests though the bottom and the top of the modules

- Test periods without charge and discharge

- Discharge tests through the top of the modules

- Discharge tests through the top and the bottom of the modules

- Activation of solidification by boiling $\mathrm{CO}_{2}$ on outer surface of modules

Further, calculations with CFD models have been carried out in order to elucidate the heat exchange capacity rates to and from the salt water mixture for charge and discharge periods with different operation conditions. Furthermore, experience on filling in the salt water mixture in the modules has been gained.

The following experience was gained from the investigations:

- Stable supercooling is achieved in the first and second module if all crystals are melted

- Supercooling is not achieved in the third module, most likely due the irregular inner surface of the salt water mixture room caused by the 4 steel bars or by unmelted crystals remaining in the pipes used to fill in the salt water mixture

- The activation of solidification by using boiling $\mathrm{CO}_{2}$ is reliable

- No problems on reliability/durability of the salt water mixture so far

- The measured heat content of the modules is reasonable close to the calculated heat content of the modules

- The heat exchange capacity rates to and from the first module are far lower than the required $500 \mathrm{~W} / \mathrm{K}$, both when using the copper absorbers and by using water in direct contact with the surfaces of the module.

- The heat exchange capacity rates to and from the second module are close to the required $500 \mathrm{~W} / \mathrm{K}$, if both the upper and lower heat exchangers are used.

- The second module is too heavy to fill in horizontal position. Only $271 \mathrm{~kg}$ salt water mixture, corresponding to $208 \mathrm{l}$, that is $69 \%$ of the potential salt water mixture volume of $300 \mathrm{l}$, was filled in the module. Air remained in the salt water room during the tests.

- The pressure established by circulation pumps circulating water through the heat exchangers of the second module is so high, that it resulted in deformation of the module, see Figure 3.2.12.

- The heat exchange capacity rates to and from the third module are, assuming that the module is upscaled to 320 l, close to the required $500 \mathrm{~W} / \mathrm{K}$ [Fan et al., 2012].

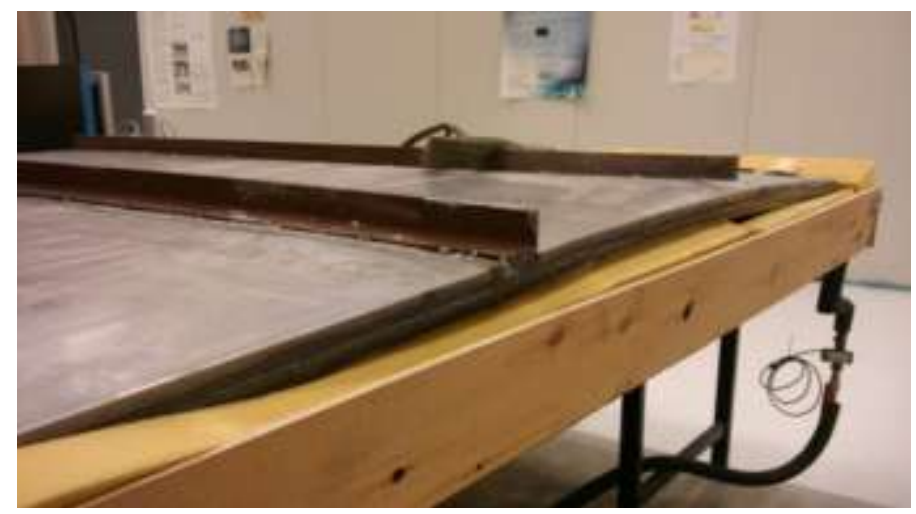

Figure 3.2.12: Photo of the damaged second heat storage module. 
Based on the test results and experience gained with the modules the following recommendations for the design of heat storage modules can be given. A height of about $5 \mathrm{~cm}$ of the salt water mixture room of a heat storage module is suitable. Heat exchangers above and below the salt water mixture room with water rooms with a height of $2 \mathrm{~mm}$ and with parallel channels, through which water is flowing, are suitable. The heat exchangers must be point welded to the outer surfaces of the salt water room to make a durable construction.

The inner part of the salt water room must be smooth without any "equipment" to stabilize the construction. The holes used to fill the salt water mixture into the salt water room must be placed at the end of the module, so that the module can be completely filled in a vertical position. The holes must be designed, so that no crystals can be placed outside the dimensions of the salt water mixture room.

\subsection{Solid Adsorption Closed-Cycle Active Solar Heating}

A closed-cycle solid adsorption solar heating system has been developed in a series of EU and nationally financed projects (HYDES [Welteroth and Mittelbach, 2001] and MODESTORE [Jaehnig et al., 2006]) as well as part of IEA-SHC Task 32. The results presented here are the outcome of the project parts carried out by AEE INTEC, Austria. In a new research project started in March 2012 (EU financed project COMTES) the system concept from the previous projects is being further developed in collaboration with ITW (University of Stuttgart, Germany) in order to work with a new sorption material (zeolite) and to deliver heat not only for space heating but also for domestic hot water preparation.

\section{Concept}

The hydraulic layout of the system concept (see Figure 3.3.1) consists of

- solar thermal collectors (e.g. evacuated tube collector or evacuated flat-plate collector)

- sorption heat store with integrated heat exchangers for charging and discharging.

- evaporator/condenser connected to a horizontal ground heat exchanger or boreholes as low temperature heat source and heat sink.

- vapor transport between sorption heat store and evaporator / condenser by pressure differences under vacuum conditions.

- separate container to store liquid water that has been desorbed and condensed

- small domestic hot water store to be able to withdraw sufficient thermal capacity for domestic hot water preparation.

The solar thermal collectors can charge either the sorption heat store or the domestic hot water store or both at the same time. For charging the sorption store temperatures between $180^{\circ} \mathrm{C}$ and $200^{\circ} \mathrm{C}$ are needed. Therefore, at least highly efficient evacuated tube collectors have to be used.

The desorbed water is condensed in the condenser heat exchanger. The condenser heat exchanger is connected to a ground heat exchanger or boreholes to ensure condensation during desorption operation. The same ground heat exchanger or boreholes are used to deliver the heat of evaporation for adsorption operation. The condensed water is stored in a separate container. 


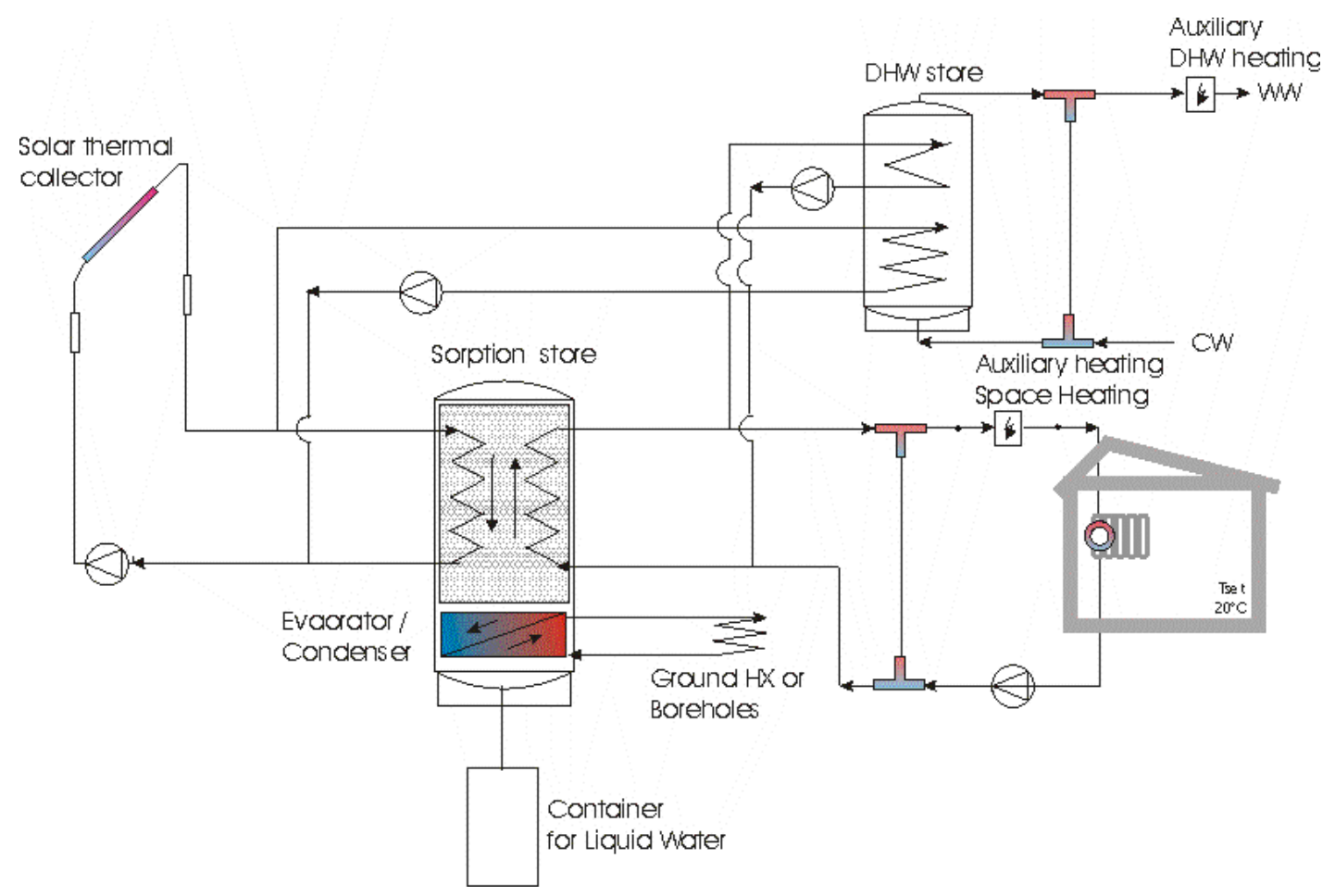

Figure 3.3.1: System concept of a closed-cycle sorption heat store, source: AEE INTEC, Austria.

In case that there is not enough heat in the DHW store to cover the DHW load, the DHW store can be charged from the sorption store if there is enough sensible heat available. During winter operation, the space heating load is covered directly from the sorption heat store - either by using the sensible heat available in the store or by evaporating water from the separate container via the ground heat exchanger and adsorbing it until the desired flow temperature for space heating is reached.

The DHW store is charged directly from the solar collectors and the upper part can be recharged once a day from the sorption store by adsorbing water until the set temperature for DHW is reached.

\section{Status of development}

Two generations of system concepts have been built within the projects HYDES and MODESORE mentioned above. In both projects, silica gel and water have been used as working pair. The second generation system has been installed in a single-family house and operated for one complete year. Figures 3.3.2-3.3.4 show some impressions from the installation of this pilot plant.

The system concept applied in this pilot plant differed somewhat from the one described. In this system, heat for evaporation was gained only from the solar thermal collectors and the heat of condensation was dissipated at night also via the collectors. In addition, the sorption heat store was used for space heating only and not for domestic hot water preparation. 


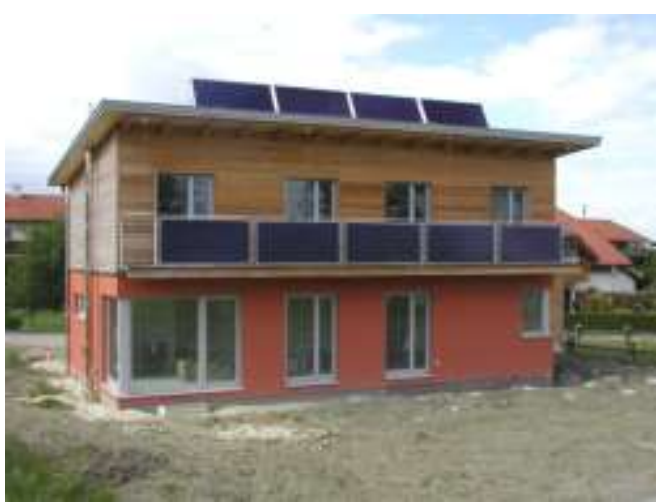

Figure 3.3.2: Single-family house in Upper Austria with two solar thermal collector arrays (on the roof and integrated in the balcony), source: AEE INTEC, Austria.

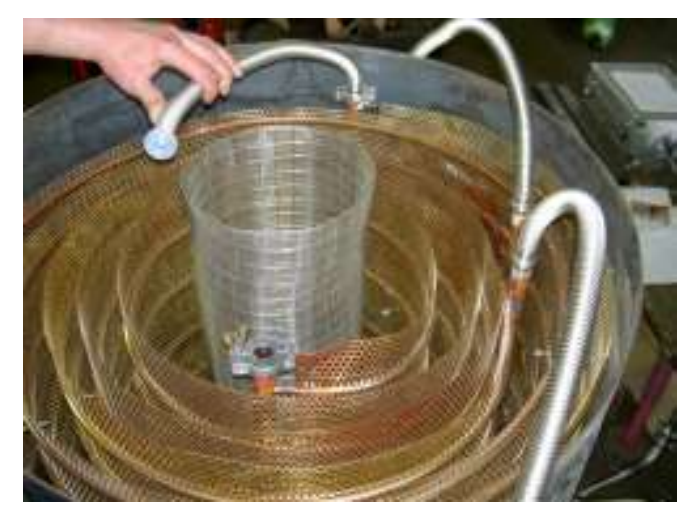

Figure 3.3.4: Spiral heat exchanger made from perforated sheet copper, source: AEE INTEC, Austria.

The operation of the system was satisfactory. It has been shown that sorption storage with the used material combination is technically feasible. However, the temperature lift that can be achieved technically useful is only technically useful in a relatively small range of water contents. As sons as the silica gel is very dry, the temperature lift is sufficient. But starting at a water content of approximately $13 \%$, the temperature lift is not large enough to compensate for higher losses in heat exchangers, pipes and tanks. That means that the energy density of the material that can be used in a real application is much smaller than both the theoretical one and what has been measured under laboratory conditions. The used material had been chosen because it is manufactured in mass production and therefore inexpensive.

In a new research project started in March 2012 (EU financed project COMTES) this system concept has been further developed in order to work with a new sorption material (zeolite) and to also deliver heat for domestic hot water preparation. So far only simulation studies of this new concept have been performed. However, it is planned to further develop the system concept and to build a laboratory and a demonstration system during this project. 


\subsection{Use of PCM as Passive Storage System in Building Envelopes}

\section{Concept}

The use of PCM inside building envelopes (both walls and roofs) increases the heat storage capacity of the building and might improve its energy efficiency and hence reduce the electrical energy consumption. In summer, during daytime the sunshine and high temperatures result in a heat wave penetrating the walls of the buildings. PCM absorbs the excess heat through melting process, delaying the heat wave inside the building, and even reducing the peak. During most of the day the room temperature remains comfortable and the cooling system consumes less energy (Figure 3.4.1).

During nighttime, when temperatures are lower, the PCM releases the stored heat to both the internal and external ambient, keeping again the room temperature comfortable and closing the cycle by solidifying.

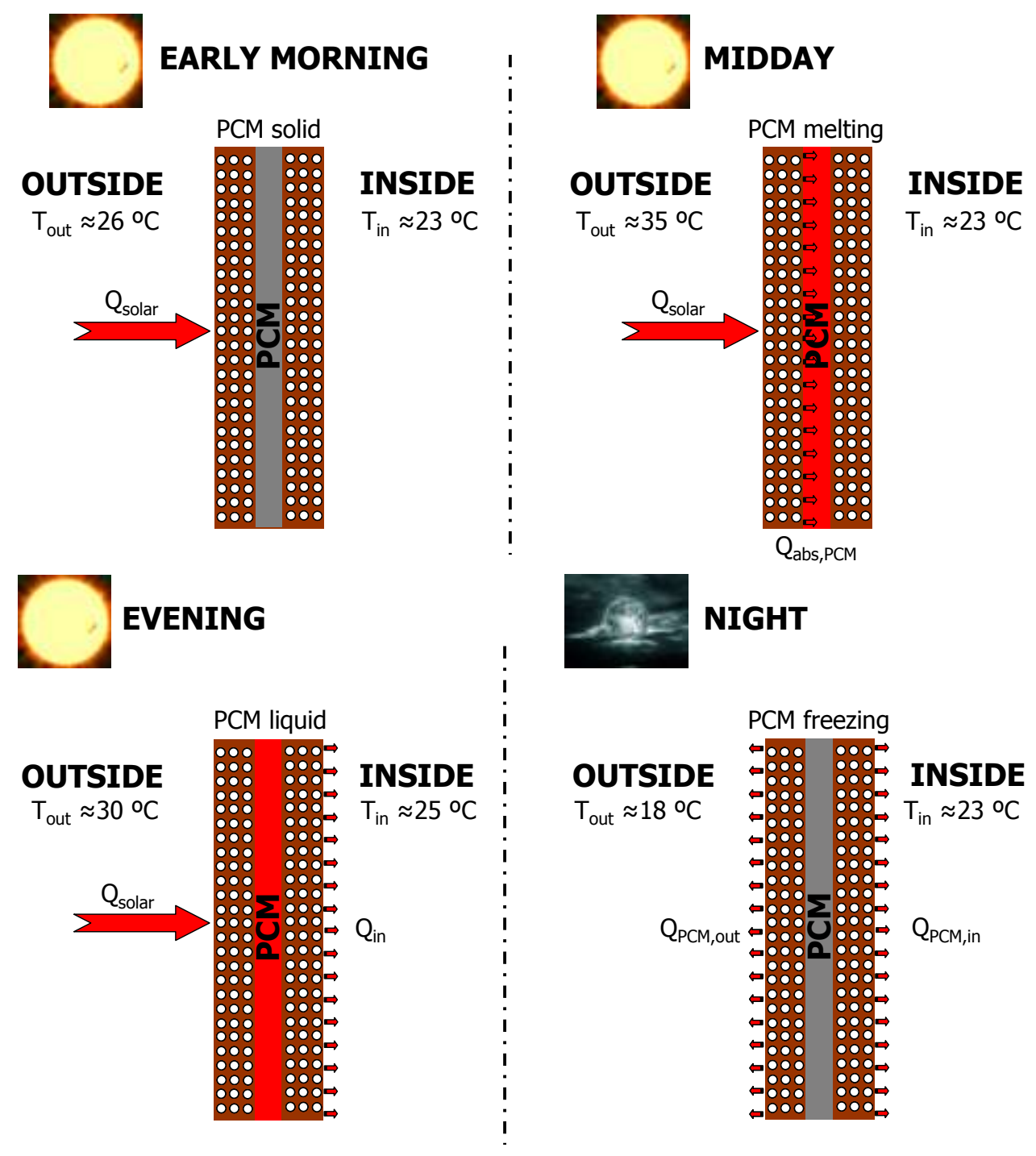

Figure 3.4.1: Operating principle of PCM in buildings. 


\section{Status of development}

An experimental set-up located in Puigverd de Lleida is used to evaluate passive and active systems for building energy efficiency. This installation consists of several cubicles, with internal dimensions of $2.4 \times 2.4 \times 2.4 \mathrm{~m}$ (Figure 3.4.2), operating under real conditions.

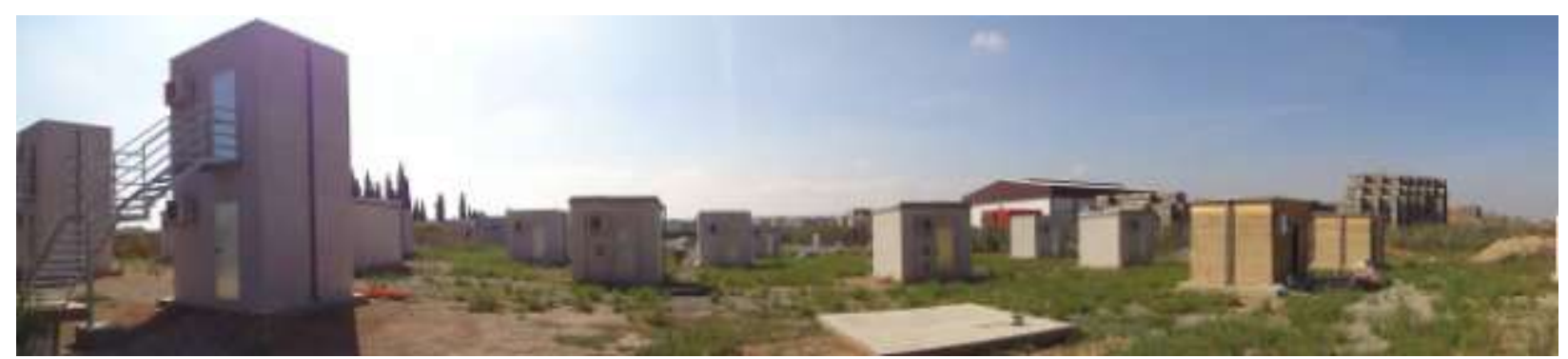

Figure 3.4.2: Experimental set-up in Puigverd de Lleida.

Five of those cubicles are used to test the incorporation of PCM in building envelopes as passive system. These five cubicles were built with three different types of construction:

1. Conventional brick cubicles. Three cubicles built using conventional brick (typical Mediterranean construction) with or without insulation, and with or without PCM.

a. Reference: Built with conventional brick and air chamber (without insulation).

b. Polyurethane: Built with conventional brick, air chamber and $5 \mathrm{~cm}$ of sprayed polyurethane.

c. Polyurethane and PCM: Built with conventional brick, air chamber, $5 \mathrm{~cm}$ of sprayed polyurethane and an additional layer of macroencapsulated PCM (RT27) on the South and West wall as well as on the ceiling.

2. Alveolar brick cubicles. Two cubicles built using alveolar brick with or without macroencapsulated PCM.

a. Reference: Built only with alveolar brick.

b. Alveolar+PCM: Built with alveolar brick and an additional layer of macroencapsulated PCM (SP-25-A8) on the South and West wall as well as on the ceiling.

All the cubicles were fully instrumented and data was registered at $5 \mathrm{~min}$ intervals to evaluate the thermal performance.

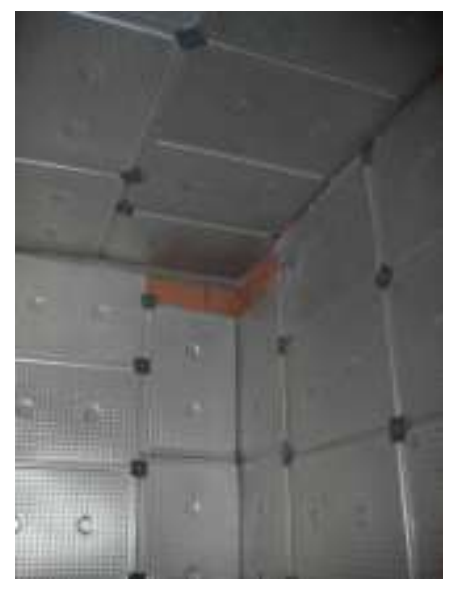

Figure 3.4.3: Alveolar brick cubicle with macroencapsulated PCM.

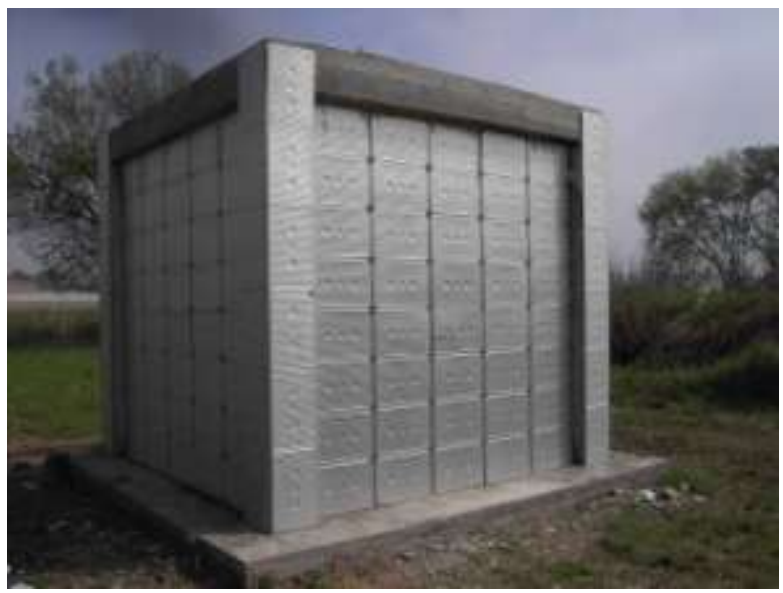

Figure 3.4.4: Conventional brick cubicle with macroencapsulated PCM. 
Main results showed $17 \%$ of energy consumption reduction by the use of PCM as passive storage system in building envelopes (Figure 3.4.5).

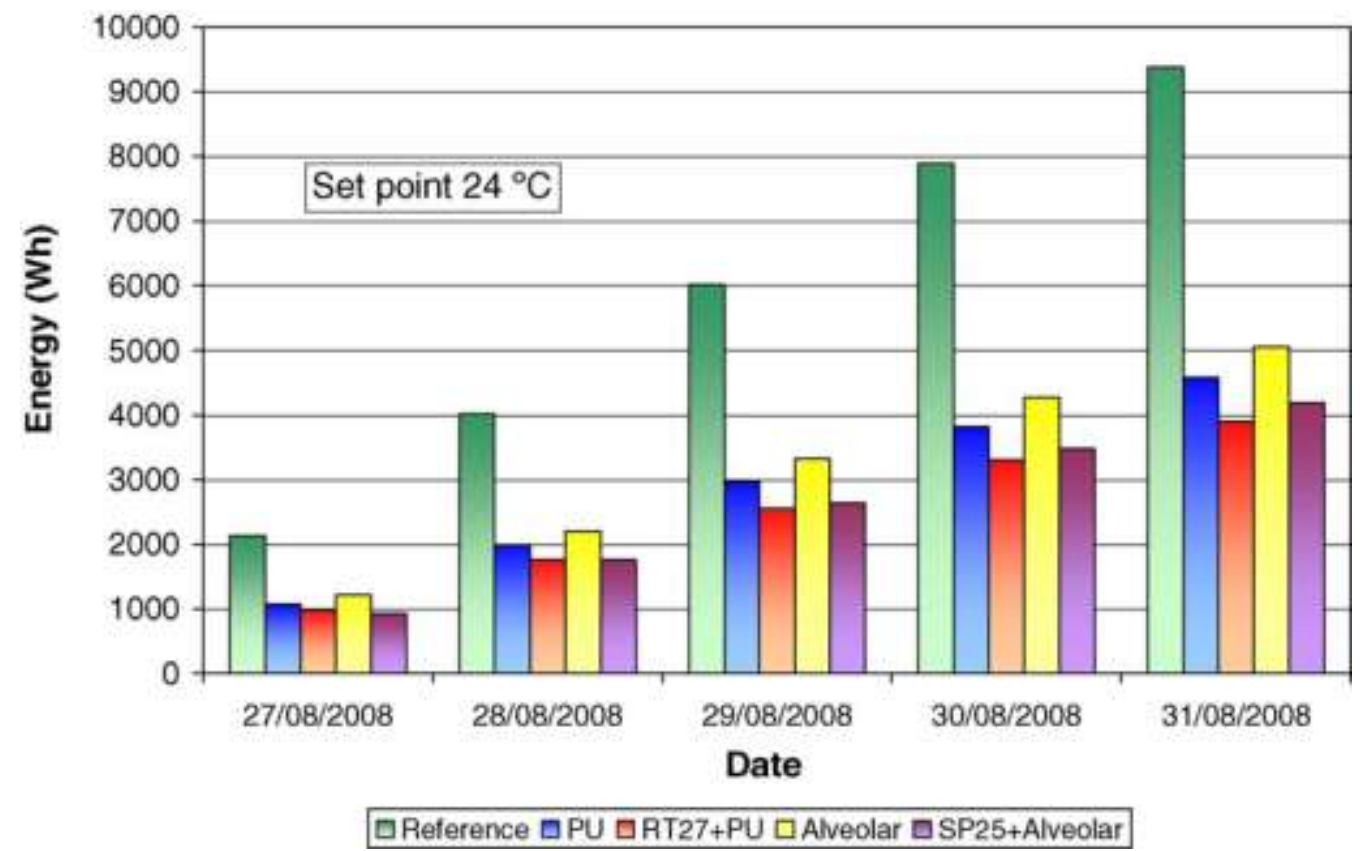

Figure 3.4.5: Accumulated energy consumption. Set point at $24^{\circ} \mathrm{C}$.

\subsection{Use of PCM Thermal Energy Storage Tanks in Heat Pump System}

\section{Concept}

The system is composed by two PCM thermal energy storage tanks coupled to a heat pump and an air handling unit (AHU). The TES units work simultaneously in order to charge and discharge the thermal energy stored by the PCM. The aim is to take advantage of the low electricity night tariff so the PCM is charged at night and discharged during the day. The heat pump is switched off during the day so that the thermal necessities are supplied by the PCM storage units. Depending on which tank supplies the thermal energy the system can be used for either summer or winter conditions. Experiments for summer conditions have been carried out up to now.

Figure 3.5.1 shows the schematics of the system and the two running modes for summer conditions. The charging mode aims to solidify the PCM of the cold tank. The heat pump supplies hot $\operatorname{HTF}\left(55-58^{\circ} \mathrm{C}\right)$ from the condenser to the hot tank and cool HTF $\left(2-5^{\circ} \mathrm{C}\right)$ from the evaporator to the cold tank. Since the temperature of the cool HTF is lower than the melting temperature of the PCM $\left(10^{\circ} \mathrm{C}\right)$ placed inside the cold tank, the material solidifies and stores cold for a later use. As seen in Figure 3.5.1 when the hot tank is fully charged (PCM is completely melted) the HTF dissipates the excess heat to the environment through the outlet coil heat exchanger (5). During the day the discharging mode runs and the heat pump is switched off so that the energy demand is supplied only by the cold tank. The cool HTF is discharged to the inlet coil heat exchanger (6) to cool the inlet air decreasing the indoor temperature of the room. In winter conditions the hot tank is used to heat up the inlet air through the inlet coil heat exchanger (6) heating the indoor. 

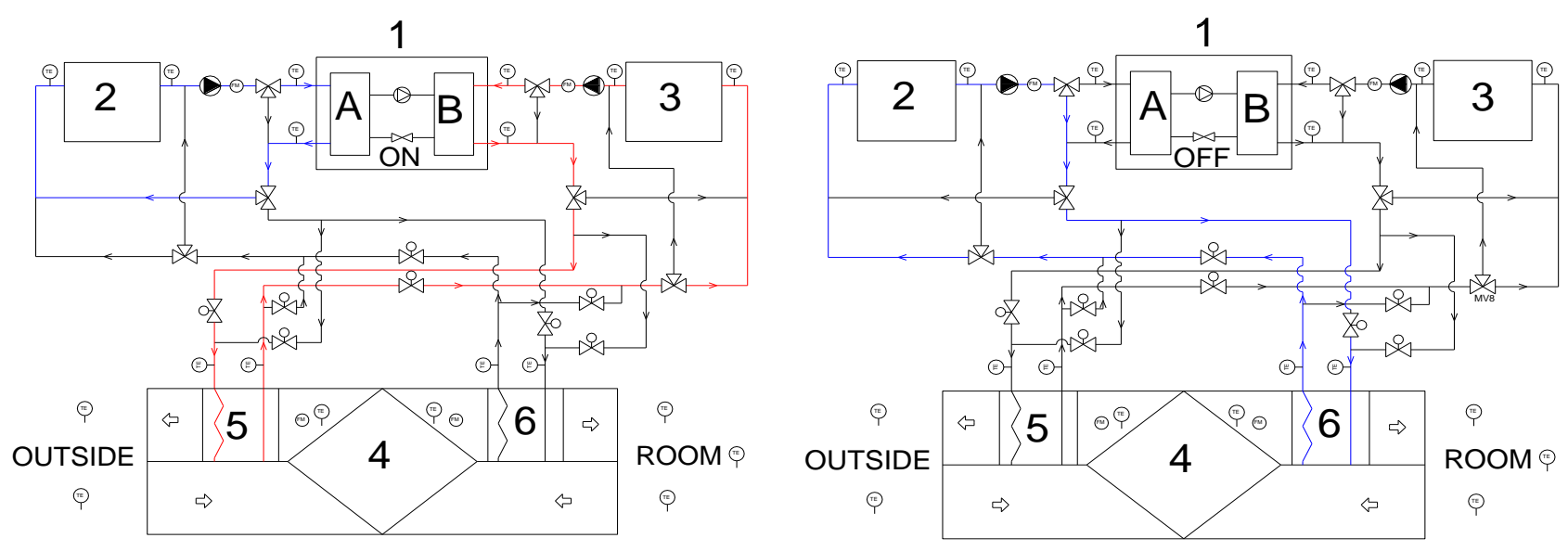

Figure 3.5.1: Schematics of the system . Charging mode (left) and discharging mode (right). 1. Heat pump (A. Evaporator, B. Condenser), 2. Cold tank, 3. Hot tank, 4. AHU, 5. Outlet coil heat exchanger, 6. Inlet coil heat exchanger.

\section{Status of development}

An experimental set-up located in Puigverd de Lleida (Spain) is used to test the real implementation of the system under summer conditions. The system is used to cool a small house-like cubicle $(2.4 \times 2.4 \times 2.4 \mathrm{~m})$ built with Mediterranean typical constructive solution. Figure 3.5.2 shows the main devices of the prototype. Both tanks have a volume of 104 liters and use salt hydrate PCM enclosed in flat slab HDPE encapsulation (500 × $250 \times 32 \mathrm{~mm})$ from PCM Products. The PCM melting temperature of the heating unit is $46^{\circ} \mathrm{C}(\mathrm{S} 46)$ while the cooling unit has $10^{\circ} \mathrm{C}$ as melting point (S10).
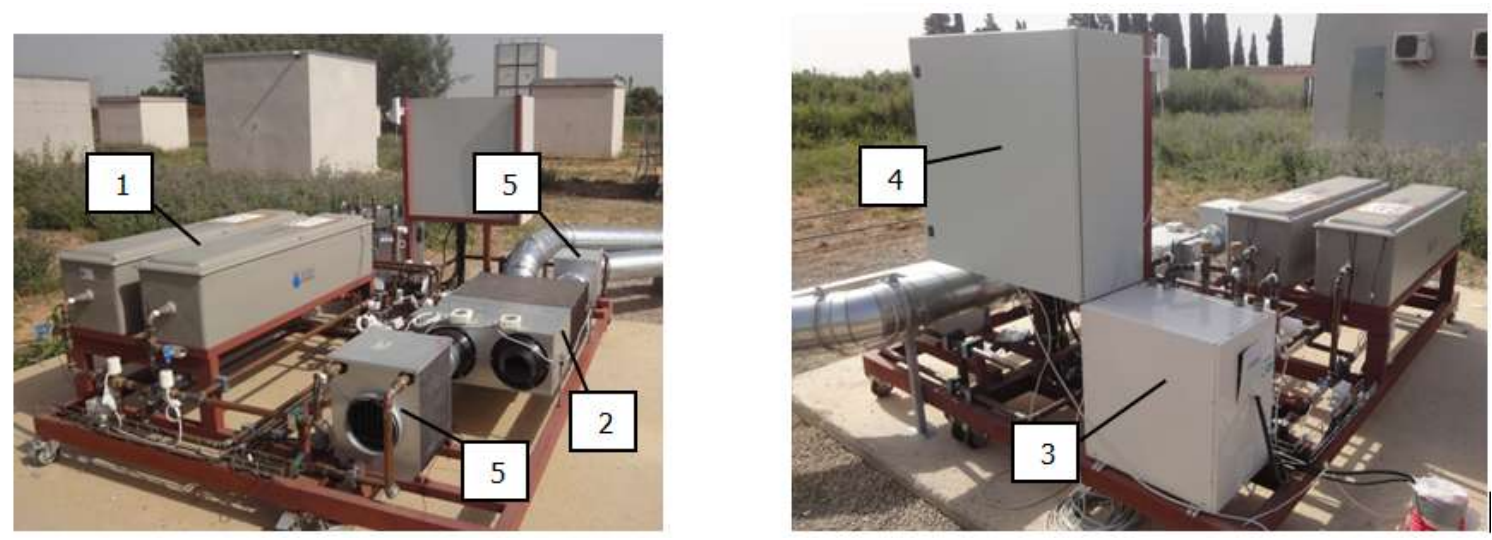

Figure 3.5.2: Main system devices. (1) PCM storage tanks, (2) AHU, (3) heat pump, (4) control panel and (5) coil heat exchangers.

A comparison between the PCM tank and the same tank without PCM was evaluated. The results show that the first configuration is able to store $97 \%$ more thermal energy and the charging time needed is $225 \%$ longer due to the solidification of the PCM. When the indoor temperature of the cubicle is controlled by the system it is observed that the time that the PCM tank is able to supply thermal energy is $29 \%$ longer than the sensible heat storage tank. The latent heat stored by the PCM allows the system to extend the discharging. Figure 3.5.3 shows the results when the indoor set point temperature is $22^{\circ} \mathrm{C}$. 


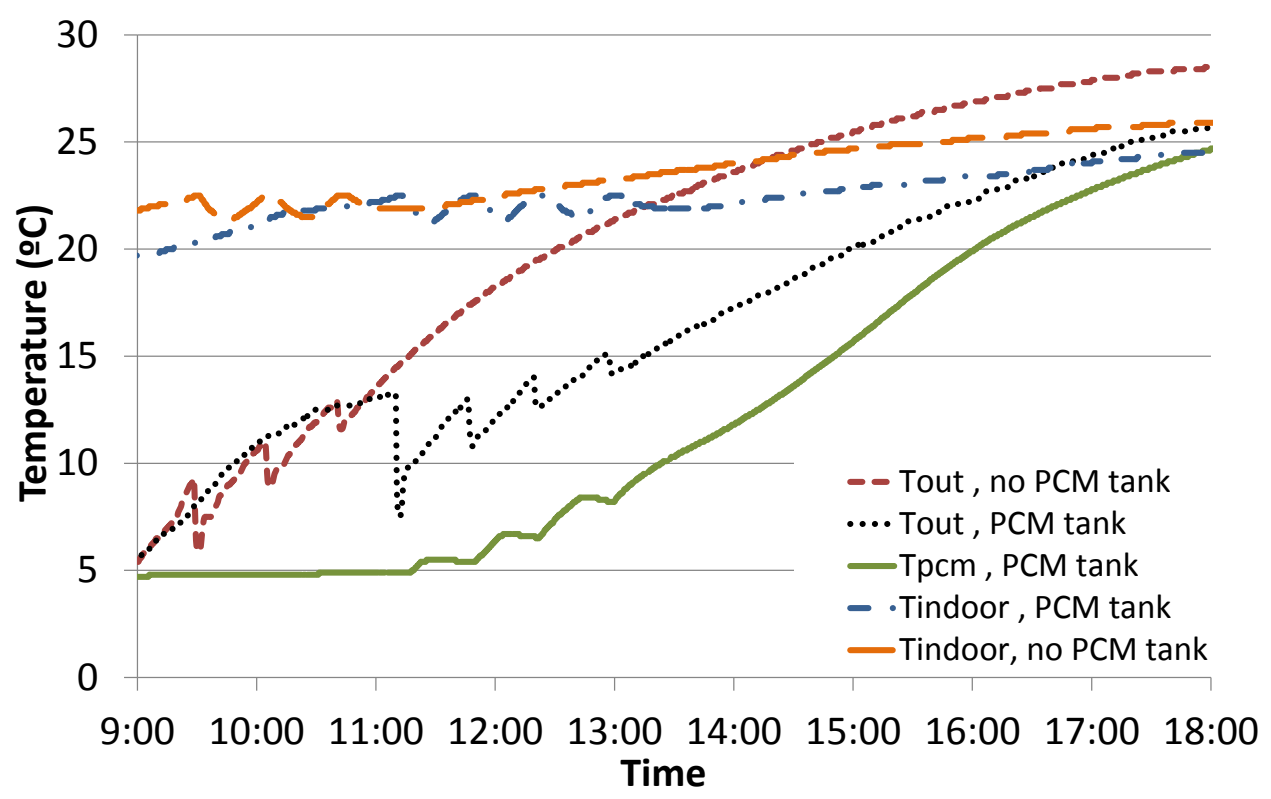

Figure 3.5.3: Outlet HTF temperature and PCM temperature of the two tanks tested.

\section{6 $\mathrm{MgCl}_{2} \cdot 6 \mathrm{H}_{2} \mathrm{O}$ Solid Desiccant for Active Solar Heating and DHW}

\section{Concept}

In the Netherlands, the main part of the residential energy demand consists of space heating and tap water heating. During the summer period, the available solar energy is sufficient to cover the tap water heating demand for houses equipped with solar thermal collectors. However, during winter, the heating demand exceeds the solar supply. Solar energy can be harvested in summer to fulfill the heat demand in winter by means of a seasonal heat storage system. However, for a passive house of $110 \mathrm{~m}^{2}$ with a winter heat demand estimated at $6 \mathrm{GJ}$, seasonal heat storage in a traditional water tank would require a tank volume above $40 \mathrm{~m}^{3}$ which is way too large to be integrated in individual houses. Therefore, more compact heat storage technologies have to be found. ECN is developing a compact heat storage system based on the reversible reaction of water vapor with a ThermoChemical Material (TCM). TCMs can have a high energy density $\left(1 \mathrm{GJ} / \mathrm{m}^{3}\right.$ in packed bed) which results for the abovementioned $6 \mathrm{GJ}$ heat demand in a storage of about $6 \mathrm{~m}^{3}$. This is suitable for integration in individual houses. Interesting TCM materials for seasonal heat storage are salt hydrates, which are available in large quantity at low cost, have high energy storage densities, are environmentally friendly and can take up and release heat under the conditions of seasonal heat storage.

The heat storage design focuses on a packed bed through which air is flown (Figure 3.6.1). During summer, the salt hydrate materials can be dehydrated by means of air heated by solar thermal evacuated tube collectors. During winter, the dehydrated salt is hydrated with moist air from the ambient. To improve the reactor performance, the vapor pressure of the incoming air is increased to 12 mbar by means of the evaporation of water with $10^{\circ} \mathrm{C}$ heat taken from a borehole. 

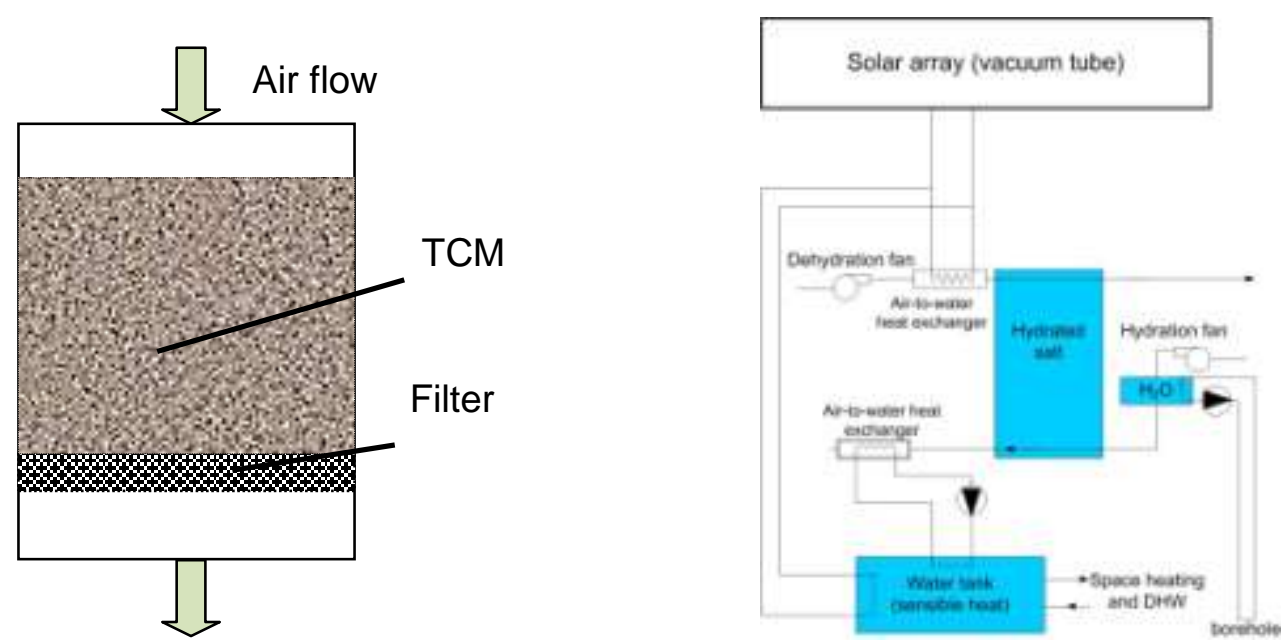

Figure 3.6.1: (a) Design of the $6 \mathrm{~m}^{3}$ packed bed reactor optimized for seasonal heat storage, (b) system sketch.

The storage design is very important for the performance. A prototype lab scale thermochemical open sorption heat storage system with a storage capacity of 20 liters was built and tested at ECN, as part of the EU FP7 project E-hub (Zondag, 2011). As TCM material, $\mathrm{MgCl}_{2} \cdot 6 \mathrm{H}_{2} \mathrm{O}$ flakes were used with a thickness of $\sim 1 \mathrm{~mm}$. The total amount of $\mathrm{MgCl}_{2} \cdot 6 \mathrm{H}_{2} \mathrm{O}$ in the reactor was $8 \mathrm{~kg}$, with a total bed volume of about17 liters. The prototype setup is shown in Figure 3.6.2.
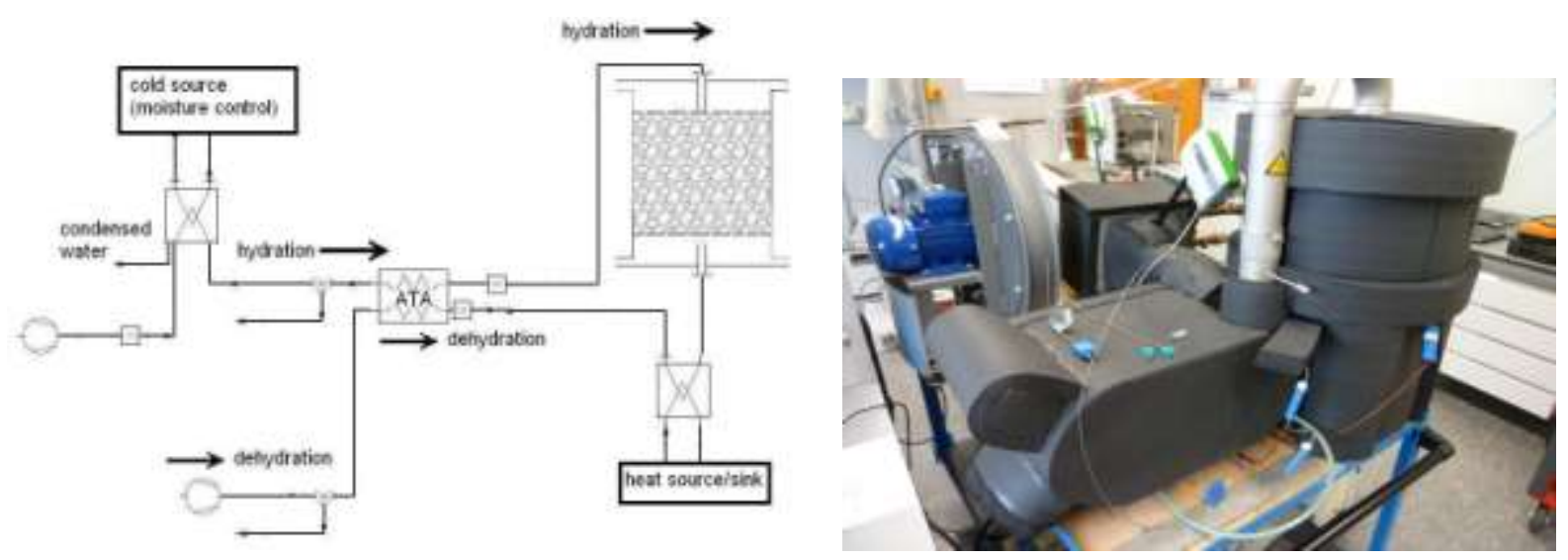

Figure 3.6.2: Lab prototype open sorption TC storage system (a) system design, (b) lab prototype.

\section{Status of development}

Materials characterization: Materials testing is ongoing mainly in a $\mathrm{PhD}$ project at ECN ( Ferchaud). In a screening of TCMs carried out at ECN, $\mathrm{MgCl}_{2} \cdot 6 \mathrm{H}_{2} \mathrm{O}$ showed a promising performance. The dehydration of $\mathrm{MgCl}_{2} \cdot 6 \mathrm{H}_{2} \mathrm{O}$ under 12 mbar of water vapour is shown in Figure 3.6.3. The figure shows clearly two dehydration steps:

1. $\mathrm{MgCl}_{2} \cdot 6 \mathrm{H}_{2} \mathrm{O} \Rightarrow \mathrm{MgCl}_{2} \cdot 4 \mathrm{H}_{2} \mathrm{O}+2 \mathrm{H}_{2} \mathrm{O}$

$$
\begin{aligned}
& \mathrm{T}_{\text {onset }}=70^{\circ} \mathrm{C} \\
& \mathrm{T}_{\text {onset }}=105^{\circ} \mathrm{C}
\end{aligned}
$$

2. $\mathrm{MgCl}_{2} \cdot 4 \mathrm{H}_{2} \mathrm{O} \Rightarrow \mathrm{MgCl}_{2} \cdot 2 \mathrm{H}_{2} \mathrm{O}+2 \mathrm{H}_{2} \mathrm{O}$ 


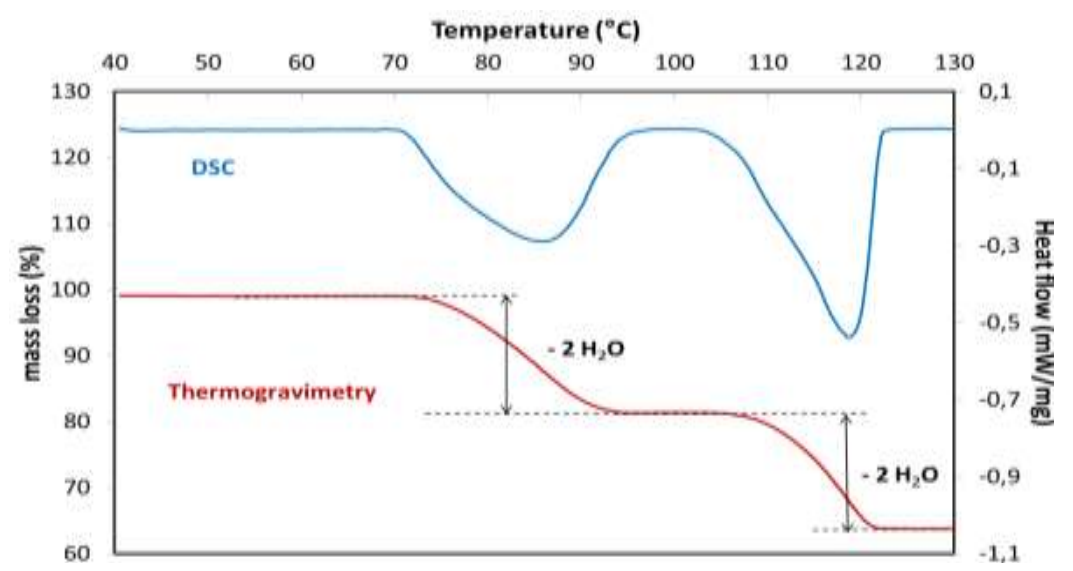

Figure 3.6.3: Dehydration of $\mathrm{MgCl} 2.6 \mathrm{H} 2 \mathrm{O}$ (heating rate $0.5 \mathrm{~K} / \mathrm{min}$ ).

Figure 3.6.4 shows X-ray diffraction results for $\mathrm{MgCl}_{2} \cdot 6 \mathrm{H}_{2} \mathrm{O}$ at increasing temperature. The figure shows that the sample remains crystalline during the entire dehydration procedure. Again, the same two dehydration steps are observed. Note that at $140^{\circ} \mathrm{C}$, also $\mathrm{MgOHCl}$ is shown, which is a result from the side reaction $\mathrm{MgCl}_{2} \cdot 2 \mathrm{H}_{2} \mathrm{O}(\mathrm{s})=>$ $\mathrm{MgOHCl}(\mathrm{s})+\mathrm{HCl}(\mathrm{g})$. This reaction is undesirable because it reduces the amount of active material and produces $\mathrm{HCl}$ gas that is corrosive to the system. Therefore, during dehydration, the temperature should be kept below $130^{\circ} \mathrm{C}$.

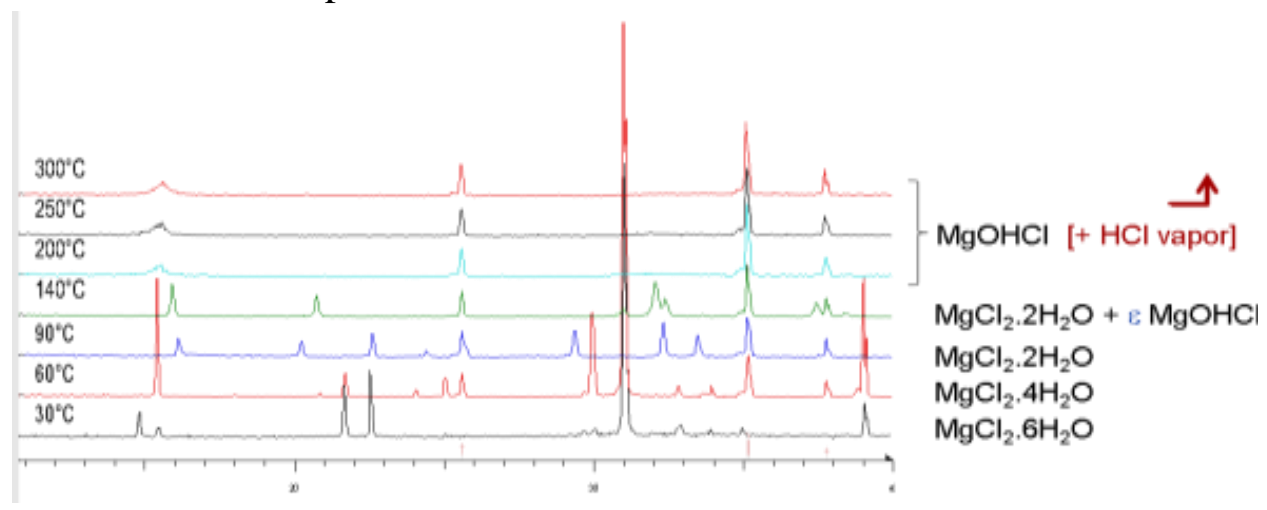

Figure 3.6.4: $\mathrm{X}$-ray diffraction of $\mathrm{MgCl}_{2} \cdot 6 \mathrm{H}_{2} \mathrm{O}$ at different temperatures.

In addition to the dehydration reaction, it is also important that the reverse hydration reaction is sufficiently fast and at sufficiently high temperature. Results for a dehydrationhydration cycle are shown in Figure 3.6.5. A significant hysteresis is found even at the low heating rates used in this study, indicating that the hydration is less fast than for instance in zeolites. However, this is still sufficient to provide tap water and space heating from a seasonal storage.

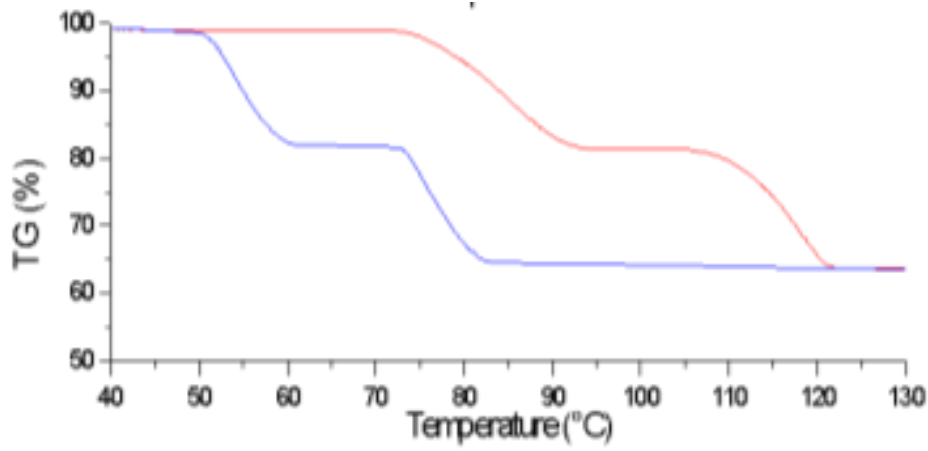

Figure 3.6.5: Dehydration-hydration cycle: mass change (Cooling rate: $0.2 \mathrm{~K} / \mathrm{min}$.). 


\section{Reactor and System development}

The lab prototype was tested for both dehydration and hydration. For the dehydration, $\sim 550 \mathrm{l} / \mathrm{min}$ of hot air at $130^{\circ} \mathrm{C}$ was flown through the bed. The temperatures in the lab prototype during the dehydration phase are shown in Figure 3.6.6.The bed temperature profiles clearly show the effect of the dehydration of the $\mathrm{MgCl}_{2} \cdot 6 \mathrm{H}_{2} \mathrm{O}$. The energy storage density was approximately $0.5 \mathrm{GJ} / \mathrm{m}^{3}$.

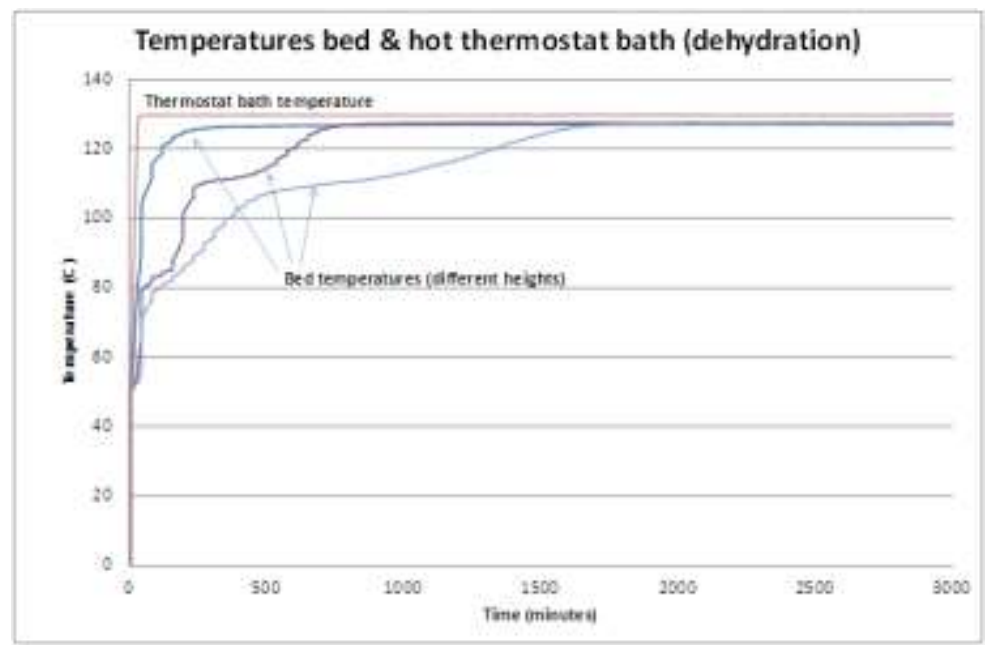

Figure 3.6.6: Charging of Lab-scale storage (dehydration of $\mathrm{MgCl}_{2} \cdot 6 \mathrm{H}_{2} \mathrm{O}$ ).

The incoming moist air was preheated to $50^{\circ} \mathrm{C}$ by the outgoing dried air via the air-toair heat exchanger (ATA) shown in Figure 3.6.2. In this way, higher output temperatures can be obtained. Flowing through the bed, the air was heated up further to $65^{\circ} \mathrm{C}$. Unfortunately, in the present setup, the heat recovery in the air-to-air heat exchanger was insufficient, resulting in significant heat loss via the outgoing air flow, reducing the performance of the system. This needs to be improved in later designs.

\section{Numerical modeling}

Different numerical models were developed over time. In Matlab, the so-called SoSyMo (sorption system model) was developed. This is a generalized multi-purpose model of the system (packed bed and evaporator/condenser) to model reactor performance in sorption systems such as heat pumps and heat storages. The model is used for both closed sorption and open sorption, and has its own materials library containing both chemisorption and physisorption materials. Typical outputs are COP's and power levels, but also other outputs can be generated, as shown in Figure 3.6.7.

In addition, a component model was built for an open sorption packed bed filled with salt hydrate, using the commercial software Comsol Multiphysics. The model makes use of the mass balance, momentum balance (modified Navier-Stokes) and energy balance equations, as well as the Clausius-Clapeyron equation to describe the thermochemical equilibria of the salt hydrate. The model was only used to describe the dehydration phase (Figure 3.6.8); hydration simulations will be carried out later. 


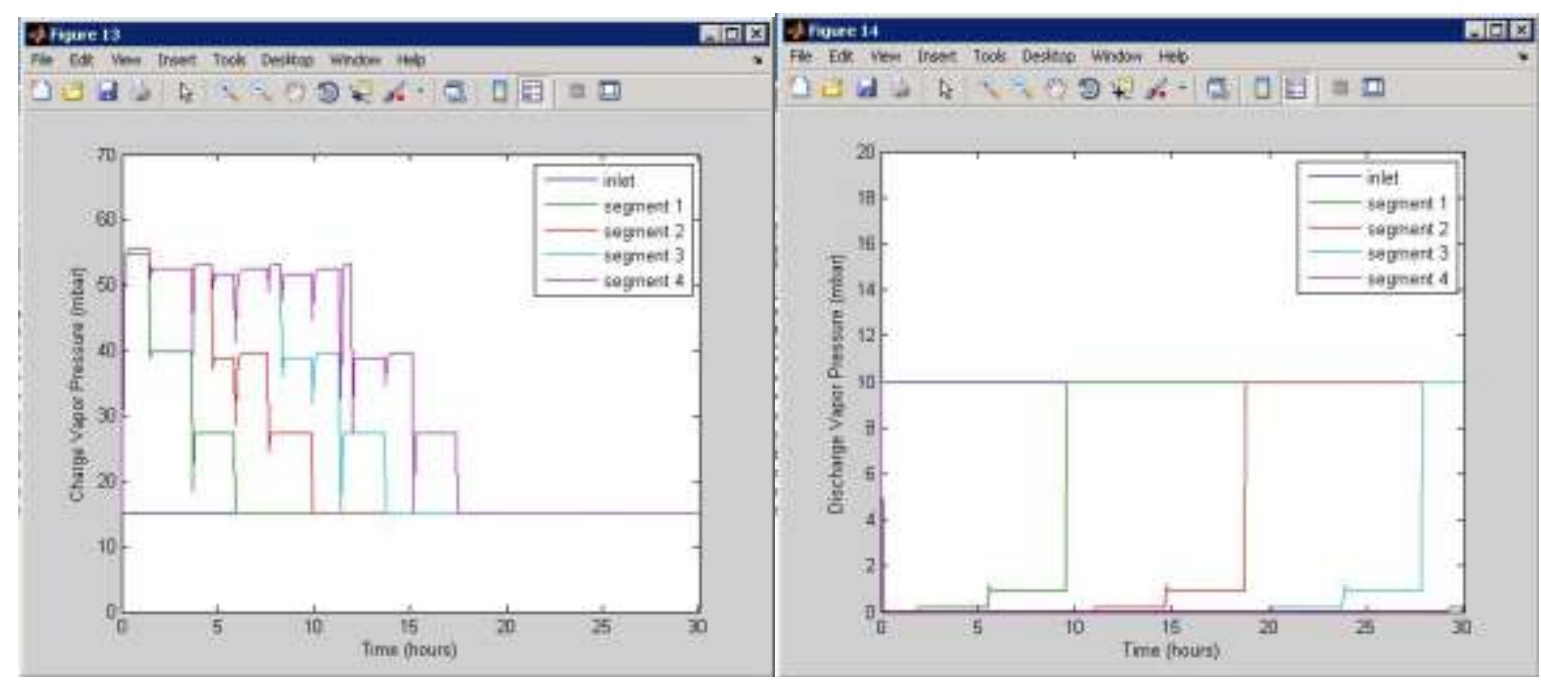

Figure 3.6.7: SoSyMo model: water vapor pressure during charge and discharge phase in an open sorption thermochemical heat storage.
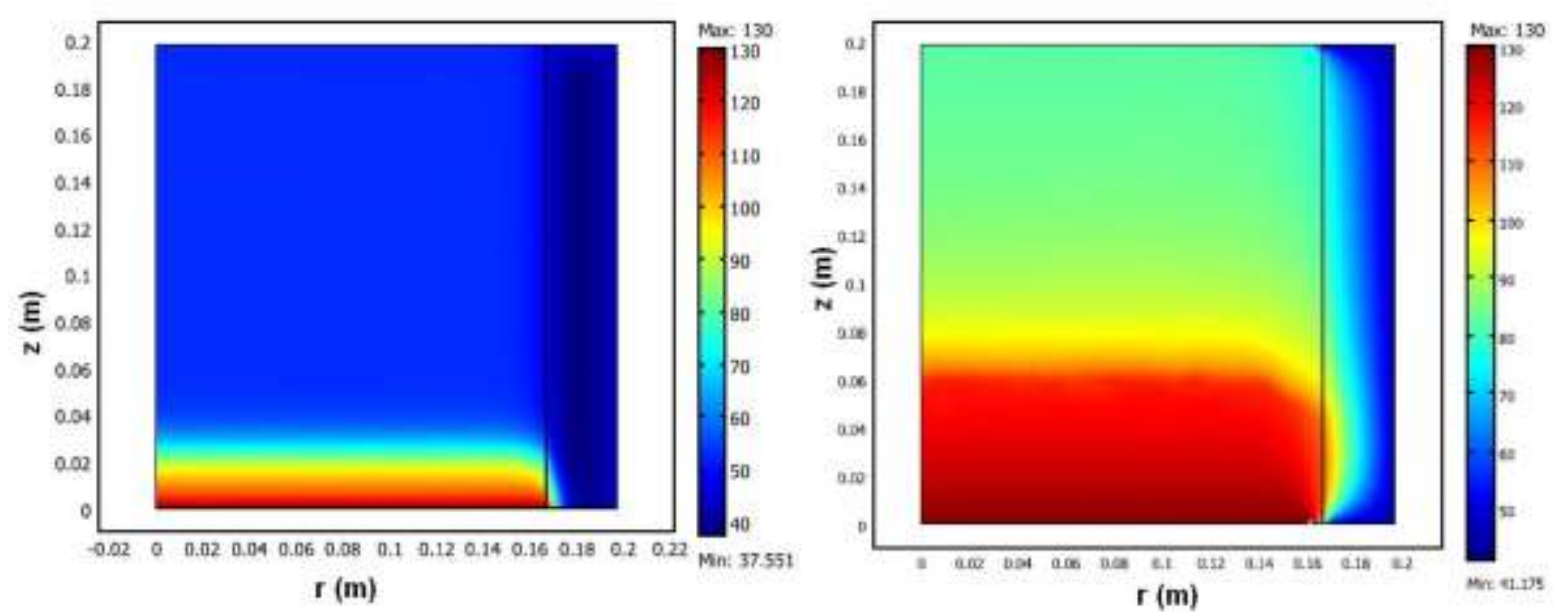

Figure 3.6.8: Comsol model: progressing of temperature front through the bed during dehydration (a) after $2 \mathrm{~min}$, (b) after $100 \mathrm{~min}$.

\subsection{Integrated Thermochemical Storage System}

\section{Concept}

In combination with renewable energy sources, such as solar heat and waste heat, thermochemical sorption reactions can supply required space heating, cooling and domestic hot water (Figure 3.7.1(a)). The objective of the work of TNO for the past years was and is to develop, demonstrate and evaluate a compact seasonal thermochemical heat storage system based on novel high-density materials. 

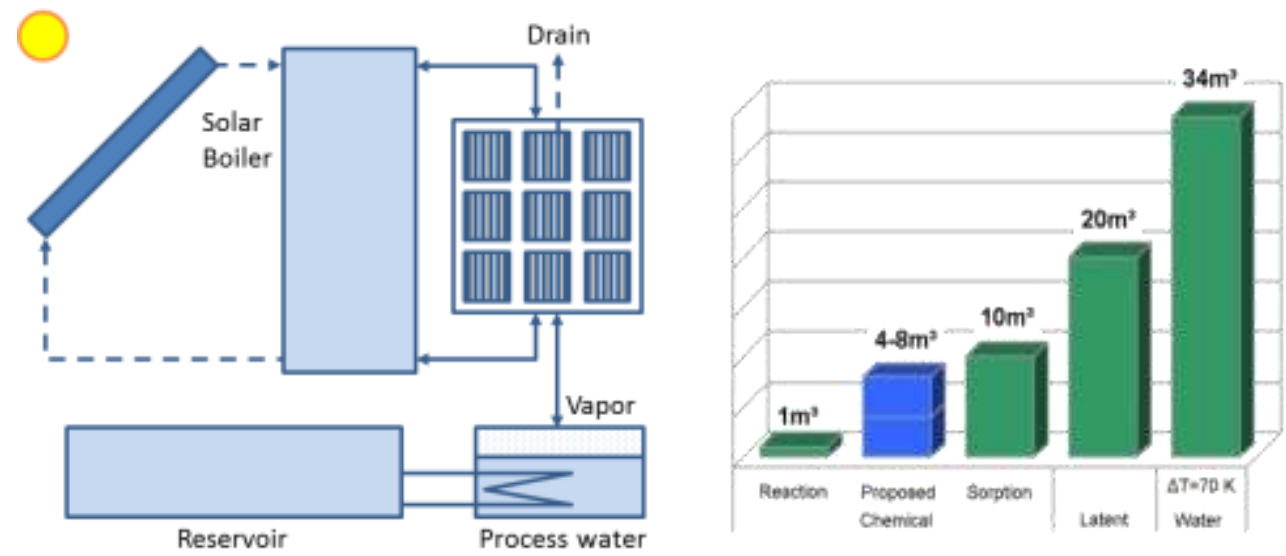

Figure 3.7.1. (a) Schematic of proposed integrated thermochemical storage system (left); (b) Volume required to store 6.7 GJ (right, adjusted from [Pinel et al., 2011]).

\section{Approach}

An initial test reactor was built using the sorption pair zeolite-water (Figure3.7.2) for vacuum operation. The focus was to study the behavior of a small thermochemical storage system as well as components and material stability in the range of $10-130{ }^{\circ} \mathrm{C}$ in an evacuated system. Both loading and unloading of the thermal store is tested thoroughly, yielding information on temperature levels required and obtained, storage capacity, energy density and output power, as well as on possible heat and mass-transfer limitations.

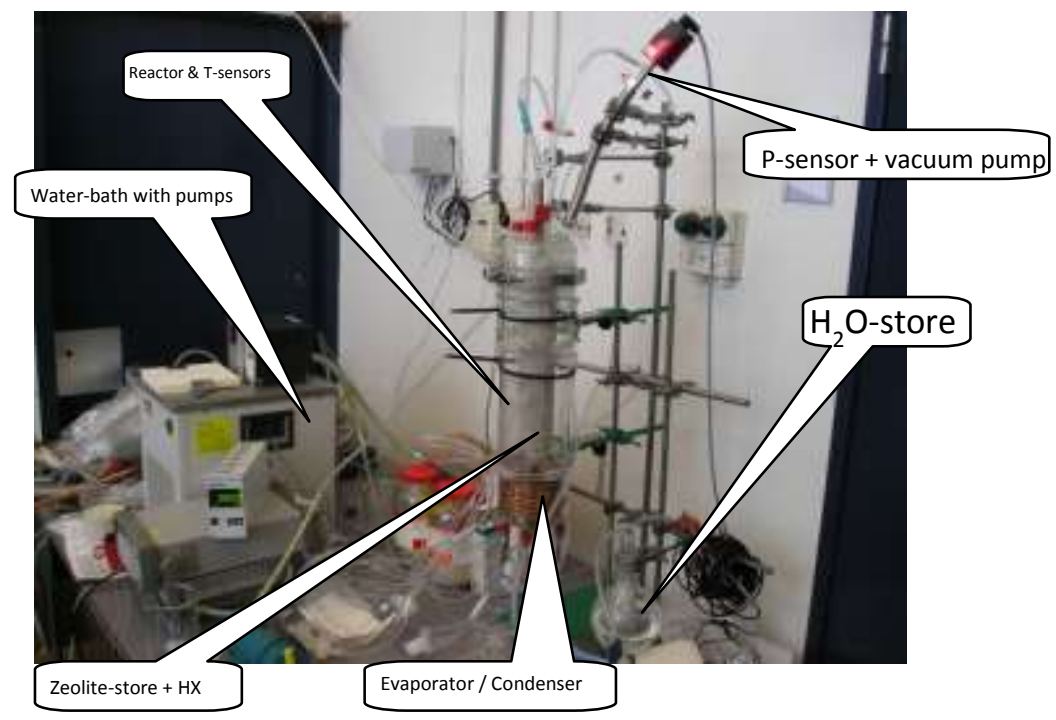

Figure 3.7.2: Initial test reactor TNO. 

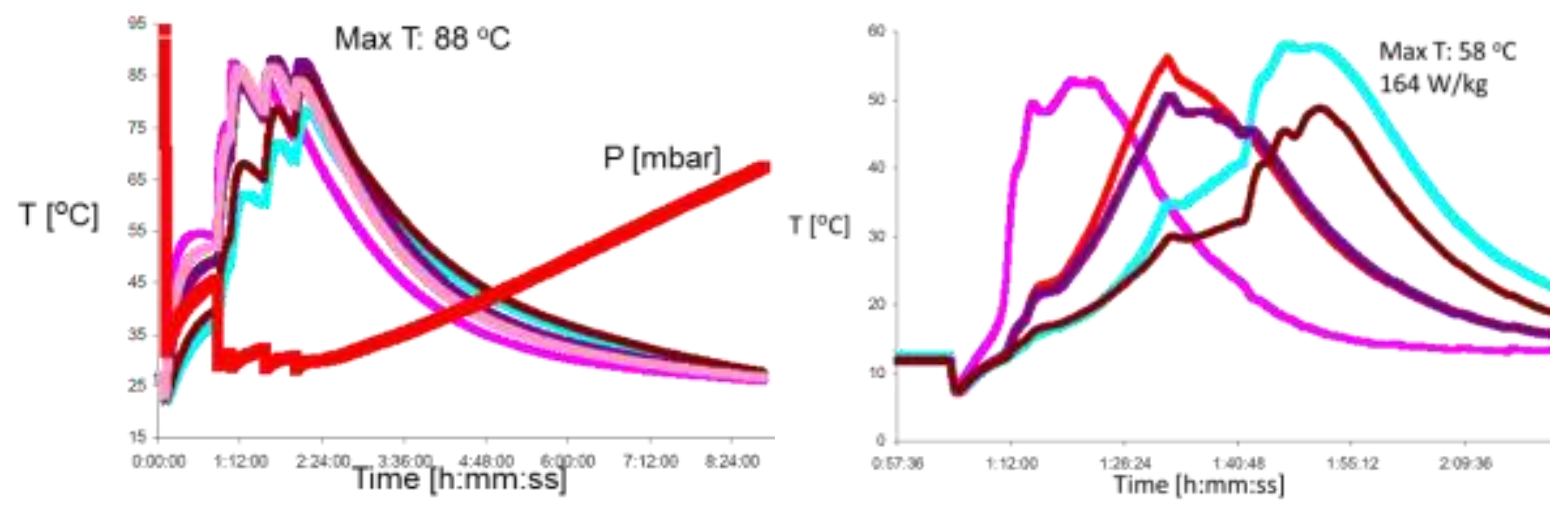

Figure 3.7.3: Results of the initial test reactor [Cuypers et al. 2012a]. (a) Good temperature output, systematic behavior observed (left); (b) Limited capacity, mass-transport and thermal transport observed (right).

First experimental results gave a good indication of expecting temperatures, capacity, mass transport and thermal transport output (Figure 3.7.3). To improve these specifications different kind of simulations were done (Figure 3.7.4).
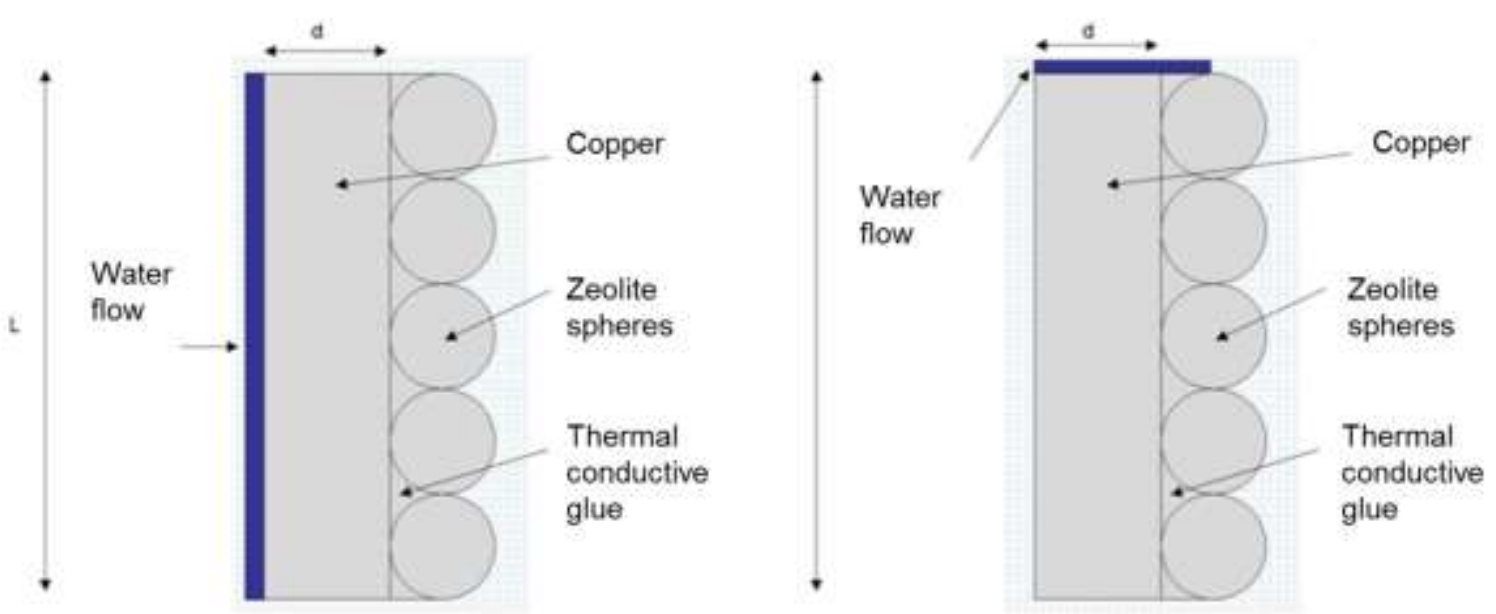

Figure 3.7.4: Comsol modeling of sorption process with zeolite spheres directly attached to heat exchanger material.

\section{Status of development}

By modeling different adsorber geometries and heat exchanger surfaces we could find an optimal system for heat and mass transport that was also cheap and easy to build (Figure 3.6.5a), consisting of copper tubing with directly attached zeolite spheres. Experimental results of the second test reactor (Figure 3.7.5(b)) showed an optimized heat and mass transfer including very fast sorption reaction times, comparable high heat transfer coefficients in a range of $70-300 \mathrm{~W}\left(\mathrm{~m}^{2} \cdot \mathrm{K}\right)$ and moderate temperature outputs as well as heat capacity. In addition, specific output power was found to be $0.60 \mathrm{~kW} / \mathrm{kg}$ and the specific capacity was 0.1 $\mathrm{GJ} / \mathrm{m}^{3}$. 

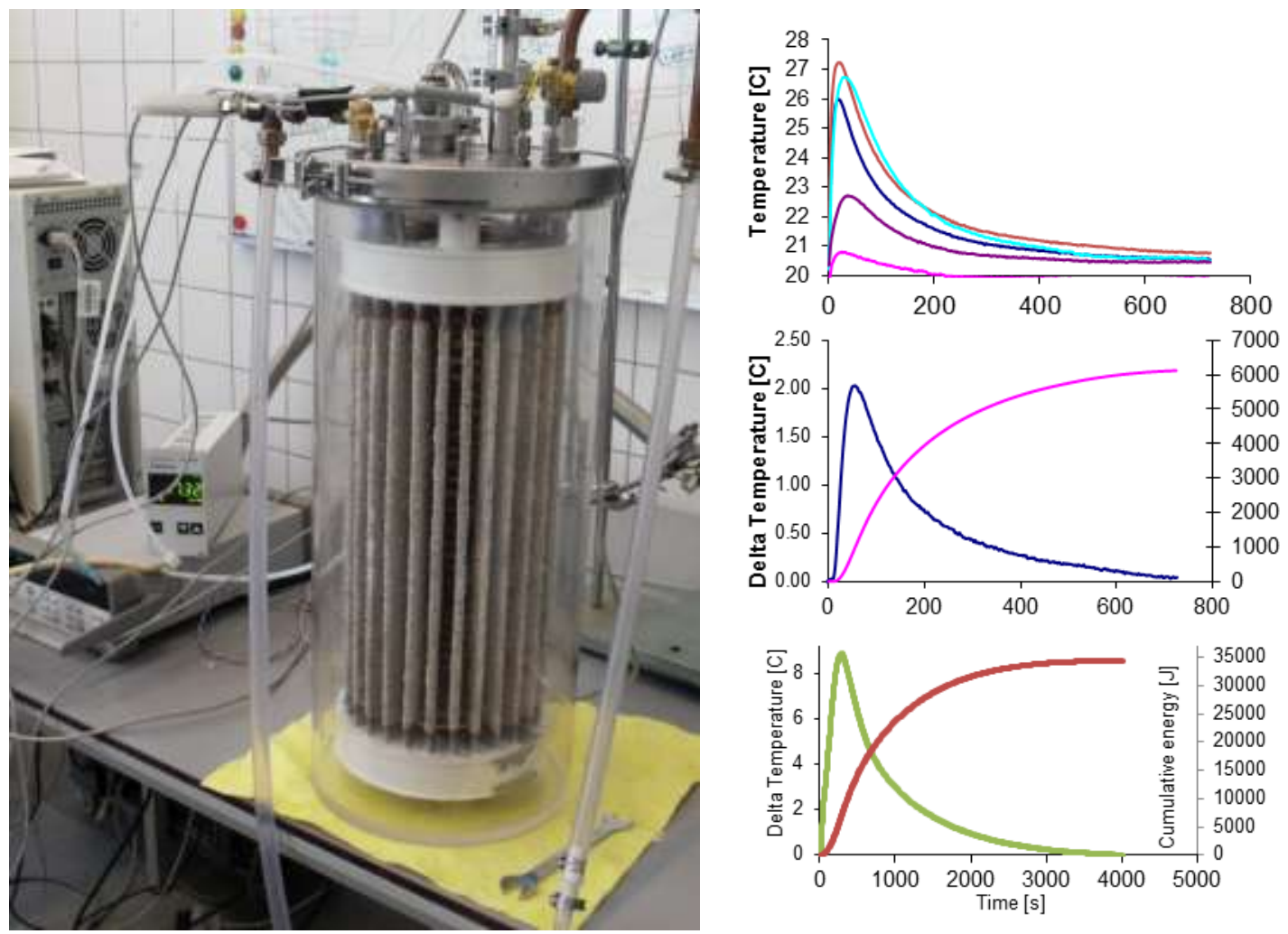

Figure 3.7.5: (a) Advanced test reactor TNO (left); (b) Results of the advanced test reactor TNO, yielding fast reaction times with moderate temperatures (single layer) and moderate reaction times with larger temperatures (multi-layer) [Cuypers et al., 2012b].

In addition to the system development using zeolite, also material developments were performed on salt hydrates having much higher thermal storage capacities. Investigations are done in the fields of corrosion, physical stability of the active composite materials, thermal and mass-transport properties, all at different temperatures and pressure levels. Used materials are $\mathrm{CaCl}_{2}$ and encapsulated $\mathrm{CaCl}_{2}$ and material properties were investigated using Differential Scanning Calorimetry (DSC) as well as with Thermo-Gravimetric Analyses (TGA).

Experiments on novel encapsulated active materials for thermochemical storage are promising; a new material has been assessed, showing good thermal behavior and reliable cycling properties while maintaining its physical shape during operation. In addition, temperature ranges for the new material are more suitable for use in a thermal storage system in combination with solar collectors due to lower dehydration temperatures, enabling its introduction in the built environment.

These results served as a basis for building several demonstrators that are currently under development (Figure 3.7.6), giving us the opportunity to demonstrate actual behavior of the developed thermal store incorporated in its envisioned system, and opening up the road towards actual commercialization. 


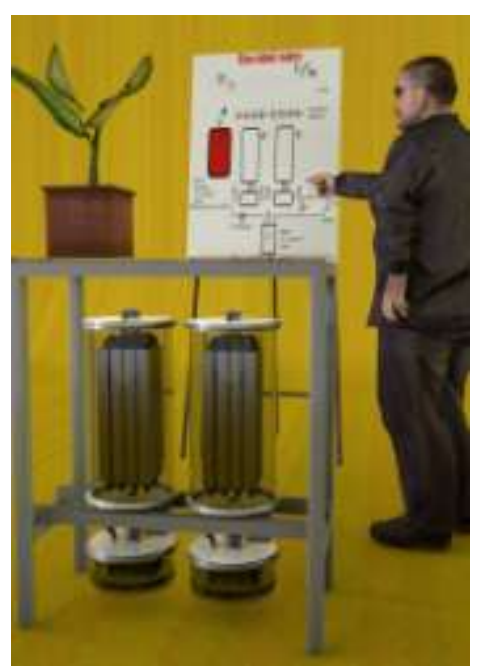

Figure 3.7.6: One of the current demonstrator set-ups.

This work was done as a group effort in good cooperation between the mentioned authors Christian Finck and Ruud Cuypers and the colleagues Jacco Eversdijk, Nicole PapenBotterhuis, Ellemieke Henquet, Henk Oversloot, Hans van 't Spijker, Ard-Jan de Jong and Aart de Geus.

\subsection{Solid Sorption/Reaction Open-cycle Active Solar Heating}

An open-cycle solid adsorption / thermochemical reaction solar heating system has been developed during the project CWS (Chemische Wärmespeicherung) funded by the German Federal Ministry of Economics and Technology (under the grant number 0327468B). A detailed system description can be found in the final report of the project [Kerskes et al., 2012]. ].

\section{Concept}

One option for an open thermo-chemical (sorption) storage concept has been investigated in a German national project called CWS (June 2008 to June 2012). The CWS concept is characterized by the following points:

- Open adsorption/hydration system using ambient air or exhaust air to provide the humidity required for the reaction

- Thermo-chemical heat store works as low capacity heat supply system

- Connection of the thermo-chemical heat store to a typical combistore of a solar thermal system via collector loop heat exchanger, TCES and collector loop can be operated simultaneously

- Combistore operates as buffer store to cover load peaks

- External reactor designed as cross-flow reactor with low pressure drop and structurally integrated heat exchangers

- Integration of air/air heat exchanger for optimal power output

- Storage material transport through the reactor by gravity forces with continuous or quasi-continuous mass flow 
- Bidirectional active storage material transport between storage material reservoirs and reactor using a vacuum blower

The integration of the chemical heat storage system into the hydraulic scheme of a solar thermal combisystem for domestic hot water preparation and space heating is shown in Figure 3.8.1. From the hydraulic point of view the connection between solar combisystem and thermo-chemical heat storage is simple. The main components of the system are the solar combistore, the collector array, the material reservoir, the reactor and a control system.

During periods of high solar irradiation (mainly in the summer) heat energy from the collector array is directly charging the combistore. When the energy provided by the collector field exceeds the heat demand for hot water preparation and space heating, the available solar energy is used for the endothermic dehydration reaction of the storage material (regeneration mode). During periods of low solar irradiation when the energy from the solar collector field cannot cover the heat demand the chemical heat store is used. The heat of the exothermic hydration reaction is released by blowing humid room exhaust air through the reactor and the thermo-chemical energy store (TCES) is charging the combistore (heating mode). Depending on the system dimension the backup heater can even be removed completely.

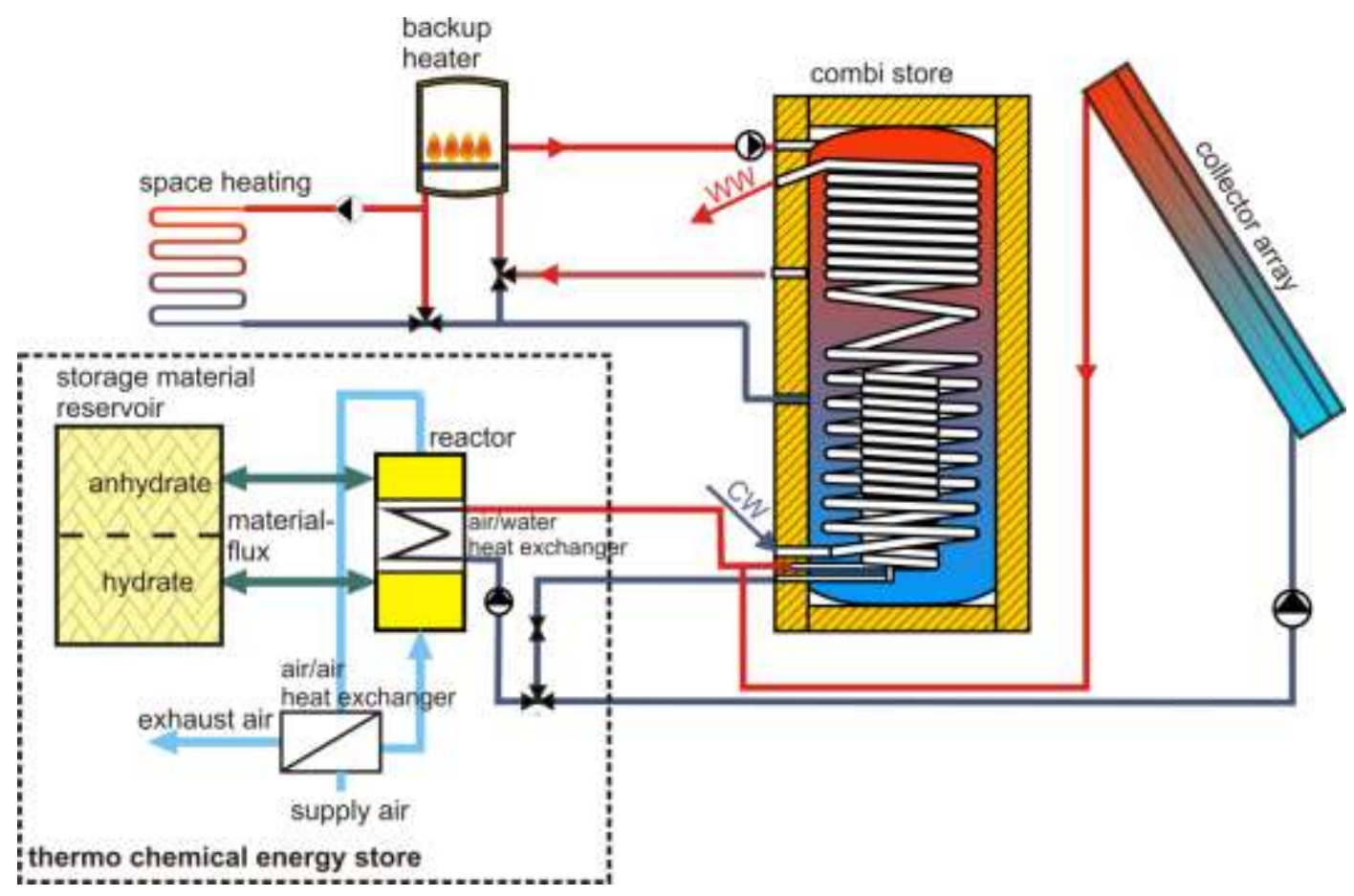

Figure 3.8.1: Schematic of the CWS concept using the example of an upgraded solar thermal combisystem.

The TCES has to fulfill two key functions: On the one hand it shall provide a storage container for the material and, on the other hand, a reactor where the heat and mass transfer takes place during the endothermic and exothermic reaction. The reaction is performed with humid ambient or room exhaust air. This has the advantage that no further energetic effort is needed for evaporating water. Another important element for an efficient process design is the 
air to air heat exchanger, preheating the supply air by the reactor outlet airflow. This results in a very low temperature difference between supply and exhaust air and hence in low heat losses via the air flow.

\section{Status of development}

A lab scale demonstrator of the thermo chemical energy store, consisting of a material transport system with material reservoir, reactor with internal heat exchanger and air-to-air heat exchanger has been set-up and tested at ITW. Further explanations and results of the CWS concept, can be found in the final report of the project [Kerskes et al., 2013].

\subsection{Simulated Technical Comparison of Systems}

\subsection{Reference Application Operating Conditions}

This section defines reference boundary conditions for the simulation of space heating and domestic hot water (DHW) systems for various climates (restricted to European climates for this report) and building loads. The reference conditions were agreed upon by the working group participants as a framework for annual simulation studies. They provide one option for the comparison of developed or conceptual systems with the current state of the art or with other system approaches. The reference conditions have been adopted verbatim from IEA SHC Task 32 [Heimrath, Haller, 2007], in which a reference environment for the simulation of solar combisystems with TRNSYS was developed. The relevant report A2 from Task 32 "The Reference Heating System, the Template Solar System of Task32" contains a detailed description of the reference system.

The reference climates represent a moderate Northern European climate (Stockholm), a moderate, Central European climate (Zurich), a Mediterranean coastal climate (Barcelona) and a Mediterranean continental climate (Madrid). The reference building is a free-standing, two storey single family building (Figure 4.1). The effective floor area on one storey, including the areas covered by the internal walls and the access areas, is $70.0 \mathrm{~m}^{2}$. The glazed area on the south façades amounts to $25 \%$ of the façade area, $10 \%$ on the east and west façades and $6 \%$ on the north façade. Both stories are simulated as one common thermal zone. The heat loads of the reference buildings are $15,30,60$ and $100 \mathrm{kWh} /\left(\mathrm{m}^{2}\right.$ a) for the climatic conditions of Zurich. All four buildings have the same architectural design with $140 \mathrm{~m}^{2}$ of floor area, but different insulation thicknesses and/or different ventilation systems. The domestic hot water load is assumed to be 200 liters per day at $45^{\circ} \mathrm{C}$. 

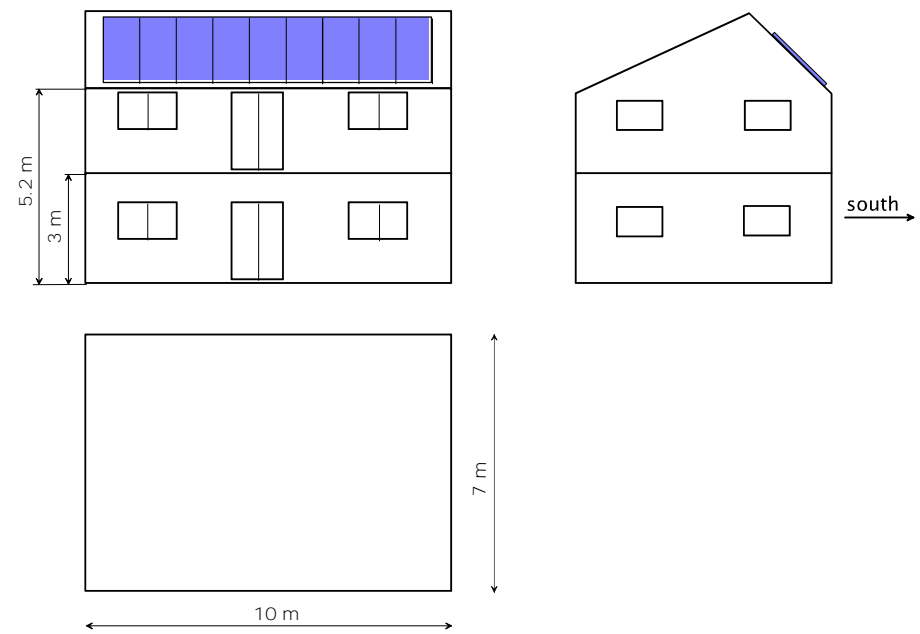

Figure 4.1: Sketch of the single-family house (SFH) used in IEA SHC Task 32 [Heimrath, Haller, 2007].

The reference simulation environment (RefSol) has been programmed with the simulation software TRNSYS. It includes meteorological data, building description files and other load-files together with the main file that contains the description of the system, the so called "deck". The "deck" also contains the description of a standard solar system, solar store, auxiliary heater, pipes, mixing valves and radiators for space heating and the settings for the control of the system (see Figure 4.2). The RefSol files have been continuously tested and improved and the final version described in the Task 32 report A2 is V45c. Test results concerning stability under changing simulation time steps or different convergence tolerances are included in section 7 of the OEA SHC Task 32 report.

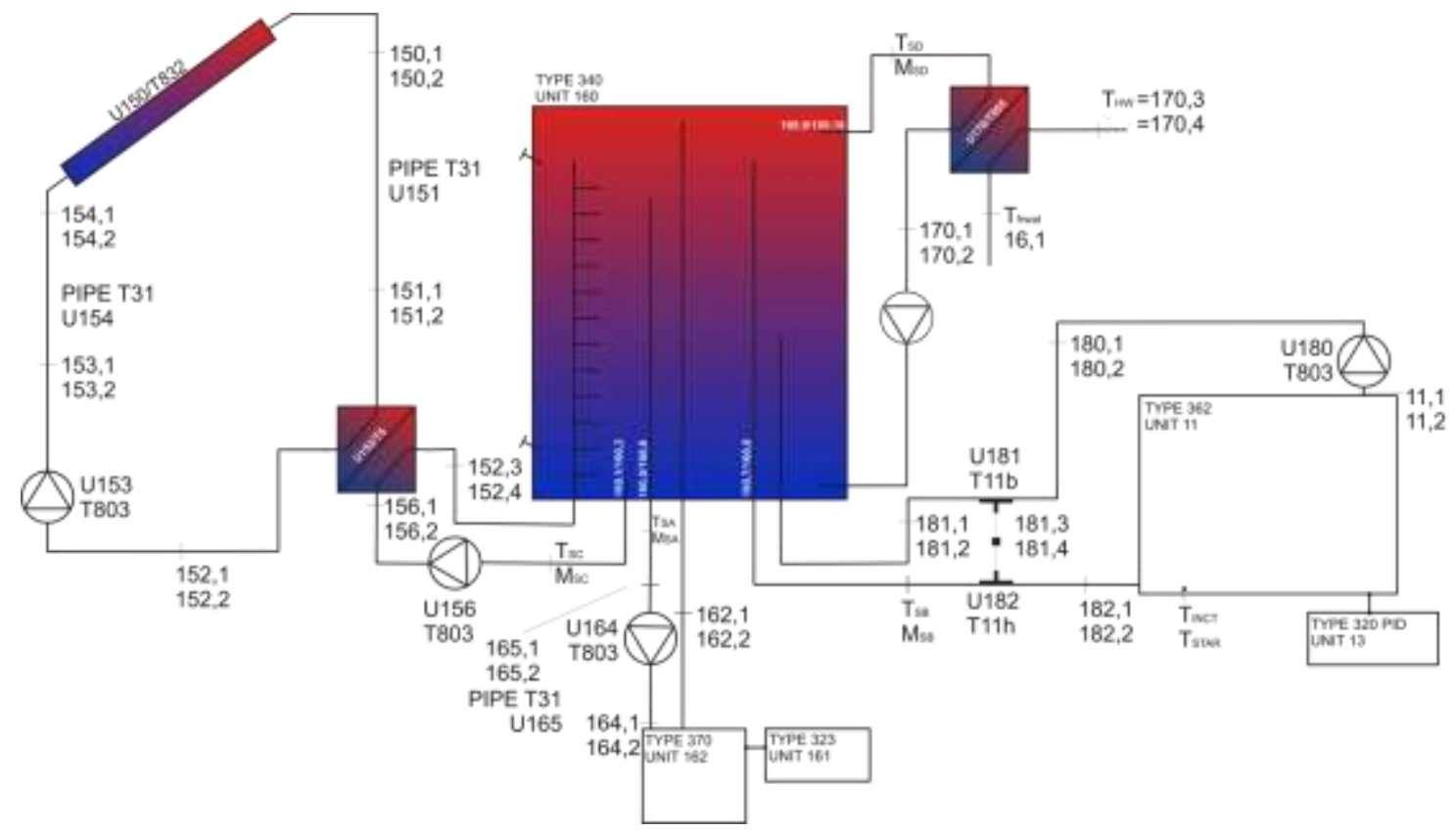

Figure 4.2: Total system layout - template solar system of Task 32 [Heimrath, Haller, 2007].

Simulation results are written to ASCII text files. An Excel spreadsheet has been worked out that will load the simulation results with the help of Macros and calculate basic indicators for the performance of solar systems that are described in section 6 of the report. 
The spreadsheet also allows for a fast checking and detecting of energy balances and calculation errors.

To assess the simulation results the fractional thermal energy savings $\mathrm{f}_{\mathrm{sav} \text {,therm }}$ is used. $\mathrm{f}_{\text {sav,therm }}$ are defined according to [Weiss et al., 2003] as the saved combined auxiliary energy consumption of the solar combisystem $\mathrm{E}_{\mathrm{aux}}$ compared with the final energy consumption of a reference system $\mathrm{E}_{\text {ref }}$ when no electrical devices other than heating elements are taken into account:

$$
f_{\text {sav, therm }}=1-\frac{\frac{Q_{\text {boiler }}}{\eta_{\text {boiler }}}+\frac{Q_{\text {el,heater }}}{\eta_{\text {el.heater }}}}{\frac{Q_{\text {boiler,ref }}}{\eta_{\text {boiler,ref }}}}=1-\frac{E_{\text {aux }}}{E_{\text {ref }}}
$$

With the energy demand of the boiler $Q_{\text {boiler }}$, the energy demand of the electrical heating element $\mathrm{Q}_{\mathrm{el}, \mathrm{heater}}$ and the energy demand of the boiler of the reference system $\mathrm{Q}_{\mathrm{boiler}, \mathrm{ref}}$. $\mathrm{Q}_{\text {boiler,ref }}$ is the sum of the energy demand of the building $\mathrm{Q}_{\mathrm{d}}$ and the heat losses of the reference system $Q_{\text {loss,ref. }}$ For a single family house $Q_{\text {loss,ref }}$ are $644 \mathrm{kWh} / \mathrm{a}$ [Weiss et al., 2003]. Assuming a similar coefficient of performance for the boiler of the reference system $\eta_{\text {boiler,ref }}$ and the boiler of the systems under investigation $\eta_{\text {boiler }}$ and no electrical heating elements, equation (1) can be simplified to:

$$
f_{\text {sav, therm }}=1-\frac{Q_{\text {boiler }}}{Q_{\text {boiler,ref }}}
$$

In addition to comparing the thermal energy consumption of the analyzed compact thermal energy storage system with a conventional reference system, the fractional thermal energy savings are compared to those of a conventional water-filled solar combistore of the same size as the compact thermal energy store. This water store has been defined in the template solar thermal system (RefSol) from Task 32. However, this template water store has turned out to be only suitable for relatively small store sizes because the insulation has been assumed to be always $10 \mathrm{~cm}$ thick regardless of the store size. As large storage tanks are typically much better insulated, an increasing insulation thickness was used for an increasing water volume of the store, as shown in Figure 4.3. The insulation material and the calculation of the UA-value for the storage heat losses were used as defined in the template solar thermal system of Task 32 .

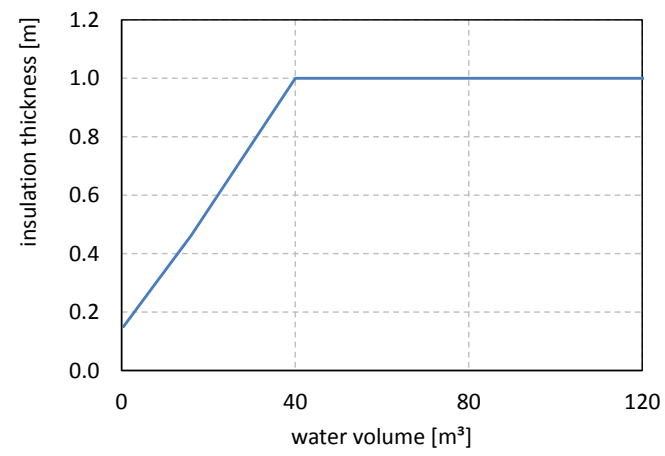

Figure 4.3: Insulation thickness for different water storage volumes used in the simulations. 


\subsection{Simulation Results and Comparison}

\subsubsection{Adsorption Heat Storage}

In this section thermal simulations of a closed and open-cycle adsorption heat storage system (see sections 3.3 and 3.8 respectively for details on the system concepts) have been performed using the boundary conditions described in section 4.1. This work was done in cooperation between the University of Stuttgart (ITW), Germany and AEE INTEC, Austria.

As water store to cover the peak heat demand e.g. during water draw offs, 2 different types of stores have been used. The open system uses a combistore with a total volume of 9001 whereas the closed system uses a DHW-store with a size of 4001

As thermochemical storage material a binder free $13 \mathrm{X}$ zeolite (Chemiewerke Bad Köstritz) were used. In Figure 4.4 the corresponding isotherm data is shown. The water load $(\mathrm{kg} / \mathrm{kg})$ of the sorbent is plotted as function of the partial water vapour pressure (mbar). This isotherm data can be used to create the characteristic curve as done for the closed system model, or it can be directly fed in form of a data table to the model as done for the open system model.

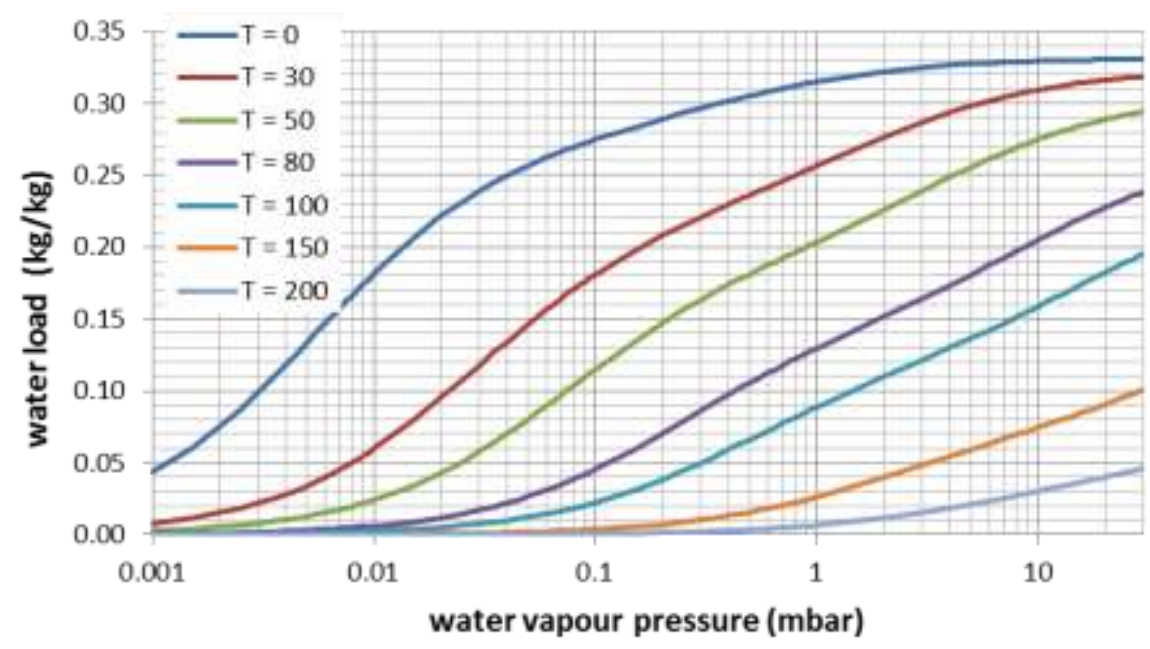

Figure 4.4: isotherm data of binder free zeolite 13X (CWK), provided by Jochen Jänchen (2012) and ITW. The average enthalpy of adsorption is $3600 \mathrm{~kJ} / \mathrm{kg}_{\text {water }}$.

A high quality evacuated tube collector (ETC) was used for the simulations because the chosen sorption material (binderfree 13X) requires significantly higher desorption temperatures than a flat plate collector can deliver. As ETC the Azzuro star collector of the company Ritter Energie- und Umwelttechnik GmbH \& Co. KG is used. All simulations were performed with a collector tilt angle of $45^{\circ}$ oriented south and for the reference building located in Zurich, Switzerland with $30 \mathrm{kWh} /\left(\mathrm{m}^{2}\right.$ a) space heating demand.

For the open system a constant collector set temperature as desorption temperature is required, to ensure always the same water content of the material leaving the reactor during summer operation. For these simulations a value of $180{ }^{\circ} \mathrm{C}$ was chosen. In the closed system concept the achieved collector and sorption storage temperature depend on the size of the collector array only.

As low temperature heat source of the closed system, it was assumed that in winter time a constant evaporation temperature for the adsorption process of $5{ }^{\circ} \mathrm{C}$ can be used. The maximum power for evaporation was set to $5 \mathrm{~kW}$. For the desorption process in summer time 
a constant condensation temperature of $30^{\circ} \mathrm{C}$ was assumed. The maximum power for condensation was set to $2.5 \mathrm{~kW}$. The heating loads (respectively cooling loads) could be achieved for instance by using a borehole heat exchanger.

For the closed system, an important parameter is the quality of the thermal insulation of the sorption heat store. The reason is that in addition to the sorption process, the system makes use of the sensible heat stored in the sorption material. A very good insulation material was used for the simulations presented in this study. A UA-value close to those of vacuum insulation panels was chosen. In contrast, the open system does not make use of the sensible heat of the sorption material. No thermal insulation is used at the material reservoir of the open system.

As an additional reference, simulations have been performed for a standard solar combisystem with a water-filled combistore. The size of the water store was chosen such that the storage volume was approximately equal to the sum of the volume of the sorption material and the additional water store in the sorption systems.

\section{Closed system model}

The model is a semi-physical model with a few parameters that have to be determined with parameter identification from measured data. These parameters are the UA-values for the heat exchangers (adsorber and evaporator/condenser) and a UA-value for the sensible heat losses from the sorption storage tank to ambient. Otherwise it is based on energy and mass balances and the physical properties of the sorption material.

The main assumptions of the model are: It is a single node model and there is no time dependency of adsorption and desorption processes

How accurate these assumptions are depends very much on the used heat exchanger that brings in the heat to the reactor and takes out heat. The tested store contained a spiral heat exchanger consisting of sheet copper and pipes soldered to it. The distance between the sheet copper layers was approximately $5 \mathrm{~cm}$. Laboratory measurements have shown that the assumptions mentioned above are reasonable for this setup. Therefore, it is assumed that the simulated store contains a heat exchanger with a similar setup to the one tested.

However, up and downscaling cannot be done easily because the UA-values of the heat exchangers and for the store heat losses have to be derived from measurements. For the simulations presented in this paper reasonable assumptions have been made but this is a major limitation of the model.

In addition, the model was only validated for silica gel Grace $127 \mathrm{~B}$. It was assumed that the new material $13 \mathrm{XBF}$ behaves similar in terms of heat transfer and reaction kinetics. Only the adsorption properties have been changed. This assumption seems reasonable because it is the same type of pelleted material with similar heat capacity and heat conduction characteristics.

\section{Open System Model}

The reactor is described as a quasi-stationary two phase model with heat and mass balances.

The following general assumptions have been made for the reactor model:

- The reactor is quasi stationary.

The mass inside a prototype reactor build up at ITW is approximately $20 \mathrm{~kg}$ of sorption material which is continuously exchanged. Compared to the total stored mass of up to $10000 \mathrm{~kg}$ of storage material, this assumption seems reasonable. 
- The reaction enthalpy $\Delta \mathrm{H}_{\mathrm{R}}$ is not a function of the water load of the zeolite.

- As the reaction inside the reactor is from complete dehydrated (or hydrated) this simplification of the model has no influence on the simulation results as $\int d H_{R}\left(x_{S}\right)$. $d x_{S}$ becomes $\Delta H_{R, m} \cdot \Delta x_{S}$, whereas $\Delta H_{R, m}$ is the mean enthalpy of reaction determined by experiments.

- The reaction yield is limited only by the chemical equilibrium of the material. The following equation is always fulfilled:

$x_{S} \leq x_{S, e q u}\left(T_{R}, x_{G}\right)$ for the adsorption (or hydration) and

$x_{S} \geq x_{S, \text { equ }}\left(T_{R}, x_{G}\right)$ for the desorption (or dehydration)

No steric hindrances or other limiting effects are known for water / zeolite reactions to inhibit the thermodynamic equilibrium.

- An ideal kinetic is assumed. The equilibrium is always achieved, either at the inlet or at the outlet of the reactor. Thus the respective in equation (4.3) is always fulfilled with equality. In literature a very fast reaction kinetic of the physical adsorption is reported (Duong, 1998).

- The chemical equilibrium (or sorption equilibrium) is defined by a correlation equation (e.g. Langmuir) or by equilibrium data in tabular form.

- The specific heat capacity of the solid and gas is no function of the temperature or of the humidity in the reactor $\left(\mathrm{c}_{\mathrm{p}, \mathrm{S}} \cong\right.$ const., $\mathrm{c}_{\mathrm{p}, \mathrm{G}} \cong$ const. $)$

- Before the reaction starts an ideal heat exchange from the entering air to the exiting sorption material and from the exiting air to the entering sorption material is assumed.

In experiments at a lab scale reactor it was found that the adsorption (or desorption) front is moving in the same direction as the gas flow through the reactor. At the gas inlet, after a short while the zeolite is fully adsorbed (desorbed). Not further reaction takes place. However, the zeolite is warmer (colder) than the entering air. Thus a heat exchange between the entering air and the zeolite was observed. Similar observation was made at the outlet of the reactor.

- As the gas flow rate $\left(\dot{m}_{G}\right)$ is by the factor of 10, or more, higher than the solid flow rate $\left(\dot{m}_{S}\right)$ and the specific heat capacities of zeolite and air are rather similar, the capacity flow of gas is also higher by at least the factor of 10 compared to the capacity flow of zeolite. In addition the air is flowing through a bed of zeolite beads with a diameter of approximately $2 \mathrm{~mm}$. From literature it is known that there is no significant temperature difference between the air temperature and the particle temperature of a flown through packed bed of this size. Thus considering the heat exchange from the solid phase to the gas phase as ideal is a simplification with almost no deviation to reality.

- The coupling in and out of heat and water is done by the gas flow through the reactor.

The reactor model has been verified in a laboratory test rig with a 1501 material reservoir using zeolite 4A. The simulated results are in good agreement with the measured data. A verification using zeolite $13 \mathrm{XBF}$ is carried out at present.

Simulation results of the open and closed system

In Figure 4.5 the results of the simulations are shown as fractional thermal energy savings as a function of the collector area. The open system gives one point, whereas the closed system a curve for each TCES size. This is due to fact that the open system is dimensioned in such a way, that the collector array is set to a size to completely regenerate the storage material at a fixed desorption temperature in summer. At the same time stagnation of the system is minimized. The results of the conventional water-filled storage tank are also shown for comparison. All simulations were done with an evacuated tube collector. 
The closed systems' output is significantly better than the conventional water store system and reaches fractional thermal energy savings close to $100 \%$ at moderate collector and store sizes. The working range of the zeolite 13 XBF goes from approximately 8 to $12 \%$ depending on the collector area to $30 \%$ (fully adsorbed).

For the open system, the fractional thermal energy savings obtained are close to the ones obtained for the closed system. The working range of zeolite 13XBF starts at a water load of $30 \%$ (fully adsorbed) to a water load of approx. $4 \%$ (desorbed at $\mathrm{T}_{\mathrm{des}}=180{ }^{\circ} \mathrm{C}$ ). The fractional thermal energy savings of the open system are for all configurations under investigation is approximately $5 \%$-points lower compared with the fractional thermal energy savings of the closed system. This effect is due to two reasons. First, the sensible heat stored in the TCES cannot be used in the open system whereas the closed system is using the TCES material store as a chemical and a sensible heat store. Second, the model to simulate the processes in the chemical heat store is different. Thus it can be stated, that the results are similar within the uncertainty range of the TRNSYS simulations.

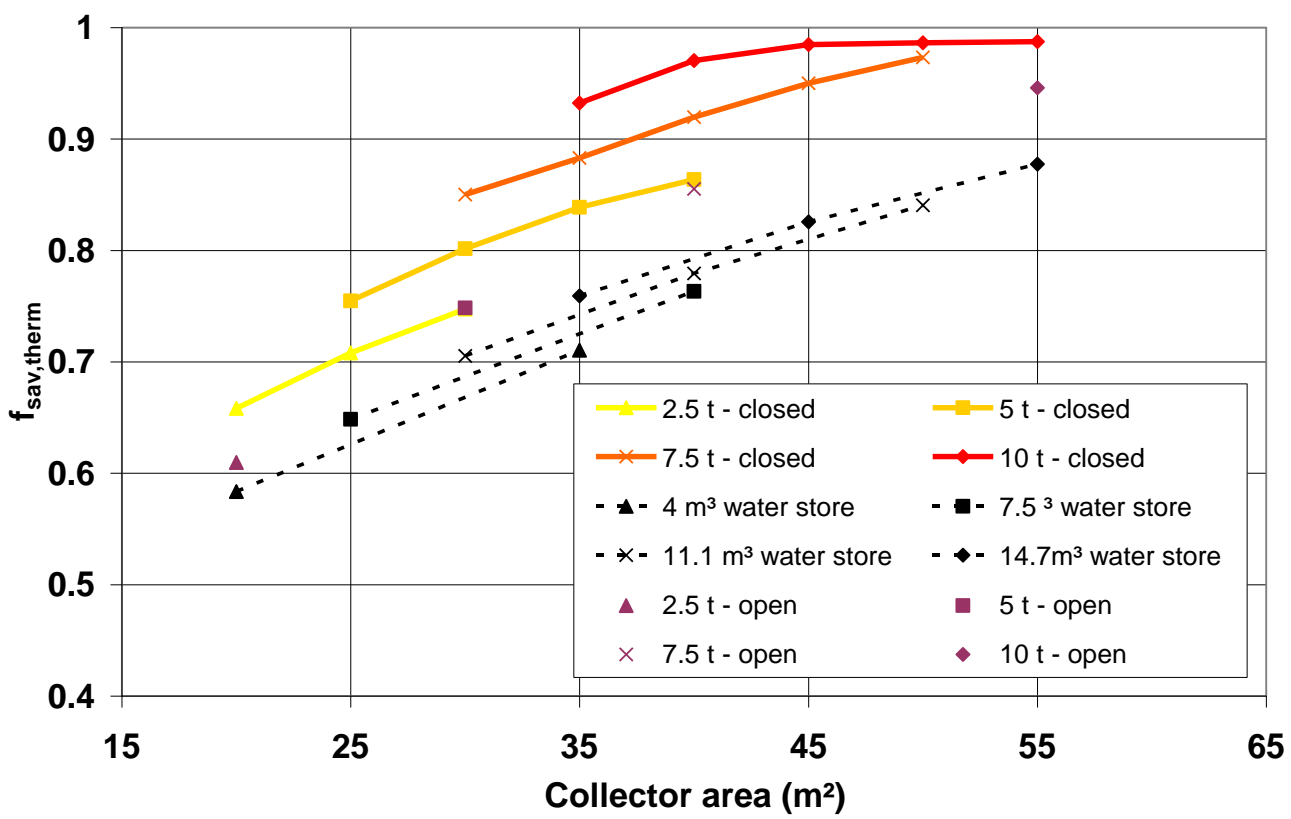

Figure 4.5: Fraction thermal energy savings as a function of the collector area for zeolite 13XBF for four different storage sizes and the two system concepts, both using evacuated tube collectors (ETC), location Zurich, reference building $30 \mathrm{kWh} /\left(\mathrm{m}^{2} \mathrm{a}\right)$.

Analysis open vs. closed system concept

The main differences within the open and closed system concept can be summarized by the following points:

- The solar collector yield is higher for the CLOSED system because of lower collector temperatures (desorption always at $180^{\circ} \mathrm{C}$ in open system, desorption at high temperatures only in the end of the desorption process (end of summer) in closed system)

- The auxiliary heating is necessary also in the beginning of the heating season for the OPEN system because of limited thermal capacity from ventilation system (limitation of water transport to the TCES). 
- In the CLOSED system, a greater part of the desorption process is taking place already in the spring whereas in the OPEN system desorption can only take place as soon as $180^{\circ} \mathrm{C}$ is reached by the solar collectors. This high temperature is already reached for several hours at the end of March. However the lion's share of desorption process takes place in the summer months.

This effect is shown in Figure 4.6. Plotted is the wet material mass (wet material reservoir, open system, red line, left axis) over time respectively the water content within the sorption store (closed system, blue line, right axis) over time.

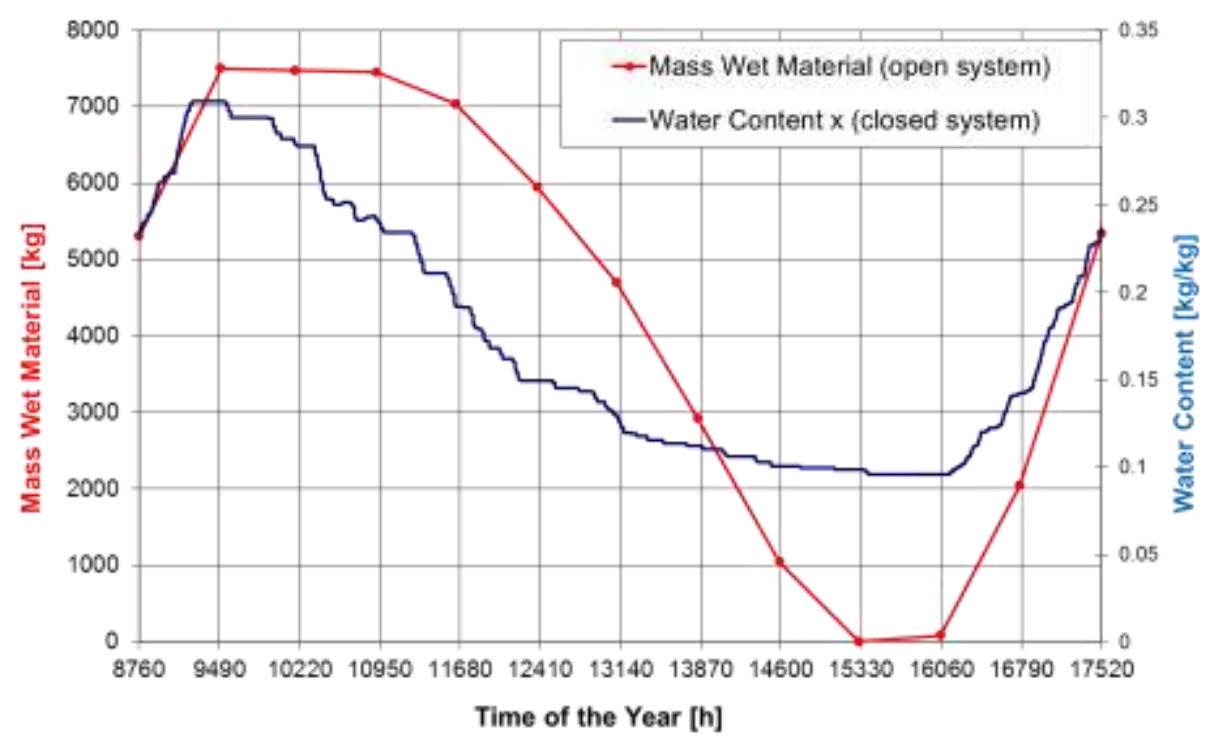

Figure 4.6: Mass inside the wet material reservoir of an open system (red and left axis) in comparison with the water content of the storage material of a closed system (blue and right axis). The TCES material is zeolite 13 XBF, ETCs are used.

- The CLOSED system shows major heat losses from the sorption store. Therefore, good thermal insulation of the store is necessary in order to make use of the sensible heat storage capacity of the store.

- The OPEN system has heat losses due to hot air leaving the reactor during desorption and due to hot and dry material that cool down to ambient conditions in the material reservoir.

\subsubsection{Water storage with integrated Phase Change Material (PCM)}

At the Institute of Thermal Engineering, Graz University of Technology, the potential for the improvement of the solar fraction by using Phase Change Material in solar combisystems was analyzed by means of system simulations with the template solar thermal system of Task 32. For this analysis the reference building with a specific space heating demand of $30 \mathrm{kWh} /\left(\mathrm{m}^{2} \mathrm{a}\right)$ was used in the reference climate of Zurich. Different configurations concerning the collector area, the storage volume and the type of storage, meaning water storage or PCM storage, were compared. For the PCM the material properties of Sodium Acetate Trihydrate were used (Table 4.1). Flat plate collectors with a selective coating, as defined in the reference system of Task 32, were used for the solar thermal system. 
Table 4.1: Material data of Sodium Acetate Trihydrate.

\begin{tabular}{l|c}
\hline Melting point & $58.1^{\circ} \mathrm{C}$ \\
Latent heat & $220 \mathrm{~kJ} / \mathrm{kg}$ \\
Density & 1400 \\
& $\mathrm{~kg} / \mathrm{m}^{3}$ \\
Thermal conductivity & 0.4 \\
Subcooling & $\mathrm{W} / \mathrm{m} . \mathrm{K}$ \\
\hline
\end{tabular}

The PCM is assumed to be integrated into cylindrical modules with a diameter of $75 \mathrm{~mm}$, which are installed in the water tank of the system. The volume fraction of PCM in the tank is $75 \%$.

\section{Simulation model}

For the simulation of the water tank as well as for the Water\&PCM tank the model Type 840 was used [Schranzhofer et al., 2006]. This is a storage model for TRNSYS which is capable of simulating a simple water tank (several double port connections and internal heat exchangers) with integrated cylindrical, spherical of rectangular PCM modules. Different PCM zones with different melting temperatures can be defined in different heights of the tank. The heat transfer in the PCM modules is calculated using a two-dimensional finite differences approach, considering only heat conduction (convective heat transfer is neglected). The phase change is modeled with the enthalpy method [Voller, 1990]. A schematic of the model is depicted in Figure 4.7.

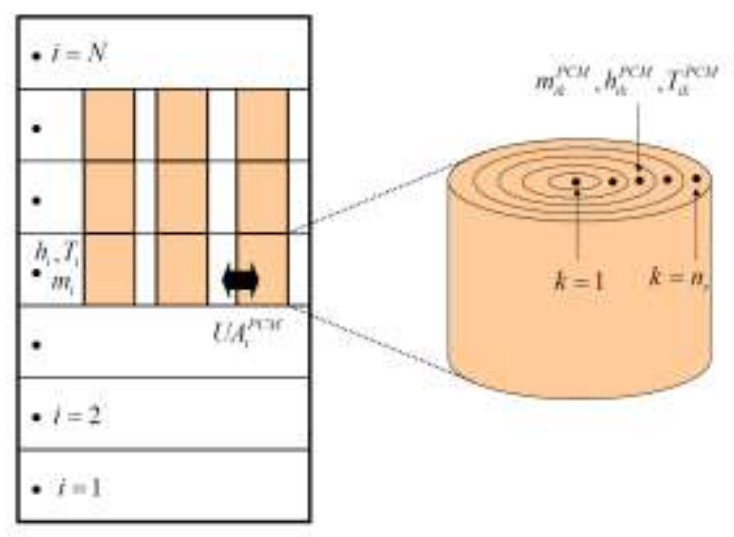

Figure 4.7: Schematic of the model Type 840 .

Although this model allows a calculation of the two-dimensional heat conduction within the cylindrical PCM modules, the conduction in radial direction was not accounted for in the simulations shown in. This means that no discretization of the modules was done in radial direction (only one node). This was done due to two reasons:

- In order to save simulation time.

- The module diameter used is quite small and therefore the effect of radial conduction is assumed to have only a small effect, especially with large storage volumes.

In additional simulations that were performed to analyze the effect of larger module diameters the heat conduction in radial direction was considered (compare Figure 4.10). Here a discretization of one node per $\mathrm{cm}$ of the module radius was used. A discretization in axial direction of the modules was used in all simulations. 


\section{Simulation Results}

Figure 4.8 shows the fractional thermal energy savings as a function of the collector area for water storage (left) and Water\&PCM (right) for six different storage sizes, both using flat plate collectors. Compared to the results shown in Figure $4.5 \mathrm{f}_{\text {sav,therm }}$ is lower for the water storage configurations, which is due to the fact that flat plate collectors are used instead of vacuum tube collectors.

The integration of the PCM results in an improvement of the fractional energy savings for all configurations (compare Figure 4.8, right). However, for small collector areas and small storage volumes - and thus for relatively low solar fractions - the improvement is not very pronounced. For higher solar fractions, where seasonal storage occurs, the advantage increases. As an example with a $16 \mathrm{~m}^{3}$ Water\&PCM tank almost the same $\mathrm{f}_{\text {sav,therm }}$ can be achieved than for a system with a $48 \mathrm{~m}^{3}$ water tank.
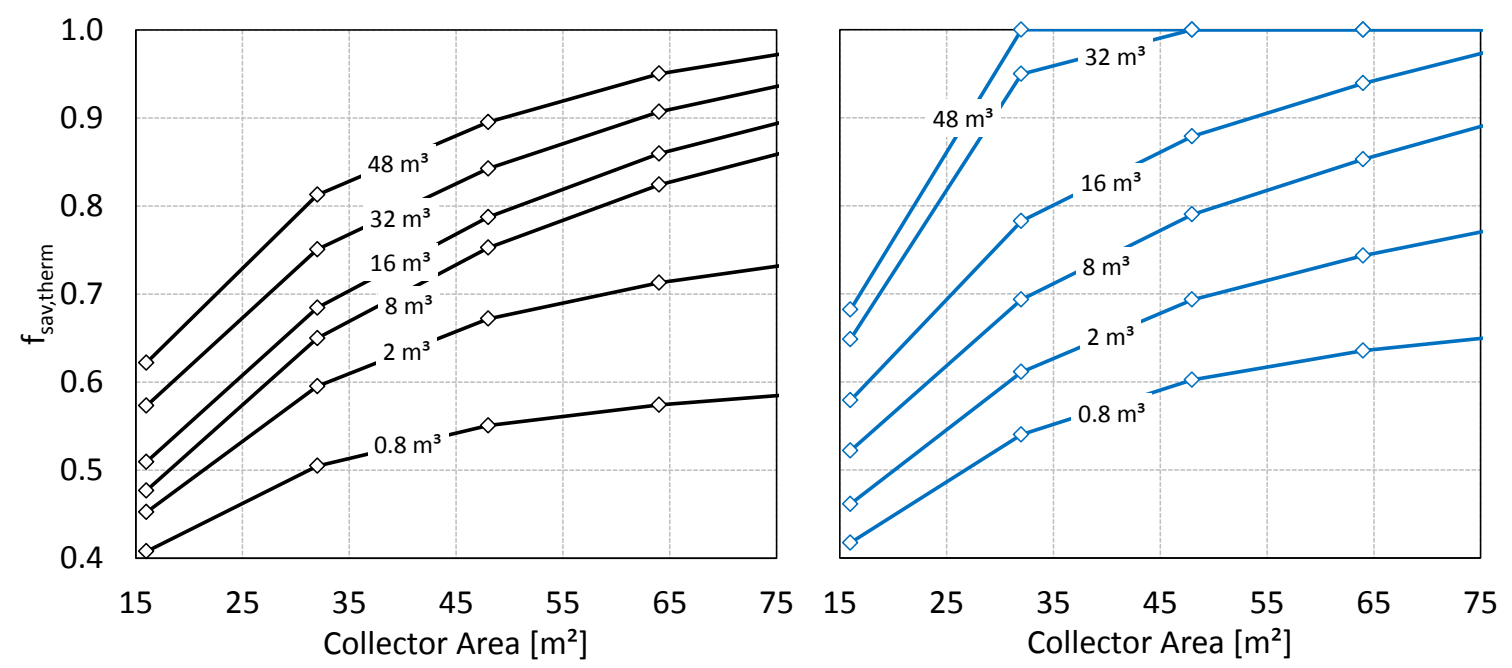

Figure 4.8: Fractional thermal energy savings as a function of the collector area for water storage (left) and Water\&PCM (right) for six different storage sizes, both using flat plate collectors.

Figure 4.9 shows the evolution of the water temperatures over the year inside the storage tank for the configuration with $32 \mathrm{~m}^{2}$ collectors and a storage volume of $32 \mathrm{~m}^{3}$. It can be seen that with the water tank the temperature at the top drops below the on-temperature of the auxiliary approximately at hour 8000 . After that the auxiliary is covering a large part of the demand until hour 1800, when the storage temperature increases strongly due to the solar input. In the case with PCM (Figure 4.9, right side) the auxiliary does not have to switch on before hour 1000, as the water temperature can be kept warm for a longer period of time by the PCM. In this case a $\mathrm{f}_{\mathrm{sav} \text {,therm }}$ of $95 \%$ is reached with the Water\&PCM tank compared to $75 \%$ with the water tank. 

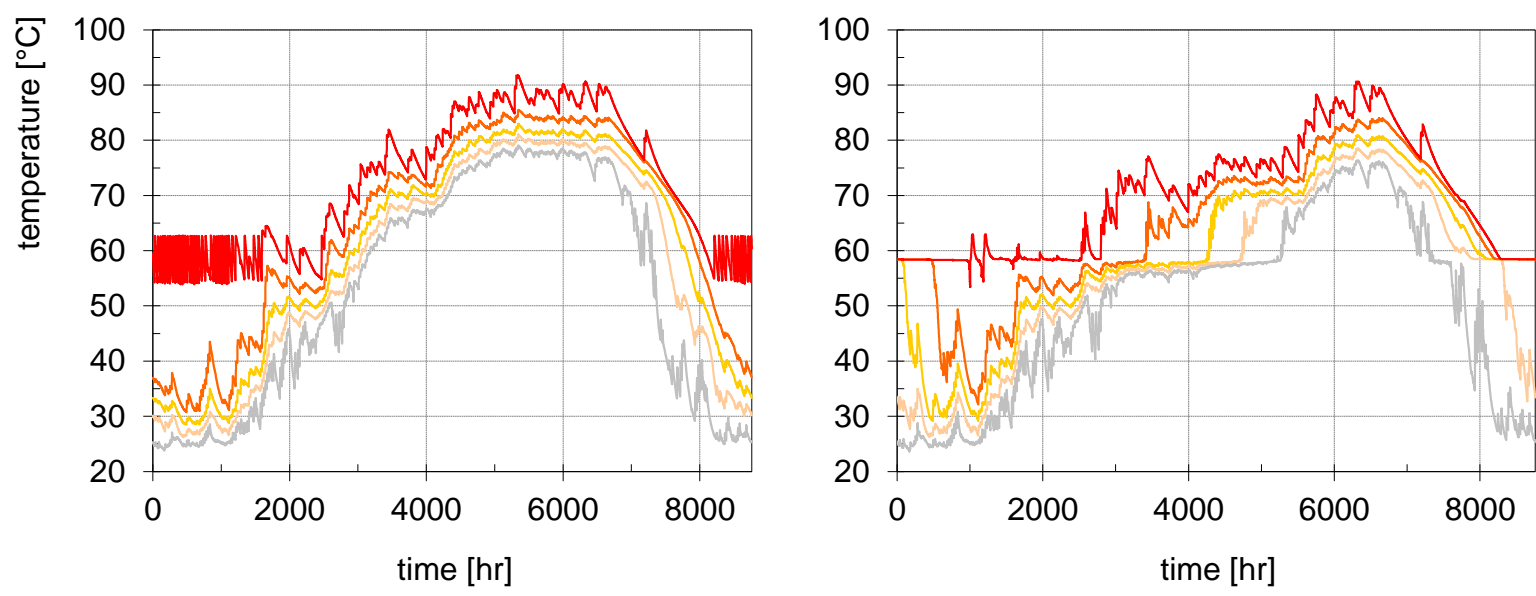

Figure 4.9: Configuration with $32 \mathrm{~m}^{2}$ collector area / $32 \mathrm{~m}^{3}$ storage volume: Evolution of the water temperatures in the storage tank in the course of the year in five different heights (from the top to the bottom); Left: water tank; Right: Water\&PCM tank.

Additional simulations should show the effect of larger diameters of the PCM modules, this time taking into account the heat transfer in radial direction. Figure 4.10 shows the results for a collector area of $48 \mathrm{~m}^{2}$ and a storage volume of $16 \mathrm{~m}^{3}$. For all configurations the diameter and the number of the modules was chosen in a way to result in a PCM volume fraction of $50 \%$. The results show that up to a diameter of $400 \mathrm{~mm}$ there is almost no change in $\mathrm{f}_{\text {sav,therm. }}$. With this diameter the number of modules reduces from 293 to 10 compared to the original configuration. With larger diameters the solar fraction begins to decrease, as the limited heat transfer into and out of the PCM (due to the low thermal conductivity) starts to be a disadvantage. It is assumed that an enhancement of the thermal conductivity of the material by using certain additives like e.g. graphite would result in an improvement also for even larger diameters.

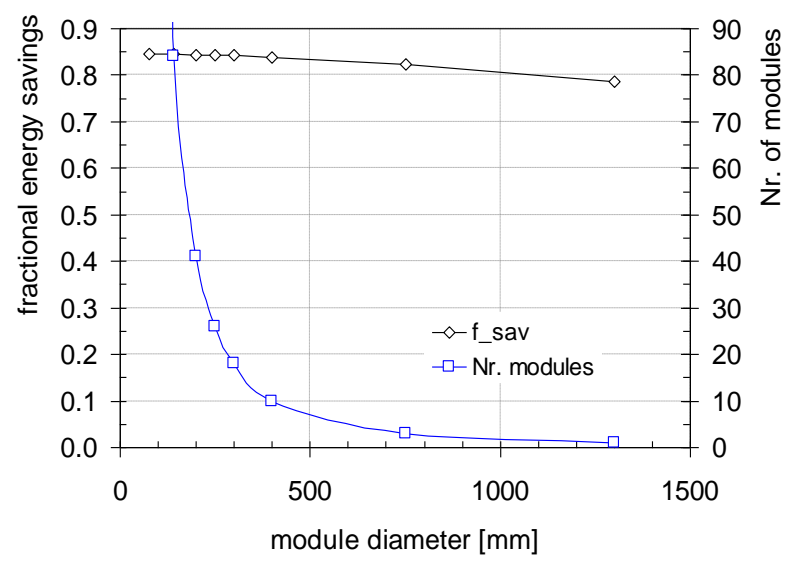

Figure 4.10: $\mathrm{f}_{\text {sav,therm }}$ using different module diameters ( $48 \mathrm{~m}^{2}$ collectors, $16 \mathrm{~m}^{3}$ storage, $50 \%$ PCM fraction).

In general it has to be noted, that the requirement for a high thermal conductivity and/or a small module diameter is strongly reduced if the necessary discharge load is low in relation to the tanks volume. This is the case for the larger tanks in the application shown here. The necessary discharge load is normally never higher than $30 \mathrm{~kW}$, which occurs when a bath tub is filled with a relatively high flow rate. Then it is a strong difference for the specific discharge load whether the tanks volume is e.g. $1.2 \mathrm{~m}^{3}\left(25 \mathrm{~kW} / \mathrm{m}^{3}\right)$ or $32 \mathrm{~m}^{3}\left(0.94 \mathrm{~kW} / \mathrm{m}^{3}\right)$. 


\subsection{Recommendations for Material and System Developments}

This report summarizes the contributions of the Working Group WB2 on applications of compact thermal energy storage for space heating and hot water $\left(20\right.$ to $\left.100{ }^{\circ} \mathrm{C}\right)$ within the IEA joint Task/Annex 42/24 for the period February 2009 through December 2012. System integration of thermochemical, specifically sorption materials, and phase change materials are at the forefront of the international collaboration.

The majority of the reported work considers off-the-shelf materials, including organic and inorganic PCMs, solid sorbents including porous zeolites and silica gel or salt hydrates such as calcium chloride or magnesium chloride, and the liquid desiccant calcium chloride. Using available materials has provided invaluable experience on how to effectively incorporate thermochemical storage materials into systems. The reported research makes stark the innovation in components and systems required to produce efficient and cost effective long-term storage for space heating and hot water. Though progress toward system development has been demonstrated at laboratory and prototype scale, significant additional efforts are needed to optimize system designs, especially with respect to heat and mass transfer and adsorption kinetics within thermochemical reactors and thermochemical storage vessels. 


\subsection{References}

Bales, C., 2005, "IEA Task 32 Subtask B Report 2: Thermal Properties of Materials for Thermo-chemical Storage of Solar", http:// www.iea-shc.org.

Bales, C., 2006, "Thermal storage with the thermo-chemical accumulator", Proceedings of Ecostock, Galloway, NJ.

Bales, C., 2008, “A report of IEA Solar Heating and Cooling programme - Task 32 Subtask B: Final Report Chemical and Sorption Storage", http:// www.iea-shc.org.

Bales, C., Gantenbein, P., Jaehnig, D., Kerskes, H., van Essen, M., Weber, R., and Zondag H., 2008, “Chemical and Sorption Storage-Results From IEASHC Task 32”, Proceedings of Eurosun, 2008, Lisbon, Portugal.

Cuypers, R, Finck, C, Henquet, E, Oversloot, H, de Geus, A, 2012 "MERITS: More Effective use of Renewables Including compact seasonal Thermal energy Storage” InnoStock Conference, Lleida, Spain, 16-18 may 2012.

Cuypers, R, Maraz, N, Eversdijk, J, Finck, C, Henquet, E, Oversloot, H, van ‘t Spijker, H, de Geus, A, 2012, "Development of a Seasonal Thermochemical Storage System", Energy Procedia, Vol. 30, pp. 207-214 (1st International Conference on Solar Heating and Cooling for Buildings and Industry 2012, San Francisco, USA, 911 july 2012).

Fan, J., Furbo, S., Chen Z, Andersen, E., and Perers, B., 2011,'Heat transfer capacity of a heat exchanger module for seasonal heat storage." ISES Solar World Congress 2011 Proceedings. Kassel, Germany.

Fan, J, Furbo, S., Andersen, E, Chen, Z., Perers, B. and Dannemand, M., 2012, “Thermal behaviour of a heat exchanger module for seasonal heat storage.” SHC 2012 Conference Proceedings, San Francisco, USA.

Furbo S., Andersen E. and Schultz, J.M., 2006, “Advanced storage concepts for thermal systems in low energy buildings. Slutrapport.” Report no. SR-06-01. Department of Civil Engineering, Technical University of Denmark, can be downloaded from: http://www.byg.dtu.dk/Forskning/hentned.aspx.

Furbo S., Dragsted J., Fan J., Andersen E. and Perers, B., 2010, “Towards seasonal heat storage based on stable super cooling of sodium acetate trihydrate.” EuroSun 2010 Congress Proceedings. Graz, Austria.

Furbo S., Dragsted J., Fan J., Chen Z., Andersen E. and Perers B., 2011, “Experimental studies on seasonal heat storage based on stable supercooling of a sodium acetate water mixture." ISES Solar World Congress 2011 Proceedings. Kassel, Germany.

Furbo, S., Fan, J., Andersen, E., Chen, Z. And Perers, B., 2012, "Development of seasonal heat storage based on stable supercooling of a sodium acetate water mixture.", SHC 2012 Conference Proceedings, San Francisco, USA.

Gantenbein, P., 2006, “Adsorption speed and mass transfer zone analysis of water vapour on the solid sorbent materials zeolite and silicagel with the focus on the heat exchanger", Proceedings of Ecostock, Galloway, NJ.

Hadorn, J.C., 2006, "IEA solar and heating programme task 32: advanced storage concepts for solar and low energy buildings", Proceedings of Ecostock, Galloway, NJ.

Haillot, D., Goetz, V., Py, X., and Benabdelkarim, M., 2011, "High performance storage composite for the enhancement of solar domestic hot water systems: Part 1: Storage material investigation", Sol. Energy, Vol. 85(5), pp. 1021-1027.

Hauer, A., 2008, “Sorption Storages for Solar Thermal Energy_Possibilities and Limits”, Proceedings of Eurosun, Lisbon, Portugal.

Heimrath, R.; Haller, M., 2007, “The Reference Heating System, the Template Solar System of Task 32, a Report of IEA Solar Heating and Cooling programme - Task 32 "Advanced storage concepts for solar and low energy buildings" Report A2 of Subtask A (www.iea-shc.org/task 32) 
Hui, L., Edem, N.K., Nolwenn, L.P., and Lingai, L., 2011, "Evaluation of a seasonal storage system of solar energy for house heating using different absorption couples”, Energy Convers. Manage., Vol. 52(6), pp. 2427 2436.

Jähnig, D.; Hausner, R.; Wagner, W.; Isaksson, C., 2006, “Thermo-Chemical Storage for Solar Space Heating in a Single-Family House", Proceedings of ECOSTOCK conference, Richard Stockton College, New Jersey, May 2006.

Jänchen, J., Ackermann, D., Stach, H., and Brösicke, W., 2004, "Studies of the water adsorption on Zeolites and modified mesoporous materials for seasonal storage of solar heat”, Sol. Energy, Vol. 76(1-3), pp. 339-344.

Jänchen, J., Ackermann, D., Weiler, E., Stach, H., and Brosicke, W., 2005, “Calorimetric investigation of zeolites, AlPO4's and CaCl2 impregnated attapulgita for thermochemical storage of heat", Thermochim. Acta, Vol. 424, pp. 37-41.

Jänchen J., Schumann K., Thrun E., Brandt A., Unger B., Hellwig U. (2012): Preparation, Hydrothermal Stability, and Storage Properties of Binderless Zeolite Beads - International Journal of Low-Carbon Technologies; doi: 10.1093/ijct/cts037

Kerskes, Henner, Bertsch, Florian; Asenbeck, Mette; Drück, Harald (2013): CWS-Verbundvorhaben chemische Wärmespeicherung mittels reversible Geststoff-Gasreakrion. Abschlussbericht. Technische Informationsbibliothek Hannover (TIB)

Kozubal, E., J. Woods, J. Burch, A. Boranian, T. Merrigan, 2001, Desiccant Enhanced Evaporative AirConditioning (DEVap): Evaluation of a New Concept in Ultra Efficient Air Conditioning. National Renewable Energy Laboratory, TP-5500-49722, 2011.)

Kozubal, E., J. Woods, R. Judkoff, 2012, Development and Analysis of Desiccant Enhanced Evaporative Air Conditioner Prototype. National Renewable Energy Laboratory, TP-5500-54755, 2012.

Le Pierres, N., Liu, H., and Luo, L., 2008, "Solar thermal storage for house heating through LiBr/H2O absorption process: preliminary energy evaluation”, Proceedings of Global Conference on Global Warming, Istanbul, Turkey.

Lowenstein, A., 2005, High Efficiency Liquid-Desiccant Regenerator for Air Conditioning and Industrial Drying. AIL Research Inc., Department of Energy Contract No. DE-FG36-03GO13170, 2005.).

Pinel, P, Cruickshank, CA, Beausoleil-Morrison, I, Wills, A. A review of available methods for seasonal storage of solar thermal energy in residential applications. Ren Sust Energy Rev, 2011;15:3341-59. from: Hadorn., JC. Advantage storage concepts for active solar energy. IEA SHC Task 32; 2003-2007. In: Eurosun $-1^{\text {st }}$ international conference on solar heating, cooling and buildings. 2008.

Quinnell, J.A, Davidson, J.H., and, Burch, J., 2011, "Liquid calcium chloride solar storage: concept and analysis", J. Sol. Ener. Eng., Vol. 133:doi:10.1115/1.4003292.

Quinnell, J. A., 2012,“Buoyancy Driven Mass and Heat Transfer in a Novel Calcium Chloride Absorption Storage Tank,” Ph.D. Thesis, Mechanical Engineering, University of Minnesota.

Quinnell, J. A., Davidson, J. H., 2012a. “Distributed Solar Thermal: Innovations in Thermal Storage,” Annual Reviews in Heat Transfer, 15, 2012.

Quinnell, J. A., Davidson, J. H., 2012b. "Buoyancy driven mass transfer in a liquid desiccant storage tank," Proceedings of the ASME 6th International Conference on Energy Sustainability, Denver, CO, July 23-26.

Quinnell, J. A., and Davidson, J. H., 2012c, "Long-term solar thermal energy storage using aqueous calcium chloride," Proceedings of the American Solar Energy Society, Washington D.C., May 13 - 18. 
Schranzhofer H., Heinz A., Puschnig P., Streicher W., 2006: "Validation of a TRNSYS simulation model for PCM energy storages and PCM wall construction elements", Ecostock Conference, 31th May - 2nd June 2006, Stockton College, Pomona, USA

Schultz, J.M. and Furbo, S., 2004, "Heat of fusion storage systems for combined solar systems in low energy buildings.” EuroSun 2004 Congress Proceeding. Freiburg,Germany.

Schultz, J.M. and Furbo, S., 2005, "Investigation of heat of fusion storage for solar low energy buildings.” ISES Solar World 2005 Congress Proceedings. Orlando, USA.

Schultz, J.M. and Furbo, S., 2006, "Heat of fusion storage with high solar fraction for solar low energy buildings.” EuroSun 2006 Congress Proceedings. Glasgow, Scotland.

Schultz, J.M. and Furbo, S., 2007, "Solar heating systems with heat of fusion storage with 100\% solar fraction for low energy buildings.” ISES Solar World 2007 Congress Proceedings. Beijing, China.

Schultz, J.M., 2008, “Type 185. Phase change material storage with supercooling.” Department of Civil Engineering, Technical University of Denmark.

Schultz J.M., Andersen E. and Furbo S., 2008, “Advanced storage concepts for solar and low energy buildings, IEA-SHC Task 32. Slutrapport.” Report no. SR-08-01. Department of Civil Engineering, Technical University of Denmark, can be downloaded from: http://www.byg.dtu.dk/Forskning/hentned.aspx

Streicher W. (editor), 2008, "Final report of Subtask C "Phase Change Materials". The overview. A report from IEA Solar heating and Cooling Programme Task 32 Advanced Storage Concepts for solar and low energy buildings." Report C7 of Subtask C, 2008. Can be downloaded from: http://www.ieashc.org/publications/downloads/task32-c7.pdf

Streicher, W., Heinz, A., Bony, J., Citherlet, S., Cabeza, L., Schultz, J.M. and Furbo, S., 2008, "Results of IEA SHC Task 32: Subtask C: Phase Change Materials.” EuroSun 2008 Congress Proceedings. Lisbon, Portugal.

Voller, V. R., 1990, "Fast implicit finite-difference method for the analysis of phase change problems", Numerical Heat Transfer 17B, 155.

Wang, D., Xia, Z., and Wu, J., 2006, "Design and performance prediction of a novel zeolite-water adsorption air conditioner”, Energy Convers. Manage., Vol. 47(5), pp. 590-610.

Weber, R., and Dorer, V., 2008, “Long-term heat storage with NaOH”, Vacuum, Vol. 82(7), pp. 708-716.

Weiss, W. (ed.), 2003, "Solar Heating Systems for Houses - A design handbook for solar combisystems”, James \& James (Science Publishers) Ltd. London

Welteroth, J.; Mittelbach, W., 2001, Final Report HYDES Project. Final Report of a Joule III Project, European Commission.

Woods, J. Burch, J., and Kozubal, E., 2011, "High solar fraction heating and cooling systems based on liquid desiccants,” Proceedings of the American Solar Energy Society, Rayleigh, NC.

Woods, J., J. Pellegrino, E. Kozubal, J. Burch, 2011, Design and experimental characterization of a membranebased absorption heat pump, J. Membr. Sci. 378 (2011) 85-94.

Woods, J. and E. Kozubal, 2013, A desiccant-enhanced evaporative air conditioner: Numerical model and experiments, Energ. Convers. Manage. 65 (2013) 208.

Zalba, B., Marín, J.M., Cabeza, L.F., and Mehling, H., 2003, "Review on thermal energy storage with phase change: materials, heat transfer analysis and applications", Appl. Therm. Eng., Vol. 23(3), pp. 251-283, 2003.

Zhong, Y., Li, S., Wei, X., Liu, Q., Guo, Q., Shi, J., and Liu, L., 2010, "Heat transfer enhancement of paraffin wax using compressed expanded natural graphite for thermal energy storage”, Carbon, Vol. 48(1), pp. 300-304. 


\subsection{Short Description of Task 42 / Annex 24}

From past IEA SHC and ECES tasks it was concluded that a broad and basic research and development initiative is needed to find and improve compact thermal energy storage materials. The IEA joint Task/Annex 42/24 brings together experts from both the materials development field and the systems integration fields. In four years, the task aims at having finished the first steps towards a new generation of thermal storage technologies.

\section{Objective}

The overall objective of this task is to develop advanced materials and systems for the compact storage of thermal energy. This can be subdivided into seven specific objectives:

- to identify, design and develop new materials and composites for compact thermal energy storage,

- to develop measuring and testing procedures to characterise new storage materials reliably and reproducibly,

- to improve the performance, stability, and cost-effectiveness of new storage materials,

- to develop multi-scale numerical models, describing and predicting the performance of new materials in thermal storage systems,

- to develop and demonstrate novel compact thermal energy storage systems employing the advanced materials,

- to assess the impact of new materials on the performance of thermal energy storage in the different applications considered, and

- to disseminate the knowledge and experience acquired in this task.

A secondary objective of this task is to create an active and effective research network in which researchers and industry working in the field of thermal energy storage can collaborate.

\section{Scope}

This task deals with advanced materials for latent and chemical thermal energy storage, and excludes materials related to sensible heat storage. The task deals with these materials on three different scales:

- material scale, focused on the behaviour of materials from the molecular to the 'few particles' scale, including e.g. material synthesis, micro-scale mass transport, and sorption reactions;

- bulk scale, focused on bulk behaviour of materials and the performance of the storage in itself, including e.g. heat, mass, and vapour transport, wall-wall and wall-material interactions, and reactor design;

- $\quad$ system scale, focused on the performance of a storage within a heating or cooling system, including e.g. economical feasibility studies, case studies, and system tests.

Because seasonal storage of solar heat for solar assisted heating of buildings is the main focus of the SHC IA, this will be one of the primary topics of this task. However, because there are many more relevant applications for TES, and because materials research is not and can not be limited to one application only, this task will focus on multiple application areas.

In the Task kick-off meeting it was decided to subdivide the Applications Subtask into three Working Groups, corresponding to three different temperature levels of thermal energy storage, as depicted below. 


\section{Structure}

To achieve the maximum amount of cross-fertilisation between the different backgrounds of the two Implementing Agreements and experts in this Joint Task, the Task is organised in a matrix-like structure (see diagram below).

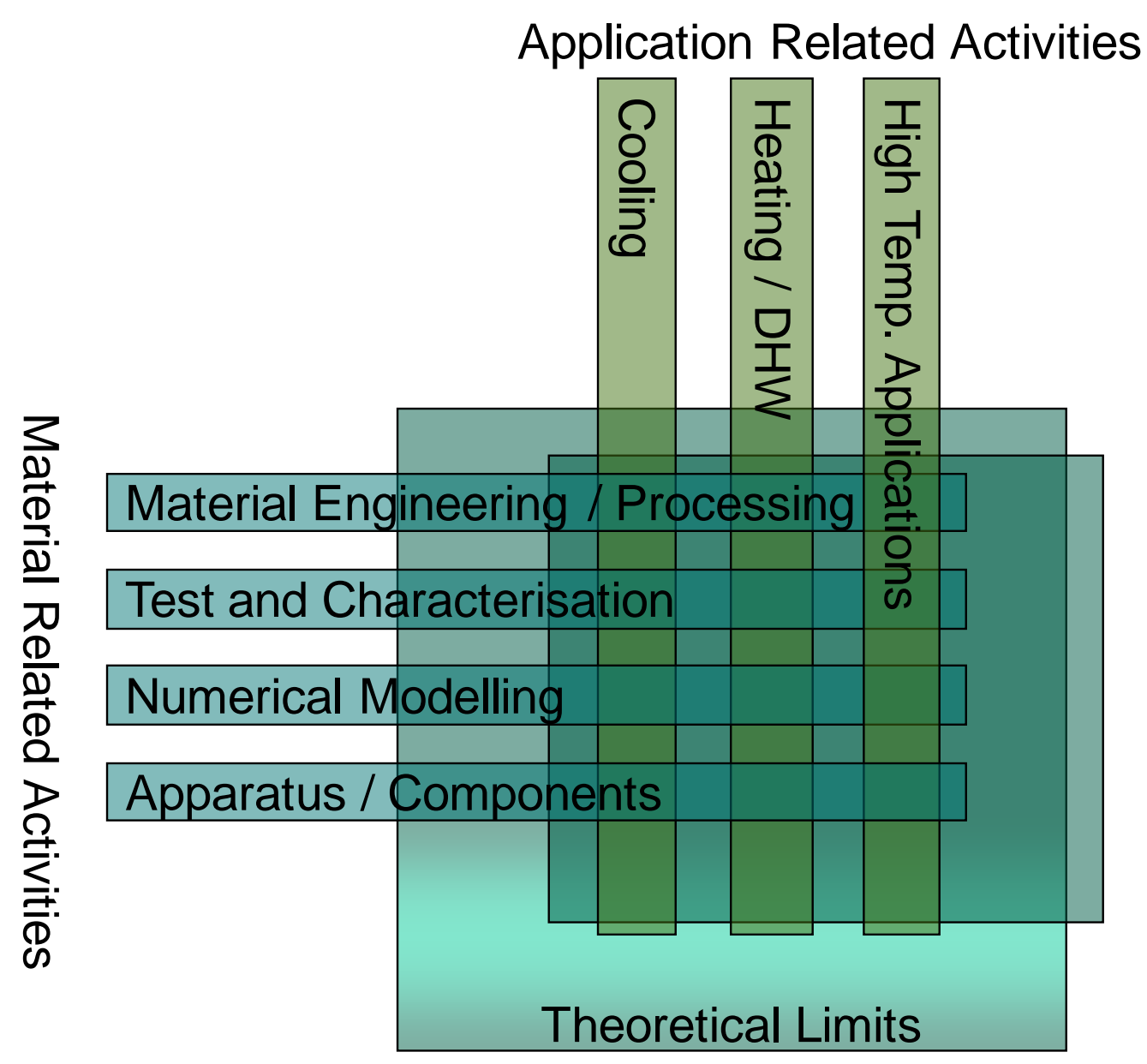




\section{IEA Solar Heating and Cooling Programme}

The International Energy Agency (IEA) is an autonomous body within the framework of the Organization for Economic Co-operation and Development (OECD) based in Paris. Established in 1974 after the first "oil shock," the IEA is committed to carrying out a comprehensive program of energy cooperation among its members and the Commission of the European Communities.

The IEA provides a legal framework, through IEA Implementing Agreements such as the Solar Heating and Cooling Agreement, for international collaboration in energy technology research and development $(\mathrm{R} \& \mathrm{D})$ and deployment. This IEA experience has proved that such collaboration contributes significantly to faster technological progress, while reducing costs; to eliminating technological risks and duplication of efforts; and to creating numerous other benefits, such as swifter expansion of the knowledge base and easier harmonization of standards.

The Solar Heating and Cooling Programme was one of the first IEA Implementing Agreements to be established. Since 1977, its members have been collaborating to advance active solar and passive solar and their application in buildings and other areas, such as agriculture and industry. Current members are:

$\begin{array}{lll}\text { Australia } & \text { Finland } & \text { Portugal } \\ \text { Austria } & \text { France } & \text { South Africa } \\ \text { Belgium } & \text { Italy } & \text { Spain } \\ \text { Canada } & \text { Mexico } & \text { Sweden } \\ \text { Denmark } & \text { Netherlands } & \text { Switzerland } \\ \text { European Commission } & \text { New Zealand } & \text { United States } \\ \text { Germany } & \text { Norway } & \end{array}$

A total of 44 Tasks have been initiated, 33 of which have been completed. Each Task is managed by an Operating Agent from one of the participating countries. Overall control of the program rests with an Executive Committee comprised of one representative from each contracting party to the Implementing Agreement. In addition to the Task work, a number of special activitiesMemorandum of Understanding with solar thermal trade organizations, statistics collection and analysis, conferences and workshops-have been undertaken.

To find Solar Heating and Cooling Programme publications and learn more about the Programme visit www.iea-shc.org or contact the SHC Secretariat, Pamela Murphy, e-mail: pmurphy@kmgrp.net. 
Current Tasks \& Working Group:

Task $36 \quad$ Solar Resource Knowledge Management

Task 37 Advanced Housing Renovation with Solar \& Conservation

Task $38 \quad$ Solar Thermal Cooling and Air Conditioning

Task $39 \quad$ Polymeric Materials for Solar Thermal Applications

Task $40 \quad$ Towards Net Zero Energy Solar Buildings

Task $41 \quad$ Solar Energy and Architecture

Task $42 \quad$ Compact Thermal Energy Storage

Task $43 \quad$ Rating and Certification Procedures

Task $44 \quad$ Solar and Heat Pump Systems

Completed Tasks:

Task $1 \quad$ Investigation of the Performance of Solar Heating and Cooling Systems

Task $2 \quad$ Coordination of Solar Heating and Cooling $R \& D$

Task 3 Performance Testing of Solar Collectors

Task $4 \quad$ Development of an Insolation Handbook and Instrument Package

Task 5 Use of Existing Meteorological Information for Solar Energy Application

Task $6 \quad$ Performance of Solar Systems Using Evacuated Collectors

Task $7 \quad$ Central Solar Heating Plants with Seasonal Storage

Task $8 \quad$ Passive and Hybrid Solar Low Energy Buildings

Task $9 \quad$ Solar Radiation and Pyranometry Studies

Task $10 \quad$ Solar Materials $R \& D$

Task $11 \quad$ Passive and Hybrid Solar Commercial Buildings

Task 12 Building Energy Analysis and Design Tools for Solar Applications

Task $13 \quad$ Advanced Solar Low Energy Buildings

Task $14 \quad$ Advanced Active Solar Energy Systems

Task $16 \quad$ Photovoltaics in Buildings

Task $17 \quad$ Measuring and Modeling Spectral Radiation

Task 18 Advanced Glazing and Associated Materials for Solar and Building Applications

Task 19 Solar Air Systems

Task $20 \quad$ Solar Energy in Building Renovation

Task $21 \quad$ Daylight in Buildings

Task 22 Building Energy Analysis Tools

Task 23 Optimization of Solar Energy Use in Large Buildings

Task $24 \quad$ Solar Procurement

Task $25 \quad$ Solar Assisted Air Conditioning of Buildings

Task $26 \quad$ Solar Combisystems

Task 27 Performance of Solar Facade Components

Task $28 \quad$ Solar Sustainable Housing

Task $29 \quad$ Solar Crop Drying

Task $31 \quad$ Daylighting Buildings in the $21^{\text {st }}$ Century

Task 32 Advanced Storage Concepts for Solar and Low Energy Buildings

Task $33 \quad$ Solar Heat for Industrial Processes

Task $34 \quad$ Testing and Validation of Building Energy Simulation Tools

Task $35 \quad$ PV/Thermal Solar Systems

Completed Working Groups:

CSHPSS, ISOLDE, Materials in Solar Thermal Collectors, Evaluation of Task 13 Houses, and

Daylight Research

IEA SHC/ECES - Task 42/24 - Compact Thermal Energy Storage 


\section{IEA Energy Conservation Through Energy Storage Programme}

The International Energy Agency (IEA), based in Paris, is an autonomous agency linked with the Organisation for Economic Co-operation and Development (OECD). The IEA is the energy forum for 26 Member countries. IEA Member governments are committed to taking joint measures to meet oil supply emergencies. They have also agreed to share energy information, to co-ordinate their energy policies and to co-operate in the development of rational energy programmes.

The R\&D programme Efficient Energy End-Use Technologies contains 14 different Implementing Agreements (IAs) of which one is the IA on energy storage. The full name of this IA is Energy Conservation though Energy Storage (ECES IA). This IA was founded in 2004 and intends to promote co-operative research, development, demonstrations and exchanges of information regarding energy conservation through energy storage.

The continued development, application and deployment of energy efficient end-use technologies has the potential to significantly reduce energy consumption and greenhouse gases in the buildings, electricity generation, industry, and transport sectors. Energy storage technologies can overcome the temporal mismatch between energy supply and demand, especially regarding renewable energy technologies, the use of waste energy and energy from ambient sources such as cold from the natural environment.

Active participants in ECES IA are at present

$\begin{array}{lll}\text { Belgium } & \text { Germany } & \text { Sweden } \\ \text { Canada } & \text { Italy } & \text { USA } \\ \text { China } & \text { Japan } & \text { Turkey } \\ \text { Finland } & \text { Korea } & \\ \text { France } & \text { Norway } & \end{array}$

Three sponsors are participating in the ECES at the moment:

IF Technology B.V. (Netherlands)

Institute of Heat Engineering, University of Technology of Warsaw (Poland)

Energesis Ingeniería, S.L. (Spain).

Other countries have signed the agreement but are not presently engaged in the activities. Further countries have recently shown interest in participating in the near future, including countries from Eastern Europe.

The work within the ECES IA is lead by an Executive Committee (XC) and the work undertaken by this $\mathrm{XC}$ is done by mutual agreements defined in Annexes as listed on the next page. The work is led by Chairman Halime Paksoy (Turkey) and Secretary Hunay Evliya (Turkey).

To find ECES publications and learn more about the Programme visit http://www.iea-eces.org or contact the ECES Secretariat, Hunay Evliya, e-mail: hevliya@cu.edu.tr 
Ongoing Annexes:

Annex $20 \quad$ Sustainable Cooling with Thermal Energy Storage

Annex 21 Thermal Response Test for Underground Thermal Energy Storages

Annex 22 Thermal Energy Storage Applications in Closed Greenhouses

Annex 23 Applying Energy Storage in Ultra-low Energy Buildings

Annex $24 \quad$ Material Development for Improved Thermal Energy Storage Systems

Annex $25 \quad$ Surplus Heat Management using Advanced TES for CO2 mitigation

Annex 26 Electric Energy Storage: Future Energy Storage Demand

Completed Annexes:

Annex $1 \quad$ Large Scale Thermal Storage Systems Evaluation

Annex $2 \quad$ Lake Storage Demonstration Plant in Mannheim

Annex 3 Aquifer Storage Demonstration Plant in Lausanne Dorigny

Annex $4 \quad$ Short Term Water Heat Storage Systems

Annex $5 \quad$ Full Scale Latent Heat Storage Installations

Annex $6 \quad$ Environmental and Chemical aspects of Thermal Energy Storage in Aquifers and Research and Development of Water Treatment Methods

Annex $7 \quad$ Innovative and Cost Effective Seasonal Cold Storage Applications

Annex $8 \quad$ Implementing Underground Thermal Energy Storage Systems

Annex $9 \quad$ Electrical Energy Storage Technologies for Utility Network Optimization

Annex $10 \quad$ Phase Change Materials and Chemical Reactions for Thermal Energy Storage

Annex 12 High-Temperature Underground Thermal Energy Storage (HT UTES)

Annex 13 Design, Construction and Maintenance of UTES Wells and Boreholes

Annex $14 \quad$ Cooling with TES in all Climates

Annex 17 Advanced Thermal Energy Storage Techniques - Feasibility Studies and Demonstration Projects

Annex 18 Transportation of Thermal Energy Utilizing Thermal Energy Storage Technology

Annex 19 Optimised Industrial Process Heat and Power Generation with Thermal Energy Storage 